Portland State University

PDXScholar

1974

\title{
An Analysis of the Mental Health Services Available to the Elderly Within Oregon: Using Multnomah County as a Special Case Study Area
}

Joan Nadine Hoss

Portland State University

Follow this and additional works at: https://pdxscholar.library.pdx.edu/open_access_etds

Part of the Gerontology Commons, and the Social Work Commons Let us know how access to this document benefits you.

Recommended Citation

Hoss, Joan Nadine, "An Analysis of the Mental Health Services Available to the Elderly Within Oregon: Using Multnomah County as a Special Case Study Area" (1974). Dissertations and Theses. Paper 1730. https://doi.org/10.15760/etd.1729

This Thesis is brought to you for free and open access. It has been accepted for inclusion in Dissertations and Theses by an authorized administrator of PDXScholar. Please contact us if we can make this document more accessible: pdxscholar@pdx.edu. 
AN ANALYSIS OF THE MENTAL HEALTH SERVICES

AVA ILABLE TO THE ELDERLY WITHIN OREGON

USING MULTNOMAH COUNTY AS A SPECIAL CASE STUDY AREA

by

JOAN NADINE HOSS

A report submitted in partial fulfillment of the requirements for the degree of

MASTER OF

SOCIAL WORK

Portland State University

1974

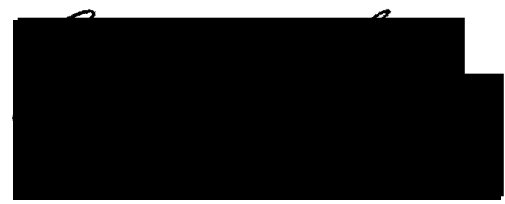




\section{ACKNOWLEDGEMENTS}

I wish to gratefully acknowledge the help and guidance provided by Ed Valentine, a professional staff member of the Oregon Student Public Interest Research Group; Vern Davis, the Director of the Oregon Mental Health Association; Ada K. Wilson, Assistant Professor of Social Work and Director of the Aging Program for the School of Social Work, Portland State University; and Dr. Walter Klopfer, Professor of Psychology, Portland State University.

I also wish to thank the following people for their help in the prepartion of this report: Sharon White, Julene Knapp, Anna Lee Stevens, Lyndel Stride, and ${ }^{\bullet B i} 11$ Allen. 


\section{PREFACE}

This investigation was conducted under the auspices of the Oregon Student Public Interest Research Group (OSPIRG). This author was employed by OSPIRG during the summer, 1973, as an Intern. During this period of employment the primary field research for this report was conducted, with this author fully responsible for the design and execution of this investigation, and this report presenting the findings of the investigation.

Since this report is serving the purpose of publically presenting the findings of this OSPIRG investigation, the term OSPIRG appears frequently in the text as the source primarily responsible for the report.

However, for the purposes of meeting the research requirement for the Master of Social Work degree, it should be fully understood that this author was entirely responsible for this investigation and report. 
PAGE

ACKNOWLEDGMENTS

PREFACE

LIST OF TABLES

vi i i

RESEARCH METHODOLOGY

INTRODUCTION.

I BACKGROUND INFORMATION

A Cultural Perspective on Growing 01.d.......... 9

Denrographic Data........................ 13

Estimates of the Prevalence of Mental Illness

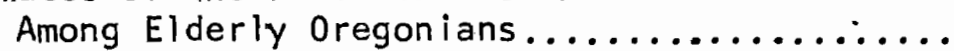

Can the Elderly Benefit from Traditional Mental Health Services...................... 28

Mental Health Care and the Law.............. 38

I I COMMUNITY BASED MENTAL HEALTH SERVICES.............. 48

Multnomah County Mental Health Section........... 49

Crisis Clinic, Psychiatric Outpatient Clinic and Social Services Unit, the University of Oregon Medical School................. 60

Privately Administered Counseling Centers......... 64

Project ABLE, an Example of a Service Delivery System......................... 69

Conclusions and Recommendations.............. 73 
CHAPTER

PAGE

I I THE STATE MENTAL HOSPITAL SYSTEM............... 77

The Currently Used Alternatives to Hospitalization. 80

The Elderly Residing Within State Mental Hospitals.

87

Admissions Data

Modality and Length of Treatment

Discharge Data

The Impact the Movement Out-of-the-Hospital

has had on Elderly Patients.............. 124

Conclusions and Recommendations............. 128

IV THE ROLE OF SHELTERED SETTINGS IN THE CARE OF

MENTALLY ILL ELDERLY OREGONIANS ................ 134

What are Sheltered Settings?................. 134

How Many Elderly Persons are Living in Sheltered Settings?.......................... 140

The Role of Sheltered Settings in Caring

for Mentally 111 Elderly Persons........... 143

Summary............................... 157

Conclusions............................. 159

Recommendations........................ 160

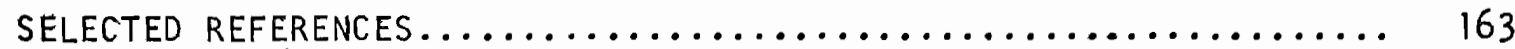

APPEND IX

A. Examples of the Questionnaires used to Solicit

Information............................. 168

B. Number of Suicides within Oregon by Age and by Year.... 179

C. Data used to Determine Prevalence of Alcoholism

Estimates............................... 180

D. Transportation Needs of the Elderly within the

City of Portland. 
E. Criteria used for a Diagnosis of Organic Brain Syndrome, an Example of a Mental Status

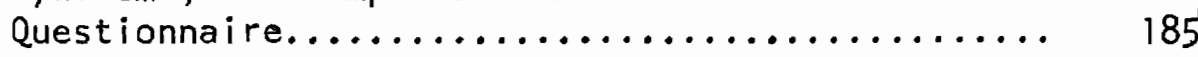

F. Reality Orientation Therapy................. 188 


\section{LIST OF TABLES}

I Weighted Average Thresholds at the Poverty Level

in 1969, by Size of Family. and Sex of Head,

by Farm and Nonfarm Residence, United States.....

II Multnomah County Mental Health Section Data for

New Admissions; January 1, 1973 - June 30, 1973... 50

ill Data from Privately Administered Mental Health

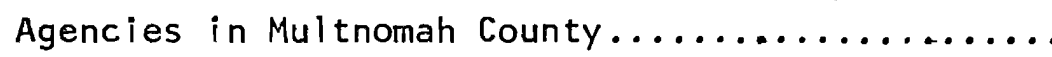

IV Tentative Diagnoses Assigned During the Pre-Screening

Process Comparing Elderly and Non-Elderly

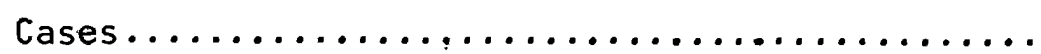

V Alternative Planning Dispositions, Multnomah Co.

Mental Health Section, Pre-Screening Project,

September, 1972 - June, $1973 \ldots \ldots \ldots \ldots \ldots \ldots \ldots . \ldots$

VI Admissions Data for State Mental Hospitals by Admission

Category, Year, Age, Number, and Percent of Total

Intake per Categary by Age Group............ 88

VII Commitment Proceedings Data from Multnomah County.

October, 1972 - September, 1973.............. 92

VIII Geriatric Admissions to State Hospitals by

Age and by $y e a r . \ldots \ldots \ldots \ldots \ldots \ldots \ldots \ldots . \ldots . \ldots . \ldots$

IX Geriatric In-Resident Patients at End of Year by

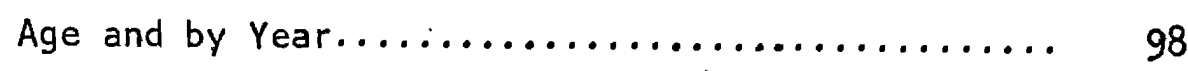


$X$ Length of Stay Since Admission for Released and

In-Resident Patients at Each State Hospital

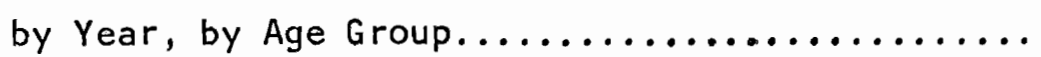

XI Average Length of Stay by Diagnosis for Discharged

Patients at Dammasch State Hospital, January,

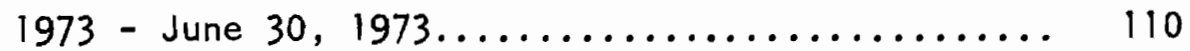

XII Release Data for the State Mental Hospital by Release

Category, Year, Age, Number, and Percent of

Total Release per Category by Age Group......... 114

XIII Disposition of Released Elderly Residents at Dammasch

State Hospital, 1970-71 through 1972,73........ 118

XIV 01d Age Assistance Recipients Living in Shettered

Settings in Multnomah County for the Month

of sune, 1973.

142

XV Data Obtained from Nursing Homes in Multmomah County..

148

XVI Data Obcained from Homes for the Aged in Multnomah

County.............................. 149 
RESEARCH METHODOLOGY

The purpose of this study was to identify the mental health services available to the elderly residents of Oregon, and to assess the effectiveness of these services in providing mental health treatment to elderly persons.

In order to reasonably narrow the scope of this study, the investigation of mental health services wes limited primarlly to those agencies which are publiely: funded and controlled by state or local bodies. In addition, Multnomah County was selected as a case study area in order to further narrow the scope of the study. Multnomah County was selected because of the convenience of its geographical location for this researcher and OSPIRG personnel, but more importantly, because Multnomah County is one of the most:urbanized areas of the state, with a large number of mental health services geographically accèssible to its elderly residents. Additionaliy, this county contains approximately $31 \%$ of all elderly residents in Oregon.

This study began with two basic hypotheses, each of which was operationally defined so that measurable indices supporting or contradicting the hypotheses could be collected during the course of the investigation.

The Pirst hypothesis was that there is a social obligation to provide mental health care whìch is suitable, available, anda accessible to those in need of this care. In order to operationally define this hypothesis a number of factors needed to be considered.

This issue of a 'social obligation to provide mental health care' was investigated in relation to explicit laws, policies, and institutions 
which pertain to mental health care generally, and mental health care for the elderly in particular, in order to determine whether there was, in fact, a social commitment to provlde mental health services to needing individuals, including the elderly. Subsumed within this hypothesis was the assumption that both financially and technically these services could be provided if there were a social and professional commitment to do so.

The 'suitability' of mental health care was determined in relation to the ability of the elderly to benefit from different types of mental health care, where the types of mental health care which have been shown to be the most effective in treating; mental illnesses among the elderly were considered tọ be the most suitable. Suitability was also measured in terms of the level of care provided, where it was determined that the restrictiveness of the setting and the frequency and intensity of the treatment should be comparable with the scope, frequency, intensity, and duration of the mental or emotional difficultiy experienced by the elderly individual. Therefole, a continjum of mental health care, moving srom more. to Iess frequent, restrictive, and intense would be considered maximally suitable.

The terms availability and accessibility to treatment were determined by the geographical proximity of mental health services to the elderly population within Multnomah County, and their ability to utilize these services considering such problems as lack of mobility or the cultural biases among this group which predicate against the use of mental health services located w1thin publically identified "mental health clinics."

Finally, the meaning of 'those in need of mentil health care' had had to be determined. This required operationally defining the term 'mentally 1ll,' since the mentally 111 person is most in need of mental health care. 
The second hypothesis was that there is a lack of mental health services designed for, and avallable and accessible to, the ielderly residente of Multnomah County. Included within this hypdthesis was the assumption that the aged, like any other population of people, would and could utilize such services for their own care and treatment if such serizices were suitable, accessible, and avallable. The concept of services being de signed for a population required that service delivery systems be considered as well as the issues of sultability and accessibilfty of treatment services. In order to determine whether there was a lack of mental health services, the number of elderlv needing mental he alth services and the number being provided with mental health services each had to be determined and then compared. In ordep to estimate the need for mental health services measurable social indices were utilized (for example, the incidence of suicide among the aged, the prevalence of poverty, or the prevalence of alcoholism among this age group). 'In order to supplement the data abtained from these social indices, other studies which estimated the " mental health needs of elderly persons were used, interpolating the conclusions of these studies for the elderly populations of Oregon and Multnomah County. Field research was conducted in order to determine the number of elderly persons receiving mental health care in both public and private mental health agencies within Multnomah County, and in addition, the level of care (as previously defined) was considered in relation to the lack of, or adequacy of, available mental health services.

This study utilized a number of different types of research methods. First, a field survey was conducted which included personal interviews with) significant mental heal th professionals and personnel responsible for admin1stering or providing mental health, or related, services. In order to 
supplement the personal interview, three questicninares were developed and administered, in written form, to relevent agencies and personnel. (See Appendix A for copies of these questionaires.)

Relevint documents and statistics were solicited from numerous state and county agencies, including the State Mental Health Vivision, Multnomah County Mental Health Section, 'the University of Oregon Medical School, the State Public Welfare Livision, the Institute on Aging, the University of Oregon Gerontological Center, the State Program on Aging, the State Health Division, and numerous private agencies.

A review of federal and state laws related to the status of mental bealth care, both nationally and within Oregon, was undertaken.

Finally, a partial review of the literature was undertaken in relation to the ability of the elderly to benefit from different types of mental health care, the viability of the use of organic brain syndrome as a diagnostic category, and in relation to the relative successes of differont forms of mentil health delivery systems in proviang services to the elderly.

By working under the auspices of the Oregon Student Public Interest Research Group, many documents, and the time of some agency's personnel were made available to me which probably would not have occurred had I not been preparing a document for a public agency for publication. Some of this information was released as the result of recent legislation pertalning to "the public's right to know" disclosure lawa. 
INTRODUCTION

The purpose of this investigation was to identify and evaluate the mental health services which are currently being offered to elderly residents of the state of Oregon.

A. major difficulty in analyzing mental health services is that the concept of mental health is ambiguous. Some professionals view mental health services largely as those programs which treat and rehabilitate the mentally ill patient. others view services largely in terms of helping individuals and families cope adequately with the pressures of everyday living. The variant points of view have developed depending upon whether illness or health is stressed. Health implies early intervention and enhancing individuals' coping abilities, given a range of degrees of stress and/or disability. We are not dealing with either/or states, but with a health continuim (Stephanie Freedman, Multnomah County Mental Health Planner) (1)

Dr. Gerald Caplan, in Principles of Preventive Psychiatry,

proposed a model of therapeutic intervention at three distinctive levels of intervention: primary, secondary, and tertiary.

The basic premise of primary prevention is that there are normal stresses in living which occur in the lives of all people in the community. Such stresses would include marriage, the birth of a child, illness, a change in residence, or entry into the job market. People have differing abilities to hanalle these stressful situations. Borrowing from the public health model, primary prevention addresses itself to identifying these stresses and the conditions which strengthen or weaken the people exposed to them. By this strategy, programs can be designed to Iower the incidence of mental illness, reduce the intensity or harmful pressure, and increase poeple's capacity to handle future problems. In primary prevention the emphasis is. on designing programs which reach large numbers of individuals in the community, not on individual casework. 
Secondary prevention addresses itself to lowering the rate of prevalence of disorder in the community; prevalence being the rate of established cases in the total population which is vulnerable to the disorder. This reduction can be accomplished by either lowering the rate of new cases by altering factors leading to the disorder, or by lowering the rate of old cases by shortening the duration of care needed. Tertiary prevention is aimed at those individuals suffering from mental disorder, and its goal is to restore their capacity to contribute to the occupational and social life of the community. Tertiary care often requires reconstruction of much of an individual's habits and beliefs; i.e. normalization--assisting the person In establishing the pattern of a normal life--is the goal of tertiary prevention.

Primary prevention of mental disorders among the elderly would consist of programs either aimed at reducing harmful pressures exerted on this group, or increasing elderly individuals' capacities to handle this pressure in the future. Examples of such programs would be educational programs aimed at altaring cur culture's age-related biases, moving us from a youth worship bias to valuing each age group for the unique contribution which it has to make, or maintaining meaningful avenues for social contribution by the retired individual, or a program might focus on pre-retirement planning so that retiring:individuals eould buffer the shock of this major Iife transition.

This report focuses primarily upon the secondary and tertiary levels of prevention. Secondary prevention includes most of the communitybased mental health services. The clients served by these agencies are not generally socially disruptive nor dysfunctional, but they are suffering from problems in living with varying degrees of severity: 
Another form of secondary prevention would consist of attempting to lower the rate of new cases by addressing the factors leading to disorder. In the case of elderly Oregonians this would consiat of providing more adequate public transportation systems to increase their mobility, Increasing the availability of homemaker services, increasing the availability of low-cost housing, increasing their minimum allowable payment under 01d Age Assistance in order to reduce the prevalence of proverty among this group, and increasing the availability of a variety of mental health services. All of these changes would help to alleviate common sources of stress for this population.

However, these types of secondary level interventions are not generally occurring at this time. Rather, intervention generally occurs, If at all, at the tertiary level, meaning either hospitalization or institutionalization. Normalization, assisting the person in establishing the rhythm of a normal life, is usualiy the goal of tertiary prevention. However, in relation to the elderly this is often not the case. An identified emotionally and jor mentally disturbed elderly Oregonian may be channeled into a custodially-oriented institution (a nursing home or home for the aged) rather than back to the community to lead a "normal" life.

In the following pages the mental health services being provided to the elderly in Oregon will be considered. Using Multnomah County as a case study area, OSPIRG investigated the community-based mental health services which are available to the elderly within the county. Since Multnomah County is one of the most urbanized counties in the state, with a large number of mental health services geographically accessible to members of the elderly population, and additionally 
containing approximately $31 \%$ of the elderly residents of the state, OSPIRG believes that this area optimally reflects the level of mental health care availabie within the community to any elderly population throughout the state.

This investigation was also: nnarrowed to include' only publiclyy funded state controlled agencies, for the most part, since it is these agencies which have received a public mandate to meet the mental health requirements of Oregonians.

At the secondary level of prevention the Multnomah County Community Mental Health Program is the primary concern. The University of Oregon Meơical School and a number of privately administered counseling centers are peripherally considered. Project ABLE (A Better Life for the Elderly), a federally-county funded pilot project, is also considered since this program, on a restricted basis, attempts to modify: some specific causal factors contributing to mental breakdown among the elderly, and alsó demonstrates in altemative type of service delivery system. On a tertiary level of prevention OSPIRG focused on both the seris vices provided by the state mental hospitals, including pre-hospitaliza-. tion screening and post-hospitalization placement and follow-up, and the services provided by nursing homes and homes for the aged as they relate to caring for mentally 111 elderly Oregonians. 
CHAPTER I

\section{BACKGROUND INFORMATION}

This first chapter provides background information which will be helpful in later considering the mental health services being provided to the elderly within Oregon. This chapter includes the presentation of a cultural perspective with which to view the elderly and old age; basic demographic data regarding the current elderly population; estimations of the incidence of mental 1llness among the elderly Oregonian population based upon data gathered from community studies in other areas. of the country and from state indicators; an exploration of the issue of ' whether elderly persons can benefit from mental health services, particularly when they have been diagnosed as having an organic brain synrome; and, finally, includes a aiscussion of the legal status of mental health care and treatment, both nationaliy and within Oregon.

\section{A CULTURAI PERSPECTIVE ON GRONING OLD}

There is a fairly close relationshlp between chronological age and functional capacity. Some degree of mental and physical decline has taken placein all persons by the age of 65 and tends to Increase thereafter. For this reason the 65 th year is generally accepted as the beginning of old age. From the functional view many persons are relatively "young" at $65^{\circ}$ years of age. Nevertheless, the almost universal decline after 65 makes this age -. $a$ useful reference point for discussing the mental health needs of the elderly. (2)

Gerontologists have described the process of growing old as a . wasting disease. The skin begins to dry out and the hair starts to turn gray. The lenses of the eye thicken and become slowly opaque. The 
hearing mechanism loses some offits sensitivity. Fat accumulates at the . midsection. Muscles shrink and joints become stiff and sometimes swollen. This inexorable deterioration goes on deep within the body as well as the heart pumps blood with steadily diminishing efficiency and the blood vessels become less limber. The lungs take in less oxygen, kidney function is reduced by half, and the bladder's capacity is diminished. The flow of hormones from the ovaries, testes, adrenals, and pituitary dwindles. The brain shrinks as 100,000 of its cells die each day. The body becomes Increasingly vulnerable to infections and such "degenerative". diseases as cancer, arteriósclerosis," and diabetes. Should none of these prove fatal, death finally comes from that cumulative mix of afflictions known simply as old age. (15)

The clrcumstances of many oId persons' lives tend to step up latent or new functional disorders. Elderly people may feel frustrated by waning strength or hearing or sight. They may worry about the not distant future when they are likely to be feebler and poorer. They may be alone and isolated, without friends or relatives to break in on their Ionis, empty days and solitary brooding. "They may fear death, not as a young person might, but because it is really imminent. With or without good reason they may feel rejected by their children. "Bimotionally torn, they may develop a functional mental iliness with symptoms often as severe as if the cause were organic. Their thinking distorted, they may turn against the very persons who care most for them." (3)

Essentially, "In old age there are more anxiety-evoking situations, such as lonliness, ill health, and retirement, and there are fewer anxietyreducing opportunities, a formulate that accounts for senility or emotional 
breakdown in the aged." (4)

Dr. Walter Klopfer, PH.D., Clinical Psychologist and Professor of

Psychology at Portland State University points out that "older people are supposed to 'just adjust to retirement and old age--and they don't. Being old, per se, is the source of my of their emotional problems." Dr. KIopfer continued by adding,

"Many older individuals are faced with the same problems as any other age group: marital-family problems, self-esteem problems, or problems w1th lonliness and depression, along with problems of retirement. Retirement is often the time when marital problems arise. People are spending a lot of time together all of a sudden and so they start asking "Do I want to spend the rest of my life with you?" or "Who are you, anyway?" The aged are also dealing with problems of physical weakness, disease, loss, and death. old people are also not granted humanity in the area of sexuality. They are often reluctant to seek help if they are sexually dysfunctional or if they are having problems with their marital relationship as a result of sexual decline. Older women in particular have problems since most older women are widows."

Dr. Robert Davis, PH.D., Director of the Clackamas County Mental

Health Clinic offered another interesting perspective on the problems of being old by drawing a comparison between the elderly and adolescents:

Neither : I the generation in power and both have an ax to grind-: they feel resentful: toward that generation (in power).

Both feel useless, and are, in terms of social ethics. Adolescents are wanted and sought after, but in an exploitative sense, and this will happen to the aged, too, if it is discoverd that they have buying power.

Both have the same interpersonal needs--the average high school and the average nursing tome are the same in terms of the interpersonal isolation which comes from putting people out, the same types of cliques with the resulting "ins" and "outs". They both have the same physiological/psychological needs--the needs for affection and a sense of usefulness and importance, the need for emotional and sexual expression, (the aged and adolescents both need much more sexual expression than is socially permitted)--the don't touch ethic is very strong among the aged and they have to get sick to get touched. 
The need for something useful and of value to do, including entertinment and recreation, is great.

Some of the more subtle difficulties associated with old age were poignantly illustrated by Muriel Oberloder, PH.D., who is a nationally noted Clinical Psychologist who has specialized in working with the elderly.

We also tend to overlook the dangerous implications of what appear to be very common and ordinary situations. For instance, when an old person loses his teeth and must face people and eat without his dentures, we do not realize how inter y traumatic that is for him, perhaps even to the point of bringing on senility almost overnight. Instant senility might sceur when a person is advised to wear a hearing aid. Any of the harbingers. of old age can cause a radical breakdown in some people, particularly those who have prided themselves on being intact and healthy. (5)

Most of all, however, it must be remembered that the elderly are going to be most profoundly influenced by our cultural attitudes towards aging. "The psychodynamics of attitudes: toward the aged are complex. old people hold a mirror to us all. "There is a profound distaste for aging, disease, and disability. There are fears of lost virility and social influence. There is a dread of dying and death. Our own impo- -. tence is a stake." (6) The senile elderly individual may simply be reflecting the popular image of the aged: "Helpless, living in the past, forgetful, cranky, longwindêd, childish, self-centered, some old folks unconsciously meet such dismal expectations. In effect they are made dependent and maladjusted by this stereotype." (3)

Given all of these factors contributing to emotional distumances and mental breakdown among the elderly, it is remarkable that so many are. contented and high functioning individuals. "In our too-quick assumption that old age is a relentless downhill comse we ignore the life-time gathered potential of the el derly for strength as well as for a richer emotional, spiritual, and even intellectual and social life than 
may be possible for the young. Youth must concentrate on the piece-by-piece accumulation of personality and experience. Old age, in its best sense, can mean enjoyment of the finished product--a completed human being." (7)

\section{DEMOGRAPHIC DATA}

In order to provide a perspective with which to analyze the mental health needs of the elderly, a brief overview of the elderly Oregonian population follows. This data is based upon 1970 census information. The elderly population in Oregon has grown steadily, both in absolute numbers and in proportion to the rest of the population, with each census count since 1900. In 1900 the elderly comprised $3.9 \%$ of the population, in $19307.06 \%$, and in $197010.84 \%$ of the population. This trend is expected to continue.(8)

In 1970 there were 226,799 persons over 65 in Oregon, representing almost one out of every nine residents. Multnomah County, our case study area, has a total of 70,515 of these elderly residents, representing $31.1 \%$ of the elderly population of the state, and $12.7 \%$ of the resident population of the county.

In order to plan $\alpha$ evaluate services needed by elderly Oregonians, it is also necessary to know the breakdown of this population by age and -sex. The age of elderly individuals obviously contributes to their estimated life expectancy, and influences the number and the kind of services needed for this population. The sex of the individual is important because women live longer than men, and women also generally receive Iower retirement benefits than men. Taking into consideration the 
survival rates for men and women within each five year age group of persons now residing in the state, and an estimated net migration into the state that is consistent with the increase in the last decade, yields a midpoint projected estimate of 285,000 elderly Oregonians by 1985, an: increase of over 59,000 since 1970 . (8)

Oregon's proportion of elderly residents is higher than the national average of $9.9 \%$, due in part to the large numbers of persons who migrated to Oregon in past years and are now attaining the age of 65 or more. - Statistica show, however, that by far the largestportion of the elderly living in Oregon today are persons who have been living in Oregon a long time, rather than those who have come here to retire. For example, a statewide survey showed that over $20 \%$ of the elderly have lived in Oregon all of their lives, and an additibnal $53 \%$ have resided in the state for 20 years or more to almost all their lives. "In fact during the last decade $94.6 \%$ of the persons who became 65 were the result of simply 'Iiving' and growing old here in Oregon... While the remaining $5.4 \%$ of the increased population was the result of net in-migration. However, this $5.4 \%$ is less than the net in-migration of the total population, which was $7.9 \%$ for the last decade." (8)

This is an important factor to:remember when considering the types of services which the people of Oregon are going to provide for their elderly; most of these people resided here and provided funds during their working lives for the well-being of the entire state, rather than being recent immigrants who are placing an unwarranted burden on the taxpayers of Oregon. 
ESTTMATES OF THE PREVALENCE OF MENTAL ILLNESS AMONG THE ELDERLY OREGONIAN POPULATION

Before discussing the incidence of mental illness among elderly Oregonians, it is necessary to define what we mean by "mental illness." The World Health Organization has defined health as "a state of complete: physical, mental, and sociel well-being and not merely the absence of disease or infirmity." (7) Using this perspective, OSPIRG has defined the term "mentally ill" in this report to refer to any individual who, as a result of mental impairment, is unable to adequately perform his significant life functions; such as housekeeping tasks, control of financial matters, sustaining significant interpersonal relationships, maintaining meaningful social involvements, or performing basic intellectual processes. This definition of mental illness is in line with the State Mental Health D1vision which defines (ORS $426: 005$ ) the mentally ill person as someone "who, because of mental disorder is etther (a) dangerous to himself a cthers, ar (b) is unje to provide for his basic personal needs and is not receiving such care is necessary for his health or safety."

The causes of mental illness are generally clessified as being either functional. (caused by intrapersonal, interpersonal, or social stresseg), or organic (caused by trauma or damage to the tissues of the brain or nervous system.

Since the overall quality of an indivdual's living situation will affect his level of mental heclti, functioning; the person'total living $\therefore$ situation must' be considered when assessing his mental health status. In effect, the more stress a person experienes in his daily life 
due to isolation, poor interpersonal relationships, lack of money, or whatever, the more likely he is to experience mental or emotional breakdown at some time, although there are obvious variations in individuals'abilities to successfully withstand different types of stress.

Therefore, in estimating the incidence of mental illness among the elderly Oregonian population, the mental health status of the elderly needs to be assessed within a broad framework, using a holistic approach which includes consideration of the effects of social stresses, as well as consideration of the effects of medical problems, possible organic brain damage, and purely psychologically-based problems as they affect the level of mental health among the elderly.

Mentally ill elderly Oregonians are, for the most part, an unidentified population. There are no available statistics giving estimates of the incidence of mental illness among this population, nor have any research studies been conducted related to this topic in Oregon.

National studies, and community studies conducted in other parts of the country, provide some basic data from whịch we draw some loose, and admittedly inconclusive, inferences regarding the incidence of mental illness among elderly Oregnnians. In addition, OSPIRG has made some esitmates of the incidence of mental illness among elderly Oregonians based upon some commonly used social Indicators; including the incidence of suicide, esitmated prevalence of alcoholism, and the incidence of poverty among elderly Oregonians.

OSPIRG has also considered the availability of necessary social conditions, such as adequate transportation and housing, since it is apparent that people denied access to adequate transporation or housing 
experience increased pressures in their daily lives and are, therefore, more likely to suffer from emotional disturbance or mental illness.

Before we discuss the information obtained from studies conducted

in other areas of the county, it is important to note that, according to the National Institute of Mental Health

The great majority of men and women 65 and over, especially those not bedevilled by poverty, are mentally competent. There is increasing ovidence for this conclusion although no precise measure exists for the extent of mental and emotional disorders among the aging. That only $3 \%$ are under care in any kind of institution and only $1 \%$ are in mental hospitals are merely rough indications. (3)

However, while the grean majoricy $i$ : elderly persons may be mentally healthy, in relation to other age groups in the population studies show that the incidence of mental illness or emotional distarbance is much greater among the elderly than among any younger age groups.

The Baltimore Study of Chronic Disorders, (9) a study sponsored jointly by the American Medical Association, the American Hospital Association, the American Public Health Associatzon, and the American Public Welfare Association, was conducted in 1957 within the city of Baltimore. This study found that the rate of psychosis increases with age. The following table illustrates the findings of this study:

\begin{tabular}{lc} 
RATE OF PSYCHOSIS BY AGE \\
Age Group & Rate per 1000 \\
\cline { 2 - 2 } Under 15 & 0.04 \\
15 through 34 & 3.5 \\
35 through 64 & 13.0 \\
65 and older & 40.0
\end{tabular}

On the other hand, the prevalence of psychoneurosis in Baltimore per 1,000 inaividuals was uniformly distributed at 68.0 to 70.8 for all age groups,' 15 to 65 and older. 
If these rates were acceptable for approximation to the elderly population of Oregon, we would find that (based on the 1970 census) there would be about 9,072 elderly oregonians suffering from psychoes, and about 15,875 withpsychoneuroses, or a total of 24,947 mentally or emotionally disturbed elderly Oregonians.

In another metropolitan community survey; $11.5 \%$ of persons aged 65 or over were found to be mentally ill. Almost $3 \%$ were said to be suffering from psychoses, and about $7 \%$ from psychoneuroses. (2) Approximating their data to the elderly Oregonian population we would expect to find 26,082 mentally ill oregonians.

In a household survey of persons 65 years of age and older it was found that $6.3 \%$ were so disordered mentally that they met the clinical criteria for involuntary mental hospital admission. These people showed a rising proportion of mental illness with age, starting at $3.2 \%$ in the 65-69 age group and increasing to. 9.5\% in the $80-84$ age group. More than $30 \%$ of those over 85 years who were interviewed were found to meet the criteria for involuntary certification to mental hospitals. These esitmates may be low since a number of persons who were believed to be confused were kept from the survey interviewers by relatives (2).

If these figures were approximated to the elderly population in Oregon, we would arrive at a Pigure of 14,284 elderiy Oregonians who are so disordered that they would meet the clinical criteria for involuntary commitment.

A questionnaire on the extent of "confused and disoriented" patients in sectarian homes for the aged was sent to administrators of such institutions in widely scattered urban areas in the United States. 
The replies indicated that "confused and disoriented" patients who were management problems made up from $40 \%$ to $50 \%$ of the population in some homes: (2)

Nationally, Americans aged 65 and over make up only $9.7 \%$ of the population but account for $25 \%$ of the annual admissions to mental hospitals . (6)

In a study conducted by the National Institute of Mental Health (reported by the World Health Organization) (6) the following incidence of new cases of psychopathology of all types was found:

NEW CASES OF PSYCHOPATHOLOGY

$\begin{array}{lc}\text { Age Range } & \frac{\text { New Cases per }}{100,000 \text { population }} \\ \text { Under } 15 & \frac{7.3}{6.3} \\ 25-34 & 93.0 \\ 35-54 & 236.1\end{array}$

Since the aged do not exist in a vacuum independent of family and community attachments, we must also remember that the aged pose an indirect as well as a direct pshychiatric problem:

The experience of social and health agencies supports the view that there is probably a high incidence of "minor" mental disorder in the aged who have disturbed family relationships. Although their effect upon families and the general community has not been. evaluated, clinical evidence indicates that the families of aged persons themselves often require psychiatric help. (2)

The local indicators which OSPRG considered were the rate of sulcide, prevalence of alcoholism, the incidence of poverty, and inadequacies in mobility and low-cost housing.

\section{$\underline{\text { Suicide }}$}

The incidence of suicide among elderly persons in Oregon for the past ten years has remained consistently higher than their relative 
proportion of the population would indicate: The elderly comprise 10.8\% of the State's population but have on the average, accounted for $19.6 \%$ of the State's annual suicides. Obviously, a significantly larger portion of the elderly population feels desperate and alienated enough to choose death as preferrable to an unacceptable life. (See Appendix B for additional information).

\section{Alcoholism}

According to estimates derived from the E. M. Jellinck Formula, based upon a three year (1969-71) mean number of cirrhosis deaths in Oregon, there are an estimated 67,942 alcoholics in the state. (10) of those who died from cirrhosis of the liver in this three year period, $24.8 \%$ were 65 and over. (11) This yields an estimated 16,850 aged oregorians who have, or have had, alcoholic problems. Since approximately $30 \%$ of the elderly in Oregon reside in Multnomah County, OSPIRG estimates that there are about 5,055 elderly alcoholics within our case study area. Or, using an alternata measure, the State of Oregon Comprehensive Alcohol Problems Plan (10) estimates that the rate of alcoholism within Multnomah County for persons aged 20 and older is 96.3 per 1,000. Based upon this rate OSPIRG calculates that there are 6,789 aged alcoholics within our case study area. (See Appendix $C$ for additional information).

\section{Poverty}

It has long been recognized that the presence of poverty is positively associated with higher incidences of mental illness. The incidence of poverty among elderly persons in Oregon is about twice as great as it is among the general Oregon population. 
According to 1970 census data $11.5 \%$ of all persons in Oregon live below federally established poverty levels. However, about $23.6 \%$ of all elderly Oregonians live below the poverty level, and about $22.3 \%$ of all elderly residents of Multnomah County live below the poverty level.

Table I illustrates the standards upon which the determination of poverty level is based. This poverty standard assumes that people aged 65 and over require about $9.0 \%$ a year less to live on, and that single women and households headed by women require less than their male counterparts.

In terms of dollar amounts, approximately $50 \%$ of all elderly Oregonian households have annual incomes of less than $\$ 3,000.00$; and about one-half of this group have incomes of less than $\$ 2,000.00$ (Portland Action Committees Together).

\section{Mobility}

A study of the transporation needs of the elderly and the physically handicapped inthe City of Purtlano was sponsored by the Portland City Council and conducted under the auspicies of the office of Commissioner Lloyd Anderson, with the direction of Transporation Coordinator William S. Dirker, in the summer of 1972. The study is known as Project Mobility: "Access to the City."

Essentially, a reduction in mobility increases the level of stress experienced by the individual as a result of isolation, boredom, fnistration and depression and this is going to increase the likelihood of mental or emotional disturbances. 


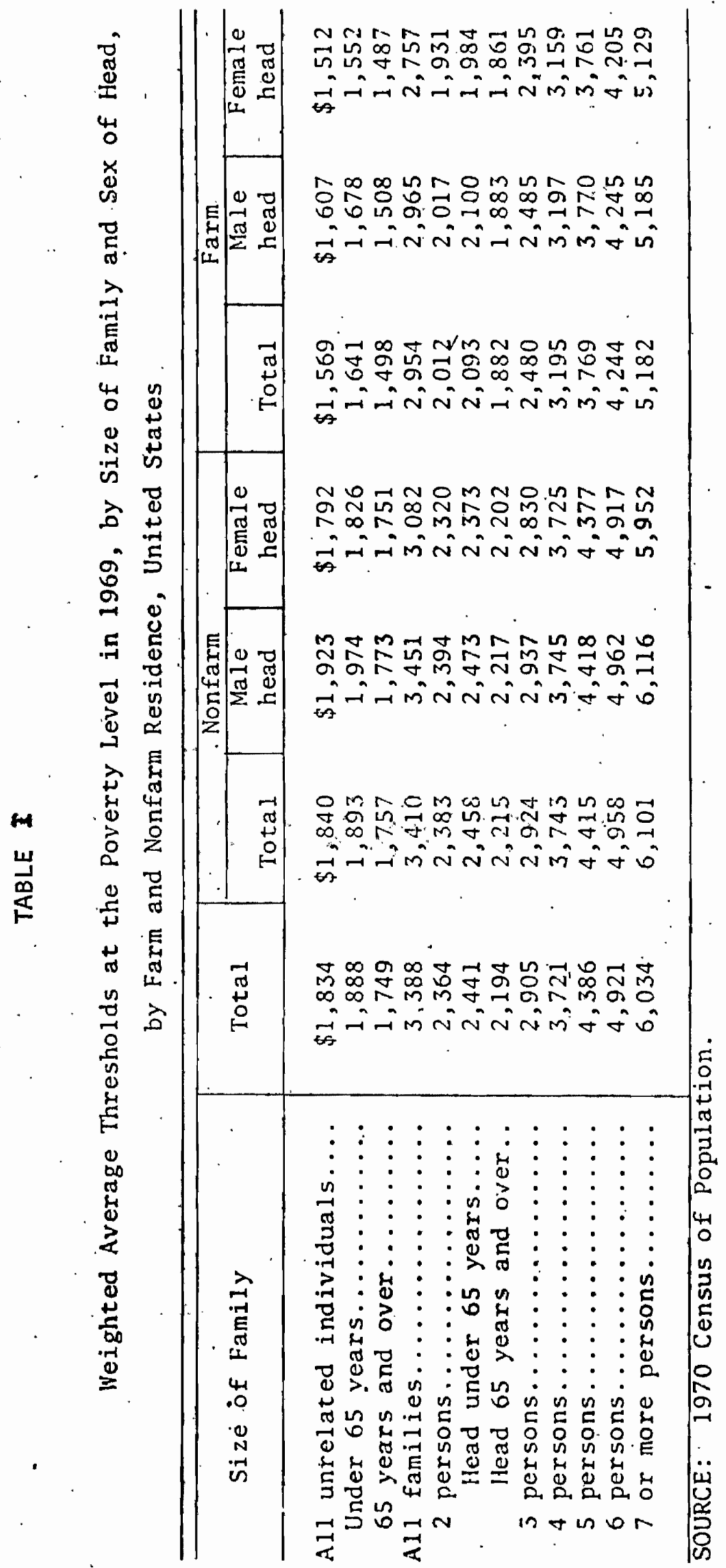


"Any limitation of mobility restricts a person's access to existing opportunities such as employment, education, recreation, and even the social and medical programs designed to assist them." "Futhermore, lack of mobility "imposes a very large cost on the impaired individual and on society as a result of reduced productivity and participation of the individual in society."(12) (See Appendix D for more complete summary of the findings of this report).

This study found that the total study population (made up of both physically handicapped and aged individuals) "is measurably less moblle than the general population. The extent of immobility of the study population is indicated by two basic conclusions: One, the study population makes an average of $40 \%$ fewer trips than the non-limited population. Secondly, the study population pays approximately $35 \%$ more per trip than the non-limited population per trip (12).

\section{Low-Cost Housing}

Before discussing the problcms of low-cost housing in the Portland area it would be informative to consider the following table which shows the dispersion of elderly Oregonians in terms of the types of housing which they currently occupy (based upon information provided by Portland Action Committees Together):

\section{ELDERLY HOUSEHOLD COMPARATIVE STUDY}

STATEWIDE (Percentages)
MULTNOMAH COUNTY (Percentages)
Single

Head of Household

Wife of Head

Relative with family

Non-relative

Group Quarters
28.3

35.0

21.0

7.6

1.6

$33 \cdot 3$

31.0

18.0

8.1

1.9

6.7 
ELDERLY HOUSEHOLD COMPARATIVE SHUDY (CONT.)

STAP EWIDE

(percentages)
MULTNOMAH COUNTY

(Percentages)

(Institutions: 5.5 )

including nursing homes, homes $f$ or the aged, hospitals, special care facilities)

(Non-Institution: .9) including boarding homes, Unknown rooming houses)

Total

$$
\frac{.1}{100.00} \quad \frac{1.0}{100.0}
$$

It is important to note that $28.3 \%$ of all elderly individuals statewide $(64,184)$ and $33.3 \%$ of the elderly in Multnomah County $(23,481)$ live alone. According to data provided by Portland Action Committees Together, a recent statewide survey. of 16,653 elderly Oregonians ascertained that single individuals have a high probability of need fince they have only one source of income and no companion to call upon.

Since we tend to think of elderly individuals Iiving in institutional settings, it is probably quite surprising that oxer $93 \%$ are living in private residences, and it is this $93 \%$ of all elderly Oregonians who might at some time be eligible for, and be in need low-cost housing.

The Housing Authority of Portland (HAP) is a locally administered program under the jurisdiction of the Department of Housing and Urban Development. The Federal Government provided funds to construct Iow-cost housing units throughout the country a number of years ago.'

The maximum allowable income levels range from approximately $\$ 4,200.00$ for an individual, to $\$ 7,200.00$ for a family of ten, and the maximum payment level is fixed at $25 \%$ of the income, according to Mrs. Drury of HAP. 
Approximately one year ago the federal govenment placed a moritorium on the payment of subsidies to low-cost housing projects, making it necessary for them to become self-supporting. This moratorium will remain in effect until at least July, 1974.

HAP has determined that it costs them, on the average, $\$ 50.00$ per unit per month to meet their operating expense's, and since they admitted too many very low-income people before the moratorium they are not now able to admit many people who cannot pay at least. $\$ 50.00$ per month. According to Mrs. Drury' of HAP their local policy is such that individuals, usually, must make at least $\$ 200.00$ a month to qualify for low-cost housing!

For elderly individuals on fixed incomes this aten times becomes an impossibility. The State of Oregon Department of Public Welfare has fixed a standard maximum allowable income for individuals who have "normal expenses" of $\$ 153.30$ per month for elderly individuals receiving OId Age Assistance, and \$220.86 for a couple receiving Old Age Assistance (including the cost but not the value of food stamps). Obviously, an individual who has a supplemented total income of $\$ 153.30$ per month cannot, at this time, qualify for low-cost housing and must, therefore, purchase housing on the open market. The elderly people who are least able to afford private housing are forced to spend a disproportionately high portion of their income to purchase this housing or they are forced to live in poor quality inexpensive housing (if any can be found).

The need for low-cost housing among the elderly becomes most evident when it is realized that there is currently a two-year waiting list for the low-cost housing units provided for the elderly in the 
Portland ietropolitan alrea.

Elderly people who are forced to spend a disproportionately large portion of their income for housing have to curtail expenditures in other areas (such as transportition, clothing, recreation, and possibly in their food purchases). As a result, obviously, lack of money and its subsequent restrictions -.. increases the stresses experiencedby the individual. Increased stresses also increase the likelihood of mental or emotional breakdown.

\section{Conclusions}

How many mentally ill elderly are there in Oregon? How many in Multnomah County?

If suicide is an indicator of extreme stress and personal unhappiness, then we must assume that a large number of the elderly are under a disproportionate amount of stress since the incidence of suicide among the aged is disproportionately high.

If alcoholism is an incicator of mental illness, then it must be remembered that OSPIRG has estimated there are 16,880 elderly Oregonians who have, or have had, alcoholic problems and that there are between 5,055 and 6,789 elderly alcoholics within Multnomah County.

We have determined that statewide there are approximately 53,400 elderly individuals living below the U.S. poverty level (a level which assumes that the elderly require about $9 \%$ less a year to live on). Within Multnomih County there are approximately 15,725 impoverished aged. The poorest of these elderly individuals cannot, at this time, take advantage of public low-cost housing because they do not make enough money to pay the minimum required to meet the operating costs of the 
housing unit. Therefore, their already tight budgets are squeezed tighter $\varepsilon . s$ they are forced to use a disproportionately large portion of their income $\because$ for housing.

The elderly within Portland have extremely limited mobility: they make $40 \%$ fewer trips and they pay $35 \%$ more per trip than the general population. The mobility restrictions placed upon the elderly living in more rural parts of the state are probably greater, since public transportation is generally less accessible. Reduced mobility implies. less access to recreation and socialization for people who are more likely to live alone and who also generally have more time avallable for such activities.

Statewide, 64,184 elderly individuals live alone, and within Multnomah County approximately 32,481 elderly persons live alone. These individuals are particularily "at risk" in terms of patentially becoming mentally ill since they have only one income source, and have no companion to call upon for everyday emotional contact.

Considering the pervasiveness of the limitations under which many of the elderly in this state live, it is small wonder that national studies have estimated the incidence of mental illness to be so high among elderly populations. When these figures were approximated to the elderly population of Oregon we found that the estimated incidence of mental illness ranged from 24,947 to 26,082 mentally ill elderly Oregonians, with 14,284 elderly Oregonians disoriented enough to qualify for Involuntary mental hospital commitment. Within the group of Institutionalized elderly persons we might expect from 40 to $50 \%$ to be "confused and disoriented." 
All of the data, admittedly loosely developed estimations and approximations, add up to a conclusion that a substantial number of elderly Oregonians are emotionally and/or mentallydisturbed, and are in need of some type of mental health care or treatment.

CAN THE ELDERLY BENEFIT FROM TRADITIONAL MENTAL HEALTH SERVICES?

Another issue that must be consione before we analyze the mental health services that are currently being provided to the elderly is the issue of whether or not the elderly can benefit from traditional mental health services. OSPIRG researched this question by reviewing the literature related to mental health care of the elderly, and OSPIRG also sought the opinions of many local profes onal mental health workers in relation to this question.

Elderly mentally ill persons are generally placed into one of two groups of mental disturbances which emerge as significant in old age: (1) those who have functiona? disorders of affect or content in the absence." of brain damage, and (2) those who have organic disorders as reflected by the presence of brain syndromes. The terms senile dementia and sedility are diagnostic equivalents to organic brain syndromes.

The elderly can suffer from any type of functional mental illness found in younger age groups: depressions, neuroses, character disorders, and psychoses. Generally, it is agreed that the ability to diagnose and. treat those forms of mental 1liness are not influenced by the age of the person. However, there is one category of mental illness--organic brain syndromes-which belongs almost exclusively to older middle-aged and elderly persors. 
According to the National Institute of Mental Health, an organic brain syndrome is defined as "a disorder caused by or associated with impairment of brain tissue function. It may be manifested by disorientation, loss of memory, and impairment of the ability to learn, comprehend, calculate, and exercise judgement. It may be psychotic or nonpsychotic, mild, moderate, or severe."

Additionally, the organic brain syndrome may be acute or chronic: an acute organic brainsyndrom is one in which "the brain damage is temporary and the brain pathology and its accompanying organic brain syndrome is reversible;" a chronic brain syndrome is one in which "the brain damage is permanent and its accompanying brain syndrome: is not reversible." (13) Acute and chronic organic brain symäromes can only be differentiated from each other by the time test, i.e. if the person recovers then the organic brain syndronsas acute, if the person does not recover then it must be chronic.

Based upon 1964 data, the incidence of psychiatric disorders requiring psychiatric hospitalization was "941 per 100,000 among the elderly population; a rate three times higher than the rate of 284 per 100,000 for those under 65." (14) The diagnosis made most commonly in these elderly patients was organic brain syndromes; "among the geriatric residents admitted for the first time $77.7 \%$ were given this diagnosis." (4 Distinguishing between functional and organic disorders, particularily chromic brain syndromes, is obviously important in terms of the treatment program indicated by the diagnosis.

The diagnosis and treatment program prescribed by the clinician is going to reflect his theoretical framework regarding what he believes constitutes normal and healthy, as opposed to abnormal and unhealthy, 
behavior among the elderly.

The disengagement theory of aging explains the tendency toward withdrawal and disorientation among the elderly in positive terms:

If an old person seems uninterested in any kind of activity, or indeed, even in his close relatives, he may not necessarily be in poor mental health. Nor is it unusual for aging men and women in their $70^{\prime} \mathrm{s}$ to detatch themselves from some of the usual rules and obligations of their earlier lives... Some people who have passed 60 make an excellent emotional adjustment by almost completely detaching themselves from earlier pursuits, concerns, and personal involvements. Their healthy self-centeredness is not equivalent to mental stagnation, but reflects a positive, satisfying, constructive philosophical concentration on the meaning of their own

lives and life in general. (3)

Implicitly, when clinicians, physicians, or anyone else responds to behavior, which among any other age group would be considerred unusual, with the statement "he's just getting old" they are adopting this disengagement theory .

In contrast to this theory, most clinical gerontologists have viewed withdrawal and disorientation among the elderly as signs of mental illness. "The most important stereotype regarding the elderly is that a certain amount of emotional instability, forgetfulness, depression and withdrawal is normal and, therefore, does not warrant, medical intęrvention," states Dr. Eric Pfeiffer, a Duke psychiatrist. "On the contrary, early treatment might prevent deterioration, institutionalization, or both."

Dr. Robert Davis, Ph.D., Director of the Clackamas County Mental Health Clinic, pointed out that there are three false assumptions which are generally accepted by the elderly themselves, and by a large number of mental health professionals: (I) if a person is senile then this 
. is a permanent condition, (2) if a person is behaving unusually and he is old, then he is senile, and (3) that aging creates changes in the brain resulting in senility. Dr. Davis pointed out that "if these assumptions are accepted then old age can only be considered synonymous with senility and craziness. He went on to say that "no medical research into the area of aging has established that there is any connection between brain changes with age and the actual changes in the capacity of the individual to maintain his psychological functioning."

Ms. Ruth Hudson, Director of the Protective Services Unit, Multnomah County Mental Health Section, continued with this same line of reasoning when she stated, "When older people exhibit symptoms they are classified as senile and written off as being hopeless. But the causes and syrptoms may"be-the same as those exhibited by a younger person' who would then be given treatment for them."

This controversy surronding the diagnosis and treatment of organic brain syndromes is crucial in terms of the mental health treatment the elderly receive in Oregon. Organic brain syndromes are assumed to be caused by deterioration of brain tissues, and by definition, chronic brain syndroms are irreversible and therefore, untreatable.

However, the integrity of this diagnostic distinction can be questioned, based upon several issues; (I) according to the National Institute of Mental Health, "even a skilled geriatric psychiatrist... cannot always positively state whether an old person's mental state is functional or organic." (3); (2) numerous research studies indicate 
that there is no relationship between actual, visible brain changes and function in eldeily people; and (3) controlled studies have shown that when elderly mentally ill individuals, including thase liagnosed as having organic brain syndromes, are given appropriate psychiatric treatment their récovery rate is as good as among any other age group.

Numerous studies, using post mortum examinations, have shown that; while demonstration of the primary characteristics of organic brain syndromes and physical deterioration of the brain do tend to parallel one another, there were "functional cases with marked cerebral changes and some patients diagnosed during life as suffering from organic brain syndrome, but showing only slight macroscopic and microscopic vascular or parenchynal abnormalities in the brain," accoräing to Dr. Felix Post, MD, a noted British psychiatrist. (16)

Physical and psychological tests have been developed to assess the extent and degree of organic impairment. However, according to Dr. Post, "there is not a sing̈le test of cognitive impairment which will in all circumstances differentiate, without an overlapping area of scores, groups of patients diagnosed as brain damaged subjects, from healthy ones." . We must also remember that "even when a patient's score is so low that it falls below the area of overlap, the impairment may not, after all, be due to pathological processes within the brain." (16)

These tests, essentially, evaluate "the individual's performance or behavior, which depends not only upon the brain but upon many other factors, such as motivation, attention, anxiety, and the individual's psychological reaction toward the testing." (16) (See Appendix E for an example of a "mental status questionmire" used to diagnose organic brain syndromes.) 
In terms of the relationship between the status of the brain and. clinical manifestations of organic brain syndromes, many variables other than age (for example, sex, race, socio-economic background, and education) can affect the cognitive function and its assessment. Investiga tions have demonstrated that "deteriorated|old people in community and demented patients in hospitals belong to the lower socio-economic groups, have never married, or have been widowed, to a significantly greater ex tent than their contemporaries" and it has, therefore, been suggested that "lack of social contacts and of opportunities to keep up interests and skifils may hasten or even precipitate senile dementia" (i.e. organic brain synaromes). (16)

However, despite the limitations of physiological and psychological testing, and the uncertainty of clinical assessments as a result of interviewing, "when all of the primary characteristics of organic brain symdrome are present, this is the diagnosis usually made regaraless of the presence of other behavior disturbances or psychotic symptoms." (14)

Dr. Muriel Oberleder, Ph.D., Chief Psychologist, Geriatric Services, Bronx Hospital, New York City, believes that anxiety associated with aging underlies and causes all senile symptoms. "We pay lip service to possible emotional and social stresses and environmental factors, but we rarely. . consider the possibility that elderly people who have had breakdowns can recover," Dr. Oberleder said. (5) "We usually think of senility as involving memory loss, disorientation, confusion, aggressive and agitated behavior, senseless rambling, phoblas, hallucinations, delusions, and infantile regressive behavior. But how different are these symptoms from ones. of any seriously regressed patient of any age? I think that they are the symptoms of psychosis, not necessarily senility. The only difference 
is that when a patient shows these symptoms after 60 he is labeled senile." (5)

"We have been brain washed into thinking that there are very erudite and definite explanations of senility," Dr. Oberleder continued. "We speak. freely of arteriosclerosis of the brain and chronic brain symdromes. We are told that we lose millions of neurons every day from our brain cells, so that our brain shrinks in measurable pnoportion to our years, and for that reason alone we must expect irreversible changes in old age. These ideas are so fixed that even when dramatic studies indicate that there is no relationship between actual, visible brain changes and function in elderly people, we tend to overlook those results." (5)

- According to the National Institute of Mental Health, "even a skilled, geriatric psychiatrist...cannot always positively state whether an old personis mental s.tate is functional or organic." (3) Abnormalities of cognitive functioning may be the result of manic-deparessive or schizophrenic disturbances, or acute depression:

Even though every writter source which OSPIRG investigators consulted on this subject agreed that the ability to accuratelly diagnose organic brain syndromes has repeatedly shown to be unsuccesisful' (ith teirms... of actually diagnosing the presence of organic braim damage) this continues to be the most prevalent diagnosis made for individwls over the age of 65, both nationally and with Oregon.

This controversy surrounding the diagnosis and treatment of organic brain syndromes is crucial in terms of the mental health treatment being provided to the elderly in Oeegon. According to data prepared by the $\cdots$ Oregon State Mental Health Division, for the years 1968-69 through 1970-71, $60.9 \%$ of those people over the age of 65 admitted to one of Oregon's state mental hospitals. were diagnosed by the hospital staff as having some type 
of organic brain syndrome, and for those over the age of 75 this proportion rose to $83.3 \%$. (See Table VIII for more detailed information.)

The significance of this diagnostic ambiguity becomes apparent when it is realized that most clinicians believe that "psychiatric disorders of later life have a particularily poor prognosis when evidence of brain impairment is present," and so therefore, "all too frequently, aggressive therapeutic approaches are reserved for patients with disorders of a functional type "(3).

Controlled studies have shown that when elderly mentally-ill individuals, including those diagnosed as having organic brain syndromes, are given appropriate psychiatric treatment, their recovery rate is as good as among any other age group.

A report issued by the National Institute of Mental Health states that "response to treatment by patients 65 and over is virtually the same as for other age groups. Regardless of the type or severity of the psychological problems, about a third can be expected to recover, another third to vastly improve, and the rest to show little or no change, or grow worse "(3).

A.J. Goldfarb, a pioneer in the treatment of the elderly, developed a special psychotherapeutic technique with geriatric patients which reportedly was ineffective with psychatic disorders, but quite effective with -.psychoneurotic disorders and patients suffering from acute and chronic brain syndromes (17).

Group psychotherapy has also been shown to be effective with elderly patients suffering from chronic brain syndormes associated with arteriosclerosis or senility. Of the 110 elderly patients treated by this form of psychotherapy, $40 \%$ showed improvement and were released from 
hospitalization (17).

Dr. Muriel Oberleder has stated,

I have had some good results with traditional psychotherapy with elderly patients. However, I have had no opportunity to follow them up, and I do not know how long our cures last, if you want $\therefore$ to call them cures... When such patients do recover we cannot expect then to continue to function well for long if they go back to the very same situations that drove them crazy in the first place. Family therapy should be used with the elderly people's family as with those of younger patients. The families have many attitudes to be changed, and many guilts to be worked with, and they must be involved in plans for the patient. Of course, generally speaking, the situations that cause breakdown in old age are part of our society, and we do not have an atmosphere conducive to emotional well-being for the aged. (5)

Finally, a relatively new treatment program, Reality Orientation Therapy, has been developed for use with severely mentally impaired elderly individuals. The program is based on the assumption that even with the most severely impaired or mentally ill individual there is the capability of improvement when he is exposed to a consistent program of reality orientation, in the most literal meaning of that phrase.

According to data prepared by the Veterans Administration Hospital, Tuscaioosa, Alabama, "a total of 227 patient have been placed into (Reality Orientation) classes, with 50 graduating and receiving diplomas, and $47(20 \%)$ of those who attended classes are now discharged or on trial visit at their homes, with their families, or in community facilities". (18)

This recovery rate is remarkable when we realize that these individur -als were seriously impaired, and their conditions were thought to be irreversible.

Dr. Del Kole, M.D., Region I Director of the State Mental Health Division, responsed to a query regarding the feasibility of providing mental health care to the elderly by saying, "people have generally written the elderly off. The apparent senility as a result of arteriosclerosis, or 
whatever, turns out to be just plain depression." He continued by saying, "the issue is quality of life for the elderly. A holistic view must be taken; if a minimal quality of life is maintained then the mental health of the individual will be maximized."

Finally, Dr. Walter Klopfer, Ph.D., a Professor pf Psychology and instructor in the Institute on Aging, Portland State University, stated that . in relation to the feasibility of elderly individuals benefitting from mental health counseling, "taking two people who are basically equal in ego strength, the one who is older is going to work harder and is more likely to benefit from psychotherapy, since he knows he has a limited amount of time left."

Essentially, then, all of these data support: the notion that elderly people diagnosed as having organic brain syndromes, as well as functional disorders, can benefit from mental health treatment.

In addition, trése data seriously question. the validity of the diagnostic classification of organic brain syndromes, based on the inability to accurately diagnose the presence of an organic brain syndrome. This is especially significat because this diagnosis implies that nomental. health treatment would be beneficial, although the ability to successfully treat individuals diagnosed as having an organic brain symdrome has been demonstrated. 
MENTAL HEALTH CARE AND THE IAW

The final area which should be explored before we look at the mental health services being provided to the elderly in Oregon is the legal status of mental health care, both nationally and within the state. of Oregon.

\section{Federal La'ws}

One primary consideration related to the legal status of mental health care is the issue of whether or not individuals have a constitutional right to mental health treatment. Until recently, no definitive court rulings had been made, leaving this question, essentially, to individual states to decide.

Within the past several years important, but conflicting, rulings have been handed down - in United States District Courts. These rulings pertained to the rights of people involuntarily committed to state mental institutions to receive adequate mental health treatment. One of the most noted rulings, affirming the constitutional right to treatment for committed indivduals, was the case of Wyatt $\mathrm{v}$ Stickney (1971). In this case, Judge CoJ. Johnson ruled that

patients at Bryce Hospital, for the most part, were involuntarily committed through non-criminal procedures and without the constitutional protections that are afforded defendents in criminal proceedings. When patients are so committed for treatment purposes they have a constitutional right to. recelve such treatment as will give each of them a realist 1c opportunity to be cured or to improve his or her mental, condition,.... and (the) purpose of involuntary hospitalization for treatment purposes is treatment and not mere custodial care or punishment.... This is the only justification, from a constitutional standpoint, that allows civil commitmerts? to mental institutions. 
Judge Johnson went on to say that adequate and effective treatment is constitutionally required because, absent treatment, the hospital is

"transformed into a penitentiary where one could be held indefinitely for no convicted offense." In defining what was meant by adeque te and effective treatment, the court stated

there seem to be three fundamental conditions for adequate and effective treatment programs in public mental institutions. These three fundamental conditions are: (1) a humane psychological and physical environment, (2) qualified staff in numbers sufficient to administer adequate treatment, and (3) individualized treatment plans.

The court subsequently operationally defined the meanings of these three fundamental conditions for the treatment program at Bryce State Hospital. In addition to this case, other courts have recognized the right to treatment: State $\mathrm{v}$ Bargy (1970), Maatallah v Warden, Nevada State Prison" (I970), and U.S. ex rel. Schuster v Herold (1969).

It should be recognized, however, that the right to treatment is by no means clearly $\in$ s vablished: In Burnahm $\vee$ Department of Public Health of the State of Georgia (1972), घinother Federal District Court ruled that there is no constitutional right to treatment. "In explaining his ruling, Judge Sidney 0 . Smith stated

the plaintiffs' complaint in the instant case is predicated squarely upon the proposition that the "adequacy" of the diagnosis, care, and treatment of patients in Georgia's mental institutions is not merely a matter of state law, but is a federal constitutional issue.

Although Judge Smith recognized that persons committed to Georgia's mental institutions might have a moral right to treatment, he disagreed with plaintiffs that Georgia was under a legal obligation to provide effective treatment.

With the exception of a recent Alabama decision discussed hereinbelow, the courts have not gone beyond recognizing a 
statuatory right to treatment in those jurisdictions where such a right exists...This court takes notice of Chief Judge Johnson's rulings in the Middle District of Alabama... This court respectfully disagrees with the conclusions reached by that court in finding an affirmative federal right to treatment absent a statute so requiring.

These two conflicting District Court rulings were both handed down within the jurisdiction of the Fifth United States Circuit Court of Appeals. Both cases were jointly appealed, and the appeals were argued in December, 1972. However, at this time, this Court of Appeals had not handed down a decision. Therefore, for all purposes, there has, as yet, been no determinization as to whether there is a federal constitutional right to receive adequate mental health treatment within public mental institutions.

In a separate legal area, the legal right to community facilities as"an alternative to hospitalization wàs upheld in 1966 in a decision by the United States Court of Appeals, Chief Judge David I. Bazelon presiding. In Lake $\mathrm{v}$ Cameron, a patient who had been previously committed to St. Elizabeths Hospital in Washington, D.C. was found not to need the many psychiatric services offered, nor to require total deprivation of her liberty. The patient, however, did not have the financial resources: to find alternative community care. Judge Bazelon ote

deprivations of liberty solely because of dangers to the ill persons themselves should not go beyond what is necessary for their protection. The court's duty to explore alternatives in such a case is related also to the obligation of the state to bear the burden of exploration of possible alternatives an indigent cannot bear.

Essestially, this ruling affirmed the right of individual to be placed in a minimally restrictive setting commensute with the 
severity of his mental disorder. It also affirmed the obligation of the state to assume the costs of exploring treatment alternatives which an indigent cannot bear.

In addition, the treatment provided to elderly Oregonians is also partially determined by Title XIX federal guidelines. In order for the State Mental Health Division to receive reimbursement for the costs of providing care and treatment within state mental institutions to elderly persons who would qualify for welfare assistance were they living in the community, the state is required to meet federal Medicaid guide'lines.

The State Public Welfare Division, via their hospital laison vorkers, is responsible for supervising the care and treatment provided to elderly persons in state mental hospitals to insure that Medicald requirements are being met for those who qualify for welfare assistance.

These Medicaid guldelines speclfy that an individualized treatment plan must be recorded in the hospital record for every case eligible to receive public assistance while recelving treatment in a state mental hospital. In addition, within 30 days of admission, the hospital record must contain

A. A written report of medical evaluation which includes diagnosis, summary of present medical findings, medical history, mental and physical functional capacity, prognosis, and explicit recommendations by the physician with respect to admission to or continued care in a mental hospital.

B. Recorded psychiatric and social evaluations.

C.A plan of care to include orders for medications, treatments, restorative services, diet, special procedures for the health and safety of the patient, activities, and plans for continuing care and discharge. ( Ig)

A quarterly review of all hospital records is also required to insure that the treatment plan, as recorded, is being carried out, or that necessary revisions in the treatment plan are made. 
The Public Welfare Division is also responsible for helping to develop plans for post-hospitalization placement in the community, or placement in the community as an alternative to hospitalization. To encourage alternative placement, the Public Welfare Devision is to provide information to a court "considering commitment to a mental hospital for possible community care and (to) participate in arranging for such care when required for any person eligible for public assistance." In addition, the Public Welfare Devision is to "partichpate in developing community care resources for mentally ill persons in their home counties" for the purposes of "education, training, and sociallization of mentally 111 people." (19)

Oregon State Laws

Within Oregon there are no state statutes which pertain, specifically, to the mental health services to be provided to elderly persons Elderly Oregonians have no legal protection to insure that they will be provided with appropriate and adequate mental health care to meet their mental and emotional needs, either through community mental heiith programs or within the state mental hospitals.

The Oregon State Mental Health Division as manded under ORS 430.021

shall direct, promote, correlate, and coordinate.all the activities, duties, and direct services in the fields of mental iliness, mental retardation, alcoholic education and rehabilitation and mental: health; and direct, promote, correlate, and coortinate the mental health activities of all governmental organizations throughout the state in which there is any direct contact with mental health programs.

Services to elderly persons are included within this mandate, with" this authoriazation subsumed under the cause- of the illiness rather than being'stipulated by the age of the client. Therefore, the elderly are 
included within the appropriate jurisdiction of the State Mental Health Division. However, elderly Oregonians, spectfically, are not guaranteed the provision of any form of specialized treatment programs. Children are the only age group which has specifically mandated treatment programs.

The State Mental Health Divison has also not adopted any policies which reflect a strong commitment to serve the elderly, as a high risk population, although the Division has adopted similar policies stressing the provision of mental health services to the mentally disabled and retarded, those with alcohol problems, and those with drug problems.

Two important bills were passed in the 1973 session of the State Legislature which reflect the current concerns and priorities of the State Mental Health Division.

Senate Bill 448 amended Oregon's community mental health clinic statutes (ORS 430.610 through 630.670), shifting the glinics from an outpatient, clinic orientation to a comprehensive, catchment-area-based mental health program. The defined population to be served was expanded to include services to the mentally or emotionally disturbed, developmentally disabled, and drup-dependent persons as well as the mentally retarded and the alcoholic.

The basic services to be provided by the community mental bealth programs (as renamed) were expanded to include "outpatient services for persons with mental or emotional disturbances, mental retardation and developmental disablities, and alcohol and drug problems," and also was expanded to include aftercare for persons within the defined population who have been released from a state hospital for the mentally ill or retarded.

Another important expansion of the community mental health programs was the added commitment to provide alternatives to state hospitalization 
within the community, subject to the funds available, for the defined population. Such alternative services are to include emergency services on a 24-hour basis (such as telephone consultation, crisis intervention, or prehospital screening), care and treatment for a portion of the day or night (which may include day treatment centers, work activity centers, and preschool programs), residential care and treatment facilities such as halfway houses, detoxification centers and other communty living facilities, independent treatment in community hospitals, and basic continuity of care.

This bill represents an important expansion of community-based mental health services. However, although services to elderly persons might be included under services to the mentally ill, drug-dependent, or other defined target groups, it is important to note that other "high risk" populations are specifically mentioned while the elderly, as a group, ane not considered to be a high priority as receiviers of treatment, although they currently represent a significant proportion of the state's mental hospital population. Also, as a group, it is estimated that there is a high incidence of mental izlness or emotional disturbance among the elderly residing in the community as well.

Senate Bill 510 modified the provisions related to the involuntary commitment of mentally ill persons. Mentally 111 persons are now committed to the State Mental Health Division rather than to a specific state hospital. In addition, this legislation altered the pre-hearing process, the hearing process itself, the length of commitment, and petitioning procedures for committed patients. Related to the elderly as a group, two aspects of this legislation were particularly; significant. 
rather than to a specific facility, it is now possible for elderly persons to be placed directly into a sheltered setting without first receiving treatment in a state mental hospital.

Secondly, this legislation contained a "bill of rights" for all committed persons which included, among other things, the right to a written treatment plan, and the right to exercise all civil rights in the same manner as non-committed persons, including the right to dispose of property, make purchases, enter into vontractual relationships, and vote, unless ajudicated incompetent.

One other recent Oregon legislative action is particularliy pertinent to the mental health services which may, in the futture, be provided to elderly Oregonians. As a result of legislation passed in the last emergency session of the State Legislature Title XIX furds have now been extended to cover outpatient mental health services as well as state mental hospital care for all people who qualify for public assistance. In the past, the state had to assume all of the costs of providing mental health care services to welfare recipients, without reimbursement from Public Welfare. Now, the State Public Welfare Division will also pay the costs of outpatient mental health care (as they paid for most medical care in the past) for persons eligible to receive public assis:tance. This will represent a substantial savings the state since Public Welfare will qualify, through Title XIX, for federal matching funds which will contribute substantially to the state's costs in providing these services.

This legislation stipulates that services must he provided by community mental health programs, but these services do mot necessarily have to be provided within a community mental health program facility. Therefore, 
this legislation would provide reimbursement for all individual or group therapy, as well as medication adjustments, provided by community mental health programs to elderly persons residing within sheltered settings who also qualify for public assistance. .

This legislation thereby makes it financially feasible to provide mental health treatment to an important population of elderly persons, those who are residing in sheltered settings, and who are mentaliy ill or impaired, but who are now not receiving any mental health care whatsoever, in most cases.

Although this legislation becomes effective July 1 , 1974, according to Glenn Drúgger, whose responsibility it is to supervise the implementation of Title XIX regulation for the State Mental Health Division, the Division has not yet begun the process of developing guidelines for utilizing these funds to provide mental health services to needing elderly persons in sheltered settings. Mr. Drugger stated, "unfortunately, the elderly still receive the lowest priority" in the provision of mentàl heal.th services.

\section{Summary}

Both federal and state laws create a fragmented, and at times contradietory, system for the provision of mental health services. This is not surprlsing considering the relative youth of the mental health field, the progressing evolution of treatment techniques and theoretical orientations related to treatment, and the high degree of skepticism related to mental health treatment of any type by much of the American public.

However, the danger in this fragmentation is that a poor level of mental health care is often provided. While state mental hospitals are 
no longer "warehouses" for the mentally ill, residents of state mental hospitals, like all'Oregonians, have not yet been guaranteed a legal right to receive adequate mental health treatment. Perhaps as significantly, recent Oregon legislation may make it possiblie for sheltered settings to assume the role formerly filled by the state mental hospitals--as "Ivarehouses" for large numbers of mentally $\mathrm{I} I l$ elderly Oregoniens. 
CHAPTER II

COMMUNITY-BASED MENTAL HEALTH SERVICES

\section{INTRODUCTION}

'UsIng Multnomah County as a case study area, OSPIRG investigated the community-based mental health services which are available to the elderly within the county. Since Multnomah County is one of the most urbanized areas of the state, with a large number of social services geographically accessible to members of the population, and in addition, contains approximately $31 \%$ of the elderly residents of the state, OSPIRG felt that this area would optimally reflect the level of mental health services available to the elderly throughout the state.

Mental health treatment agencies contacted included the Multnomah County Mental Health Section; the University of Oregon Medical School Crisis Clinic, the Psychiatric Outpatient Clinic, and the Social Services Unit; and a number of privately administered agencies providing personal counseling. In addition, OSPIRG peripherally considered the services provided by Project ABLE (A Better Iife for the Elderly), sinee this program attempts to modify some of the specific causal factors contributing to mental breakdown among the elderly.

OSPIRG considered the following aspects of communty mental health treatment to be particularily important: (1) the number of elderly individuals being served, (2) the types of treatment which they are receiving (the modalities used and length of treatment), (3) the types of specialized treatment programs established for the elderly which are being offered, or being planned for implementation, by the agency (e.g. 
a home visiting counseling program, or specialized socialization groups), (4) the numbers of professionals employed by the agency who have had training in gerontology, and the types of in-service training programs offered by the agency regarding mental health problems of the elderly, and (5) the types of consultative services which they provide to interested parties, particularily nursing homes or homes for the aged within Multnomah County.

In addition, OSPIRG solicited the opinions of professionals working within these agencies, regarding the current mental health services available to the elderly, any possibse changes or additional services which they would recommend, and their viewpoints regarding the problems involved with providing mental health care to the elderly.

Information from private psychotherapists, physicians, private hospitals or medical groups, ministers, and other neighborhood resources was not generally solicited. Investigation of rec ational organizations available to the elderly was also omitted. Recreation provides an invaluable source of timulation, surport, and a sense of 'group involvement for elderly individuals. However, this OSPERG investigation was more directly concerned with those elderly individuals who are in need of in-depth mental heałth treatment.

The services offered by the Multnomah County Mental Health Section will be considered in detail in relation to the five variables mentioned previously. Then the University of Oregon Medical School units, privately administered counseling agencies, and Project ABLE will each be looked at briefly. Finally, an assessment of these services and specific recommendations follow. 
The Multnomah County Mental Health Section has four area clinics: the Downtown branch, a unit at the Albina Multi-Service Center; a unit at PACT (Portland Action Committees Together) in southeast Portland, and a unit in the northeast portion of the county. This section also operates a School Mental Health Project which serves east county schools, and Project ABIE Protective Services Unit, which serves only those individuals over the age of 60 who are threatened with likeli institutionalization were these services not provided to them. Due to the eligibility restrictions of the Protective Services Unit, these services will be distinguished from those provided by the mental health clinics.

The Number of Elderly Provided With Mental. Health Services

According to the Multnomah County Mental Health Section, cumulative data from their "Admission Face Sheets" for the period January 1, 1973 through June 30, 1973 , indicate that the clinics admitted a total of 104 individuals aged 65 or older during this six month period as new clients, only $6.2 \%$ of the 1,668 clients admitted (see Table II). Data regarding the number of clients served, as opposed to admitted, was unavailable since they compile only information on new admissions.

The Protective Services Unit admitted a total of 81 of these elderly clients. Therefore, excluding these clients, the mental health clinics admitted a total of only 23 elderly clients during this six month period, only $1.4 \%$ of their total admissions.

Obviously, the Multnomah County Mental Health Section is serving a disproportionately small number of elderly clients. Since the elderly 


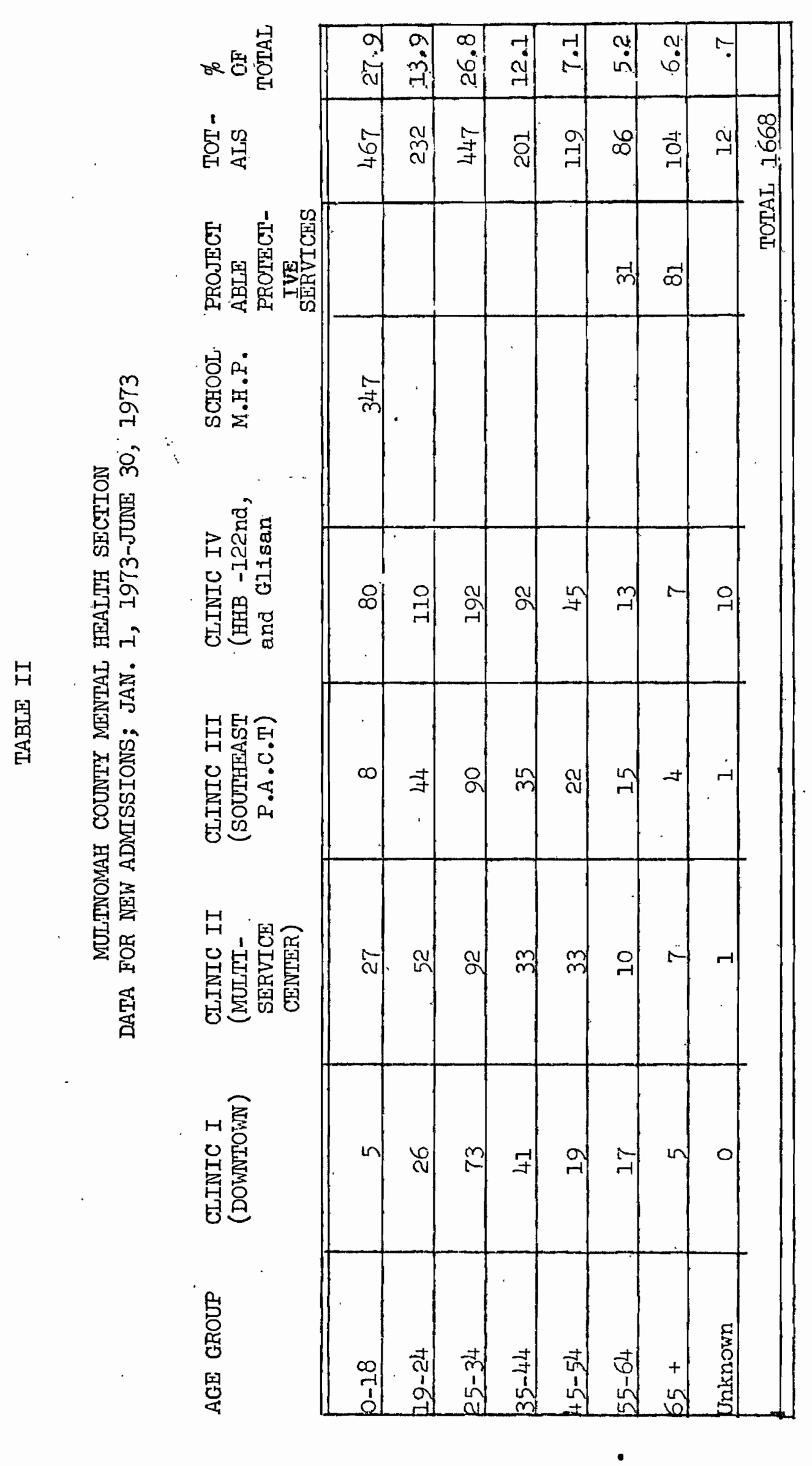

.50 
account for $12.7 \%$ of the population within the county, on the basis of sheer numbers we would expect to see a much larger number of elderly clients being served. In addition, the studies cited previously (see Chapter I) have indicated that the elderly are a particularily high risk population wtth a much higher rate of psychopathology than other age groups within the population, auggesting that a rate much higher than $12.7 \%$ of the client population would be the most reasonable.

When Dr. King, M.D., Director of the Downtom branch of the Mental Health Section was asked why so few elderly were seen by the clinics, he responded that "the clinics will serve older people just like anyone else, but the person has to make his own appointment." He then went on to say that they will sometimes make exceptions to this policy, as in the case of referrals from Community Health Nurses. Dr. King added that he thought that "older people are getting attention from private physicians and the University of Oregon Medical School," Implying that they were being adequately served by other community resources. This OSPIRG investigation does not bear out this assumption--there appears to be a dirth of elderly clients at all mental health treatment agencies within the county, with few exceptions.

In fact, Community Mental Health Clinics throughout the state serve comparably few elderly individuals. Data contained in the Annual Report Community Mental Health Clinics, prepared by the State Mental Health Division, for the years 1969-70 through 1971-72 indicates that in 1969-70 the total number of elderly individuals admitted was 111 ( $0.9 \%$ of the total of 12,245 admissions), in 1970-71 the number was 139 ( $1.1 \%$ of 12,892 admitted), and in 1971-72. the total number was 99 (only $0.7 \%$ of 
of 13,802 admitted). With the elderiy representing only about $1.0 \%$ of the annual admissions to Community Mental Health Clinics, this group is obviously not receiving a proportionate amount of mental health care from the states' community mental health programs.

Nationally, the aged have not received much attention from most community mental health centers. A recent survey of federally assisted centers found that people over sixty-five years old make up $12 \%$ of the catchment area populations but less than $6 \%$ of the centers' populations. In fact, only one center in ten sees.as many aged as would be expected just on the basis of their numbers in the catchment areas...The small amount of service given to the aged is occurring in the presence of indictions that maladaption and mental illness are very frequent among them. (21)

However, on the whole, Oregon's Mental Health Minics do not even begin to meet the rather poor national average of treating about $6 \%$ elderly persons. Oregon has shown national leadership in many areas, including the assurances of human rights. It is only reasonable that the same quality and leadership be expected in the area of mental health treatment, particularly regarding the elderly .

As a minor digression; one other mental health treatment source will be momentarily considered.

Alcoholism was mentioned as one indicator of mental illness. It was estimated that there were over 5,000 alcoholics among the elderly population in Multnomah County. OSPIRG solicited information from the State Drug and Alcohol Section regarding the number of elderly individuals treated in their programs. However, they do not complle statistical data on the basis of the age of their clients, and so data regarding the number of elderly treated is not available. Dr. Del Kole, Region I Director of the State Division of Mental Health, did state that within the Drug and Alcohol Section there are few elderly people being served because "alcoholics and drug users tend to have shortened life spans--they tend to burn 
out or die before they reach old age." However, Mr. Laverne Jones, Director of Edgefield Manor, the county operated nursing Home/home for the \&ged, stated that about $60 \%$ of their patients have had alcohol problems sometime in their lives. Although this may reflect a heavy influence from the Burnside population, it appears that elderly persons with alcohol problems tend to be institutionalized rather than receiving treatment on an out-patient basis through services such as those provided by the Drug and Alcohol Section.

The Type of Treatment Services the Elderly are Receiving

Unfortunately, the computerized record-keeping system used by the county has not been capable of cross-correlating variables. Therefore, we know how many individuals of different age groups have been admitted, their ethnic identities, their income levels, and their levels of education, but we can say nothing about the relationships between these variables. A notable ommission in this collection of data has been information regarding the modality of treatment provided (i.e. individual counseling; group counseling, or medication) or the Iength of treatment. Neither Multnomah County, nor the State Mental Health Division, has any statistical information related to either modality or length of treatment.

The State Mental Health Division is now in the process of adopting a new computer system which will allow for orosg-correlation of data, and so this basic problem will soon be allieviated. However, the new forms being used to report each county's data to the state still contain no information pertaining to the modality of treatment or the length of treatment provided to an individual. 
Without this information assessment of the effectiveness of programs seems virtually impossible.

According to Glenn Hitchcock, a computer programmer for the State Mental Health Divison, Biometrics Section, this new computer program can easily be altered to include this information. OSPIRG recommends that these forms be altered to include this information immediately.

How can programs be appropriately evaluated without such information?

Although OSPIRG was unable to obtain statistical data which would indicate the modalities or the length of treatment provided to elderly individuals, we can draw some inferences based upon comments made by professionals within the clinic system. Dr. King, Director of the Downtown Branch, stated that when they do treat elderly individuals at his branch office they "tend to have a medical emphasis:" $90 \%$ are seen by Dr. King and "they have medical problems as well as psychological problems." Dr. King continued, "We don't do any therapy, nor do the older people need it. We sometimes supplypsychotropic medications and try to arrange transportation and other supportive services through Community Health Nurses, and then the Nurses have the responsibility for establishing ongoing relationships between the older person and the clinic." Dr. King went on to say that "older people don't need much counseling. They need medical treatment and supportive services and sometimes medication...01der people are independent and resistant to treatment." The studies and opinions of other mental health professionals cited previously have refuted Dr. King's spinions, which appear to be age-related biases used to support his reluctance to engage in treatment with the elderly, rather than factually based truths regarding treatment of 
elderly individuals. If $\mathrm{Lr}$. King's attitudes reflect the views of most professionals within the Section it is doubtful that any in-depth treatment is being offered the few elderly individuals who do seek help there.

Additional support will be given to the notion that there is a real lack of commitment to serve the elderly within the Multnomah County Mental Health Clinic System when the specialized programs and training received by the mental helath professionals within the clinic system are considered.

The Protective Services Unit as a specialized program with the Multnomah County Mental Health Clinic System, has a staff equivalent of

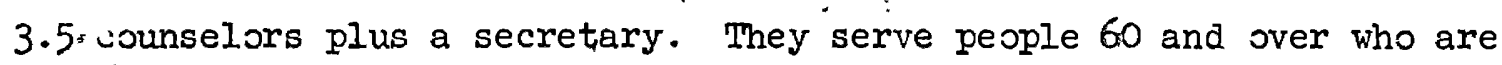
unable to care for themselves and are in danger of being institutionalized if they were not to receive this care. Ms. Ruth Hudson, the director of this unit, explained that Protective Services "functions as an advocacy. agency. We attempt to compensate for lacks in the individual's life." In handling cases they try to solicit help from relatives and members of the community, but their cases are not fime-limited, so that they can maintain contact to ... watch for crisis periods when their intervention is needed. They do not do a lot of in-depth counseling, but rather, they provide supportive counseling. The emphasis is on providing environmental. supports for the individual, such as planning for alternative housing, arranging for needed medical attention, getting people involved in community activities or providing an arena for discusing personal feelings or difficulties.

Between June, 1972 and August, 1973 the Unit Among these cases the following list of services itas provided. However, these figures are not mutually exclusive, and one person may be represented 
in more than one treatment category.

26 were prescribed psychotropic medications

21 were seen by a psychiatrist (either as an out-

- patient or as a resident of a psychiatric ward)

16 were hospitalized for psychiatric reasons

57 were given some psychological counseling by the Protective Services staff (some of which involved consultation with a psychiatrist)

I received counseling from a mental health worker at the Clinic on a weekly basis.

The Protective Services Unit has provided a spectrum of mental

health services to a portion of their clients. However, it is djsconcerting to note that only one individual received on-going weekly counseling from a mental health worker at the Clinic, especially when we consider that, due to eligibility restrictions, all elderly people seen by this Unit have severely impaired functioning and are facing possible institutionalization.

The Specialized Treatment Programs Provided to, or Being Planned for, the Elderly.

Other than the Protective Services Unit, which is located in the East County Clinic, there are no specialized programs for the elderly provided by the Clinics, according to Robert W. Goodman, Ph.D., Assistant Coordinator, Multnomah County Mental Health Section.

The services provided by the clinics are exclusively office-based; that is, the elderly individual must go to one of the clinics in order to receive mental health treatment. This precludes the passibility of receiving service by a large number of elderly individuals within the county. The recently completed Project Mobility study (12) showed that as a result of both physical and financial limitations in the ability to utilize available transportation systems, the elderly within Portland, as a group, have very restricted mobility. (For additional information see 
Appendix D).

It is precisely this type of restriction in mobility which makes the elderly more vulnerable to mental breakdown. However, the Multnomah County Mental Health Section has not compensated for mobility restrictions among the elderly by creating a delivery system which would make their services more accessible.

Another obvious group of neglected elderly individuals are those residing in nursing homes or homes for the aged. Institutionalized elderly persons are not usually in a position to manage visits to the Mental Health Clinic office. The lack of available mental health services, and the need for services to these people is documented in detail in a later section of this report. (See Chapter IV).

Providing services in neighborhood recreational facilities, churches, physcian': offices, making home visits, or offering mental health services within sheltered settings are a few obvious alternatives.

When Dr. King was asked why the Clinic System had no other specialized programs for the elderiy, he responded that $65 \%$ of their clients are between 19 and 25 years' of age, and $80 \%$ have incomes below $\$ 3,000.00$ per year. So, usually their clients are young and poor. He explained that the clinics try to design services for the population which is actually being served, so most of their programs are oriented toward providing adult psychlatric care.

OSPIRG would like to suggest that the nature of the clinic's delivery system attracts primarily young individuals, an age group which is also heavily represented in client populations at private counseling centers and services provided through the University of Oregon Medical School. Young people are more likely to initiate contact with a mental 
health clinic since they have been raised in an atmosphere which encourages attention to mental health needs. In contrast, elderly persons, for cultural reasons, are ashamed of being identified as "mentally ill" by seeking help at a mental health clinic, according to Mrs. Ada Wilson, Assistant Professor of Social Work, and the Director of the Aging Program at the School of Social Work, Portland State University .

The Kinds of Elderly-Related Mental Health Training which Staff Members of The Multnomah County Mental Health Section Have Received.

According to data provided by Robert Goodman, Ph.D., Assistant Coordinator of the Multnomah County Mental Health Section, there are 36 staff members employed by the Section (30 full-time professionals, 1 part-time professional, and 5 full-time paraprofessionals). Of these 36 staff members only those placed in the Protective Services Unit (3.5 staff members) have had any training related to mental health work with the elderly. The Protective Services' staff have had graduate school training and additional on-the-job training pertaining to working with the elderly.

As we have already discussed in a previous section of this report (see Chapter I, A Cultural Perspective on Growing Old), old age requires special adaptations on the part of the individual. old age, in many ways, can be likened to adolescence in relation to the turmoil and degree of change required of the individual. Adolescent developmental problems have long been a popular area of study among mental health professionals, and indeed, Dr. Goodman reported that numerous members of their staff have received practiom training, in-service training, and training in graduate schools related to work with adolescents.

Admittedly, professional attention to the special problems of the elderly is a much more recent phenomenon. However, Oregon is fortunate 
to have two research centers devoted exclusively to the study of problems among the elderly, the Gerontological Center at the University of Oregon and the Institute on Aging located at Portland State University. The Institute on Aging offers a number of excellent graduate courses related to mental health work with the elderly.

The fact that most professionals employed by the Mental Health Section have failed to avail themselves of any of this information, and. In addition, the section has falled to utilize these available resources for use in in-service training programs for members of the staff, further indicates a lack of interest and commitment on the part of the Mental. Health Section to providing adequate mental health services to the elderly of Multnomah County.

The Consultatlve Services Provided to Nursing Homes, Homes for the Aged, or Other Groups Working With the Elderly

OSPIRG questioned the administrations of 16 homes for the aged and nursing homes in Multnomah County. One of the questions which we asked was who do they contact wher they have an elderly resident whom they think is in need of psychiatric care. Of the sixteen homes contacted, only four mentioned Multnomah County Mental Health as a passible source of referral. Most of these homes utilized their personal "house physicians" to deal with their distarbed or disturbing patients.

Mr. Laverne Jones, Director of Edgefield Manor, stated that he had utilized the services of the Multnomah County Mental Health Clinic on one occasion. However, it was necessary for him to arive his patient to the clinic since they do not make visits to sheltered settings.

The Multnomah County Mental Health Section has even shown a reluctance to provide an in-service training workshop to Northwest Pilot 
Project. Northwest Pilot Project requested consultative services over a year ago, but this workshop has not yet been arranged. This agency offers recreational programs, transportation services, and also offers mental health treatment to elderly individuals residing in northwest Portland. During the first fiscal quarter of 1973 they provided services to approximately 725 elderly Portlanders. Obviously, their breadth of services would warrant consideration for consultative services in the area of mental health treatment for the elderly.

The fact that Multnomah County Mental Health Section provides very little consultative service to sheltered settings or other organizations serving elderly individuals further implies their lack of interest (or perhaps expertise) in promoting quality mental health care for the elderly. This is especially surprising since provisions of this type of consultation was by law ORS 430.630 an explicit priority of community mental health clinics.

\section{CRISIS CLIIRC, PSYCHIATRIC OUTPATIENT GIINIC, AND SOCIAL SERVICES UNIT}

THE UNIVERSITY OF OREGON MEDICAL SCHDOL

\section{The Numiver of Elderly Clients Being Served}

Unfortunately, OSPIRG again found that their records were not correlated or compiledby age, so no concrete statistical data was available to indicate the number of elderly clients being seen by each of these service units at the Medical School.

Mr. Les Hunter, Director of Social Services at the University of Oregon Medical School and Teaching Hospital, together with several of the social workers from his staff, did provide some estimates regarding the 
number of elderly being served.

Approximately one-third of the Social Services client load (or about 400 cases) is comprised of elderly clients. In addition, Mr. Hunter estimates that the Multnomah General Hospital serves an additional 120 to 150 elderly clients per month with social services. Therefore, approximately 525 to 550 elderly patients per month are provided with social services (which are not necessarily mental health services) within the hospital setting.

Mr. Hunter also stated that the psychiatrists and social workers generally have contact with elderly clients through in-hospital consultations rather than through the Crisis Unit or the Psychiatric Outpatient Clinic, which are explicitly mental health treatment units.

A Bocial orker employed in the Psychiatric Outpatient Clinic agreed with $\mathrm{Mr}$. Hunter's assessment. She explained that the clinic does serve some elderly clients, but since their primary concern is with providing their student psychiatrists with "good teaching cases" they do not take many elderly cases, nor many people generally for medication management only. She explained that they do have a psychiatric day treatment program which offers people daily psychiatric care in one of three groups. The number of people participating in the ge groups usually ranges from 15 to 25 , but of these she estimated that three or less were over 65 years of age.

This social worker explained the lack of elderly clients by saying "they usually have physical problems as well as mental problems so the Psychiatric Outpatient Clinic concentrates on physical treatment plus environmental support, and sometimes medication treatment also, rather than mental health counseling." She went on to add, "the best therapy 
for an elderly person is community and social involvement."

The Modalities of Treatment Provided

Mr. Hunter stated that patients hospitalized for medical reasons often have psychiatric problems as well. Physicians will then request psychiatric consultations for these psychiatric problems. The social services staff provides basic preparation for the psychiatrist, or will often provide counseling intervention directly. Patients are often given psychotropic medications for management purposes, as the pritiary mode of treatment. From the rather sketchy information that was available it appears that most of the elderly clients provided with psychiatric care receive this care while they are hospitalized for medical problems. This care may consist of individual counseling and, perhaps, psychotropic medication while they are in the hospital.

Follow-up social services are not provided by the Medical School staff. Public Welfare service workers are contacted if the individual is either receiving, or appears to qualify for public assistance. Other elderly persons in need of additional mental health care might be referred to the Outpatient Clinic, Martnomali County Mental Health Section, or a private counseling agency.

However, it appears to be unlikely that many of these elderly persons are actually receiving follow-up care. Data indicates that few elderly individuals are served by these agencies. The Psychiatric Outpatient Clinic, which is the only clinic at the Medical School which provides long-term mental health treatment, provides mental heaIth treatment to very few elderly clients, according to a social, by the Clinic. As we have already documented, Multnawah County Mental 
Health also sees very few elderly persons. Information regarding the private agencies is documented in a following section of this chapter, but basically a relatively few number of elderly persons are seen at private agencies, also.

Those who move from the hospital setting to a nursing home or home for the aged are also not likely to receive any attention to their mental health needs. The data which OSPIRG received from a sample of nursing homes and homes for the aged within Mulnomah County indicate: that these homes neither employ, nor do they generally utilize, mental health professionals in the care of their distrubed or disturbing patients. (See Chapier IV).

It appears that elderly individuals identified as in need of some type of mental health treatment while they are hospitalized for medical reasons are lost from the service system once they are discharged from the hospital. Approximately 525 elderly patients receive some type of social service each mo.th while they are hospitalized. If only a small portion of these patients are needing services specifically oriented toward mental health treatment this still represents a large number of elderly individuals in need of treatment who are being ignored once they are released from the hospital.

\section{Specialized Elderly Programs.}

-. No specialized mental health treatment programs designed specifically for the elderly are being offered, nor are any being planned at this time, by the Medical School Social Services Unit, Crisis Clinic, or Psychiatric Outpatient Clinic. 
In summary, the University of Oregon Crisis Clinic and Psychiatric Outpatient Clinic, in particular, do not appear to be providing services of any substance or degree to eldelly persons. Although they justify this lack of service under the guise of being a "teaching facility" the mental health needs of elderly Oregonians are, nevertheless, being ignored by what is, basically, a publically funded agency austensibly providing mental health services to a wide spectrum of the community, as well as training future mental health proressionals.

Indeed, the quality of education provided to these students might well be enhanced by some added exposure to what is, by all measures, a population group experiencling a high rate of mental disorder and particularily in need of mental health care.

\section{PRIVATELY ADMINISTERED COUNSELING CENTERS}

\section{The Number of Elderly Persons Served}

Table III sumnarizes the data which was obtained from private counseling centers within Multnomah County. Again, record-keeping practices, and a lack of available funds for computerization, prevented most agencies from providing detailed information regarding the numbers of elderly clients : which they are seeing. However, most agency administrators agreed that their agencies were seeing comparatively few elderly clients. Notable exceptions to this case are Jewish Family and Child Services, Family Counseling Service of Portland, and Northwest Pilot Project, an organization devoted to working exclusively with elderly persons residing in Northwest Portland.

We requested the number of elderly clients having been served during 


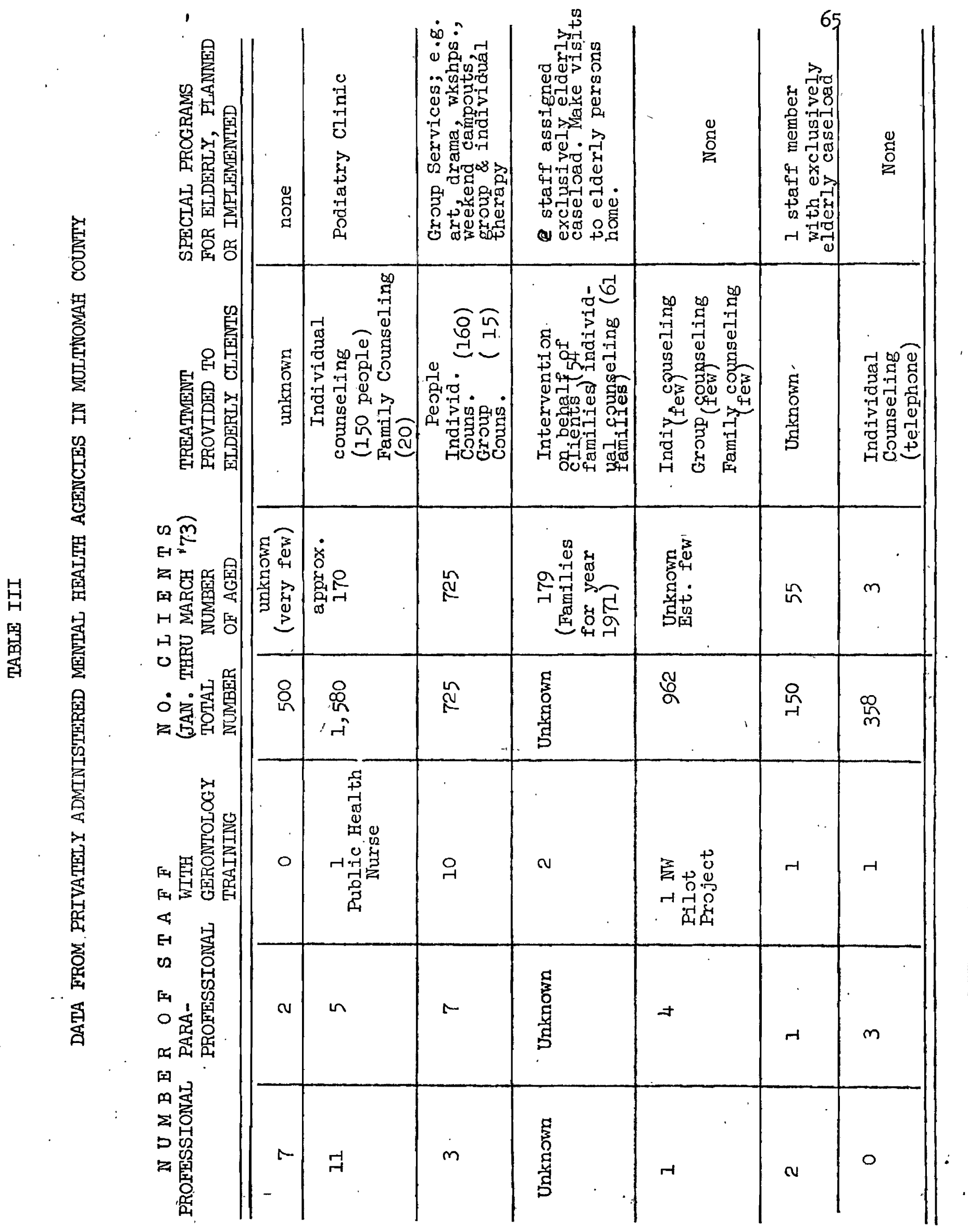


the first fiscal quarter (January through March) of 1973. Those agencies - from which we were able to obtain information (with the exception of Family Counseling Service) indicated that they had served approximately 985 elderly individuals in some way during that three month period, with about 345 receiving some type of mental health counseling. In addition, Family Counseling Service provided data for the year 1971. During this year 179 families with at least one individual over the age of 60 were served. Of the 115 cases closed during this year, 61 of the families received individual counseling (pertaining to family and individual. relationships, or environmental or situational difficulties) and 54 families received intervention on behalf of the client. .

The Modality of Treatment

The data OSPIRG received indicate. thatmost of these agencies provide individual counseling, and to a lesser degree group counseling and family counseling. None mentioned the use of psychotropic medications. Data regarding the length of treatment not available.

The Specialized Treatment Programs offered or Being Planned for Implementation

Northwest Pilot Project, which serves the largest number of elderly clients of any agency, is devoted exclusively to prowiding services to this age group. They offer group services such as art and drama workshops, weekend campouts, and community decision-making projects. In addition, they offer a transporation service, and they coordinate volunteer efforts to provide friendly visitors, and rolunteer homemaker services to elderly persons. There are other agencies within the county which provide these typesof recreational or supportive services to the elderly, but Northwest Pilot Project also offers inatvidual and group 
counseling. A psychiatrist provides consultative services on a half-day per week basis. Northwés Pilot Project also coordinates the efforts of some of the outreach workers from Project ABLE, allowing them the resources of individuals paid to identify and coordinate the referral of elderly individuals identified as in need of various social services, including mental health care.

Jewish Family and Child Services restricts its eligibilty to Jewish individuals residing within the County. They have one caseworker assigned to work specifically with elderly clients and he provides counseling services to these individuals.

Finally, Family Counseling Service has a professional social worker and a paraprofessional assistant assigned to work exclusively with elderly clients. A combination of counseling and supportive services aIs offered. Ms. Lydia Strnad, MSW, whose caseload is made up entirely of elderly individuals, stated that she does counseling with older people regarding their psychological problems and combines this with the provision of concrete supportive services, such as providing rides or arranging appointments with physicians. She also explained that she conducts many of her interviews in the homes of her clients since it is often very difficult for older people to come into the office. However, these added services result in a substantially greater expenditure of time per a se on the part of the therapist.

None of the agencies from which we received information planning to implement additional programs oriented toward serving the elderly at this time.

It is significant to note that those agencies providing services to 
a significant number of elderly persons all have staff members assigned specifically to work with this population. This tends to confirm the necessity, at this time, of having programs or persons specifically oriented toward providing mental health services to the elderly if this population is to be adequately served.

The Number of Professionals Employed tho Have Had Training in Gerontology and In-Service Training Programs Related to the Elderly

Every private agency from which we received information, with the exception of one, had at least one employee with training in gerontology; the origin; of this training was not generally given, but it does appear that Northwest Pilot Project has been instrumental in providing training and experience to individuals who later went to work for other counseling agencies or "hotlines."

Northwest Pilot Project also appears to be the only agency to offer in-service training programs to the staff regarding work with the elderly. It is not surprising ihat this agency would have this type of training since they work exclusively with elderly people. However, it is disappointing that the staffs of the other agencies do not have the time or interest to organize some in-service training programs. A mental health worker confidentially told an OSPIRG investigator that, although their agency has a person assigned to work with elderly persons there is not much overall agency support for this work.

The most significant factor related to the services provided by these private agencies is that, "as a whole, private agencies are serving slgnificantly more elderly persons than are publically-funded mental health agencies within Multnomah County. 
This primarilly is due to the fact that three privately administered agencies have personnel specifically designated to provide mental health care to elderly persons.

\section{PROJECT ABLE, AN EXAMPLE OF A SERVICE DELIVERY SYSTEM}

Project ABLE (A Better Life for the Elderly), is a federally and county funded pilot project, which has been operating within Multnomah County since May 1, 1972. This project is operated under the auspices of the City-County Commission on Aging, with Ms. Caroline Sullivan, as Coordinator of the project.

The purpose of the Project $A B L E$ is to provide community services to elderly persons who would likely face institutionalization were these services not provided. Therefore, the services of ABTE are not available to all elderly persons within the county, but rather, are restricted to an . elderly population identified as being "at risk" in facing possible institutionalization.

Project ABIE is made up of seven distinctive componants: counseling and referral, protective services, transporation, homemaker services, nutrition services, legal services, and an evaluation component. All services are provided to ABLE clients free of charge.

Project ABLE is significant for the purposes of this report for three reasons: (1) it provides an outreach service delivery model, (2) the purpose of this project is to prevent institutionalization of elderly persons, where institutionalization often has profound effects on the quality of mental health experienced by the institutionalized person, and (3) because this system addresses some of the social stresses which can lead to mental or emotional breakdown, thereby making it a secondary 
.level of prevention, in Caplan's framework (1).

The counseling and referral component is organized around an outreach concept, where field counselors are placed into a number of agencies throughout the county. These field counselors often initiate contacts with elderly persons who are referred to them by other sources. Their functions are to assess the level of functioning and areas of need of these elderly individuals, and to make referrals to the other components of the project if the person needs and qualifies for services, to provide non-professional counseling and support, and to maintain contact with the elderly persons and follow-up on the provision of services. If an identified elderly person does not qualify for the ABLE program they may be referred to other community agencies. This outreach component is the mos't alstinctive aspect of Project ABLE, and significantly, these outreach counselors are non-professional.

The Protective gervices Unit is attached to the Multnomah County Mental Health Section, and is located in the northeast office of the Section. The Brotective Services Unit is staffed by an equivalent of 3.5 counselors. Clients served by this unit are considerd to be in need of more intensive mental health care than that provided by the outreach workers, as has been explored in an earlier section of this chapter. The Protective Services Unit and outreach counselors negotiate for each case individually regarding which component is to be primarily responsible for the provision of services and follow-up on the clients, to ensure that only appropriate referrals are made to this unit.

The transporation component is made up of two full-time drivers, and a dispatcher. Elderly persons are responsible for caling ahead and arranging for a ride to their destination, then this component attempts 
to organize its scheduling so that a maximum number of elderly persons can be served. Transporation may be to a physician, the bank, to a grocery store or any other necessary location.

The homemaker services are contracted to a private family services agency within Multnomah County since this agency also has homemaker service of its own. Homemaker services are, again, provided on the basis of client need, and includehousework chores and, at times, basic meal preparation. Most often, an elderly person will receive homemaker services on a weekly or bi-weekly basis, for a few hours each visit. If a person is in need of only short-term homemaker services then services are also provided on this basis.

The nutrition services are provided by a separate, non-profit organization, and have been contributed to Project ABlE free of charge. Therefore, the nutrition component is not officially, but is functionally, part of the ABLE system. Essentially, ABLE clients are being referred to a pre-existing social service which is also available to all other elderly persons in the community. Hot lunches are available within community centers throughout the county, on a tri-weekly or more frequent basis," and a small fee is charged, although the fee structure is based on a "pay as you can" concept. In addition, for persons cannot come to a community center for their meals, hot meals are delivered to them in their home on this same schedule. The purposes of this component are to maintain the nutritional guality of elderly persons' diets, and also to provide a source of social contacts within the community centers. This is the only opportunity for many elderly persons to ther with other people on a regular basis. 
Iegal services are provided by a full-time attorney who is available for consultation regarding the variety of legal matters which may be of concern to elderly persons in the community. This attorney also acts as an advocate for the personal rights of elderly persons, individually and collectively.

The evaluation component is administred through the Institute on Aging, Portland State University, and monitors the effectiveness of the program. This component, has also been responsible for gathering and processing data regarding the numbers of elderly persons provided with different types of services, the quality of the care provided to these persons, and other related issues.

During the first year of operation (fiscal year 1972-73) approximately 3,000 clients were provided with services through Project ABLE. However, in assessing the quality of services of provided, it. was determined that the Project was over-extended, and realistically only about half of these clients received consistently good quality service. Therefore, during the second year of operation the eligibility requirements were more rigidly defined to additionally limit the client population, and It is estimated that approximately 1,000 elderly persons will receive ABLE services during 1973-74 (as of March 31, 1974, 984 elderly clients had been served). During any one month of this past year approximately 500 to 600 elderly persons received some type of ABLE service.

Another factor which influenced the drop in the number of clients served by $A B E E$ during 1973-74 was a significant decrease in the funding available for the project. The budget for $1972-73$ was $\$ 631,082$ while the 
budget for $73-74$ was $\$ 546,307$ (a loss of $\$ 85,775$ ). Although a high rate of client need had been established during the first year of operation, the Project lost an equivalent of eight outreach counselors (leaving a remaining four), lost two full-time drivers (leaving two), and lost the services of three homemakers (leaving a remaining twelve). Due to the loss in the number of outreach counselors, it was estimated by $\mathrm{Mr}$. Roger Olson, the former Coordinator of the Project, that the system lost the capacity to identify an additional 150 to 250 clients a month, or approximately $90 \%$ of the system a original capacity. Therefore, the focus of the Project has moved from that of identification and referral to service delivery. This change in. priorities was due, prinarily, to a cutback in federal funding for the identification and referral component.

The result in this chànge in focus has been that Project ABLE has moved from a short-term or crisis intervention model to providing more in-depth and long-term care to its clients.

\section{CONCLUSIONS AND RECONMEIDATIONS}

Problem

Within Multnomah County; the potentialfor comprehensive mental health programs--from home health care to institutions--has not been realized. Rather, we found that older residents do not receive early and adequate care in the community but tend to be institutionalized in mental hospitals, and sheltered settings. The elderly would be better served if a whole range of potential living situations existed; their current options are too limited and reflect only a few possibilities on the continuum. 
The relevant issues are the identification of those for whom institutional care or other services constitute the plan of choice, the improvement of institutional programs, and the development of community services (28).

There are five levels of possible services to the aged which should be matched to the individurl heeds of.the client: basic services (those needed by all people), adjustment and integratton services (designed to help older people participate in the community), support services (to keep the older person in his own habitat), level of congregate and shelter care (where the older individual is protected from hazards of the open environment), and protective services (where the individual's civil rights and personal well-being are protected). (29)

\section{Recommendations:}

(1) In order to facilitate in the identification and referral of mentally ill or emotionally disturbed persons, particularily the elderly, to appropriate community mental health services, it is recommended that The State Mental Health Dirision, through the Community Mental Health Programs, establish and coordinate an outreach program, to be made up of outreach teams composed of community health nurses, mental health professionals, and paraprofessionals, for the purpose of identifying and referring for appropriate care or treatment mentally ill or emotionally disturbed elderly persons within the catchment area. (2) It is also recommended that the formation of halfway houses, formulated in Senate Bill 448, be specifically extended to include either separate halfway houses, or spaces within' other halfway houses, for elderly persons released from state mental hospitals or hospitals for the retarded. 
(3) It is strongly recommended that the State Mental Health Division develop a plan and funding proposal to provide for additional funds for Project $A B L E$ to restore its identification and referral capabilities, since this system represents a secondary level of preventitive mental health service. It is also recommended that $A B L E-l i k e$ services be developed in other urbanized areas of Oregon, with adequats funding for supportive services. (4) It is also strongly recommedded that mental health personnel from the Community Mental Health Programs be placed into other community facili: ties, such as community recreation centers, Social Security Offices, in association with medical complexes, or wherese they will be afforded a high degree of visibility and accessibility to the elderly population. The team outreach program mentioned previously could well be adapted to this system.

Problem

Multnomah County Mental Health Section, along with all other Community Mental Health Programs within the state, is serving a disproportionately small number of elderly clients. In addition, Multnomah County Mental Health Section personnel, for the most part, lack any form of specialized training regarding the mental health problems and mental health treatment of eiderly persons. The Multnomah County Mental Health Section has also failed to provide adequate consultation to interested private parties, as authórized under ORS 430.630 .

Eiecommendations

(5) It is recommended that the State Mental Health Division, through its Community Mental Health Programs, plan and implement in-service training of the mental health staffs . Such training should focus upon 
their personal attitudes toward aging, a presentation of facts regarding the process of aging, common mental health problems of the elderly, basic demographic infonmation related to the elderly Oregonian population, and special mental health treatment techniques found to be particularily effective in working with elderly disoriented people.

(6) It is recommended that the Institute on Aging, and the University of Oregon Gerontological Center design and offer graduate level courses in clinical gerontology, and make these courses available to interested professionals:and laymen . through appropriate extension programs. It is also recommended that they design and offer courses in clinical gerontology for paraprofessionals. These courses should include suitable general information about aging and the elderly Oregonian population, and specific information about mental and emotional problems and treatment techniques designed for use with elderly persons.

(7) It is recommended that the University of Oregon Medical School and Teaching Hospital adopt a specific policy of non-discrimination against : elderly persons seeking treatment at their Psychiatric Out-Patient Clinic. (8) Since no definitive study of the mental health needs of the elderly within Oregon has been undertaken, it is recommended that the state Program on Aging, in cooperation with the State Mental Health Division, be charged with the task of making a comprehensive study of the needs of the elderly, including their mental health needs, and develop a state plan for the care of elderly persons. 
CHAPIER III

THE STATE MENTAL HOSPITAL SESTEM

INTRODUCTION

The elderly population in state mental hospitals traditionally has been made up of two sepatate classes of residents: those who entered the hospital when elderly, and those who entered the hosital when younger and grew old within the hospital.

Nationally, state mental hospitals have historically been dumping grounds for large numbers of elderly individuals.

Americana aged 65 and over make up $9.7 \%$ of our population but account for $25 \%$ of the annual admissions to mental hospitals. Thus, the elderly suffer disproportionately from our non-system of non-care, characterized by insufficient financing for both health and sickness and by fragmented delivery of services. (6)

Some of these elderly individuals were severely mentally ill and in need of hospitalization, but unfortunately, many who were indigent, physically ill, or a burden on their fumilies or the community were inappropriately placed in mental hospitals.

A similar situation appears to have been the case in Oregon's state mental hospitals. The Geriatric Screening Process Study was the study of ajl commitments of elderly persons to Dammasch State Hospital over a six month period in 1970 (2l). The head hospital administrator was asked to evaluate whether the 40 elderly people who were committed were best served by the hospital setting, if there was some question, of if they definitely could have been best served by some other type of setting. His response was that 26 were best served by the hospital setting, with 4 there was some 
question as the best situation, and 10 could have been better handled in another situation if it were available; i.e. $25 \%$ of these elderly Individuals were inappropriately hospitalized. (21)

Historically, the size of state hospital populations (in terms of hospitalized patient/days) grew at a geometric rate. As a result of this growth, there has been a national trend within the past several years to decrease the size of hospital populations. This decrease in hospital population size (which has more accurately become a stabilization of the size of the hospital population within Oregon) has been aecomplished by transferring chronically long-term patients into less restrictive settings (e.g. nursing homes, homes for the aged, or board and care homes), by reducing the average length of stay of newly admitted patients, and by screening potential hospital admissions and referring a portion to alternative custodial or treatment sources.

This trend out of the hospitais has been motivated by both humanitarian and economic concerns. Iong-term hospitalization contributes to increased breakdown, or regression, in individuals as a result of their 'institutionalization; a combination of depersonalization, boredom and lack of stimulation, and maintenance of a child-like dependency status. (26) Additionally, the costs of maintaining an individual increase with each level of increasingly restrictive care. The Geriatric Screening Process Study found that "each day that the patient stays in the state hospital rather than a nursing home costs an additional \$8.90. If the patient spends the time in a home for the aged, instead of the state hospital, the saving is $\$ 14.40$ per day; and if the patient spends the time in a boarding home, the saving is $\$ 15.40 \mathrm{per}$ 
day." (2l)

This movement out of the state mental hospitals within Oregon has been particularly directed at gerlatric patients. Between the years 1968-69 and 1972-73, the total geriatric intake of patients declined $28.2 \%$ while the total intakes of patients between 18 and 65 rose $11.8 \%$. According to Mrs. Gaynell Alfred, Director of Social Workers at Dammasch State Hospital, the geriatric population at Dammasch has proportionately declined from $35 \%$ to $7 \%$ of the total hospital population in 1972-73. Mrs. Alfred gave the following reasons for this relative decline in geriatric patients:

(1) There are more facilities in the community. (2) Families are more sophisticated about what is avallable in the community. (3) The hospital has offered to find alternative placements for patients who could be managed in lieu of hospital commitment: (4) Physicians' recommendations for commitment do not occur as frequently. (5) There is a real effort on the part of Welfare caseworkers to make alternative placements, (6) The operators of congregate care homes have become more sophisticated. (7) Physicians have become mo acquainted with psychotropic me ications and so these are being used more outside the hospital.

Essentially, then, the recent historical trend has been a decline in the relative number of hospitalized elderly patients. "This trend has now been given added legal sanction and direction with the enactment of SB510.

In this chapter of the report OSPIRG analyzes a number of important issues: First, the types of alternative arrangements which are being made for non-hospitalized elderly patients; secondly, in relation to the elderly patients receiving treatment in a state mental hospitals, their relative frequency of admission to a state mental hospital, and their admission status, the diagnoses which are 
assigned to them and their relative frequency, the types of mental health treatment which they are reeeiving and their relative length of stay in the hospital; and their discharge destinations and the kind of post-hospitalization follow-up provided to them, is considered in detail. Flnally, the trend out of the hospital is analyzed in relation to its likely impact on long-term hospltalized elderly patients.

THE CURRENTIY USED ALTERNATIVES TO HOSPITALIZATION

In the past many elderly persons were residents of state mental hospitals for varying lengths of time. How many of these people no longer are going into the hospital?. What is happening to them instead? Since no widespread research has been directed towand this questions in Oregon, we are unable to give a definitive answer. However, the rapid rise in the number of homes for the aged and nursing homes within the state during the past 10 years supports the notion that sheltered settings may be replacing the state hospitals in caring for elderly mentally ill or impaired individuals.

We do know that this trend out of state hospitals is going to be continued and magnified as a result of recent state legislation. SB 448 was enacted by the 1973 Oregon State Legislature and went into effect on July 1, 1973. This bill states, in part, that it shall be the responsibility of the community mental health prograns to insure that, subject to the availability of funds pre-hospital screening examInations shall be avajlable when needed, and alternatives to hospital placement shall be developed. Following in the same veln, SB 510, also enacted by the 1973 Iegislature, provides for commitsent of individuals 
to the State Mental Health Divison rather than to a state hospital as was formerly the case. The Divison then has the option of placing a person into an alternative setting in lieu of a state mental hospital when that is considered appropriate.

The net effect of these pieces of legislation is to encourage the flow of persons out of the state mental hospitals, and to encourage alternative community-baised mental health care.

One of the key tools in alternative placements is pre-comnitment screening. According to Dr. Del Kole, M.D., Director of Region I, State Mental Health Divison, the pre-screening process utilized a combination of Community Health Nurses and Mental Health staff to develop on-the-spot treatment plans for individuals, with an advocacy and crisis treatment approach. Dr. Kole went on to say that the pre-screening process "has resulted in most people belng sent elsewhere," rather than to a state hospital, so the State Mental Health Divison is now trying to insure effective planning for these people.

Multnomah County Mental Health Section had a pre-petition screenIng pilot project in operation from September, 1972, through June, 1973. This program screened individuals, for whom mental hospital commitment petitions had been signed, in order to attempt to find alternative placements when possible. The goal was to avoid unnecessary hospital1zations. The results of this pre-sereening pilot project confirmed Dr. Kole's observations that inost pre-screened individuals are not hospitalized; of these 197 pre-sereened cases, only 41 (20.8\%) resulted in hospitalizations.

Of these 197 pre-screened cases, 38 (19.3\%) involved people aged 
65 or older. There were more people in the 65 plus age group than in any other age group, and since the elderly comprise only $12.6 \%$ of the county's population but represented $19.3 \%$ of the pre-screened cases, a much larger proportion of the elderly people than their relative numbers in the population would indicate were considered for possible commitinent.

OSPIRG obtained detailed information on these pre-screened individuals related to their assigned diagnoses, the pre-screening service provided, and dispositon of their cases. The data from the 38 elderly cases are differentially compared with the diagnoses and dispositons of the other 159 pre-screened cases involving people under 65 years of age. TABLE IV gives the tentative diagnoses assigned to both younger and elderly people who were pre-screened. The most significant factor to note is that anong the elderly group 25 of them recelved diagnoses attributing their disorder to organic causes (organie brain syndromes), while only 10 of their diagnoses attribute the disorder to functional causes. The reverse trend is found among the diagnoses assigned to the younger age groups. This is the usual pattern found when comparing the diagnoses assigned to elderly and younger populations. The implicationiof this diagnostic difference lies in the presertibed treatment: functional disonders are amenable to psychiatric intervention while organic brain syndromes are theoretically not amenable to traditional psychiatric intervention, since the basis of the disonder is damage to the tissues of the brain or nervous system, rather than due to stresses. Therefore, custodial care rather than psychiatric care is usually the prescribed form of treatment. However, numerous: research studies have 
TABTE IV

TENTATIVE DIAGNOSES ASSIGNED DURING THE PRE-PETITION SCREEINING PROCESS COMPARTMG ELDERLY AND INON-ELDERLY CASES

Tentative Diagnosis

1

Mental Retardation

Elderly Cases . Non-Elderly Cases TOTAL \# $\%$

Organic Brain Syndrome - Psychotic

$23(60.5)$

(3.1)

5
$\%$

Organic Brain Syndrome - Non-psychotic

2

(5.3)

10

(6.3)

33

Schizophrenia

6

(15.8)

2

(1.3)

4

Major Affective Disorder

0

Paranoid Statis

.0

Other Psychoses

0

Neuroses

2

(5.3)

75

(47.2)

81

Personal ity Disorders

.0

Sexual Deviation

0

Al cohol ism

i

(2.6)

8

(5.0)

8

0

0

Drug Dependence

0

Trancient Situational Disturbance

1

$(2.6)$

1

$(2: 6)$

I

(.63)

10

(6.3)

12

Conditions without manifest psychiatric disorder

None Given

\begin{tabular}{|c|c|c|c|c|}
\hline 2 & $(5.3)$ & 0 & & 2 \\
\hline 38 & $(100.0)$ & 159 & $(100.0)$ & 197 \\
\hline
\end{tabular}

Total Number

19

(12.0) 19

0

(8.2)

$14^{\circ}$

13

(4.4)

7

$(5.0)$

$9^{\prime}$ 
confirmed that it is essentially impossible to conclusively distinguish organic disorders from functional disonders and that realistically, one might conclude that the damage is irreversible only when all attempts at treatment have failed. (See Chapter I for additional information related to this issue.)

TABLE $V$ gives the altermative planning services provided and the disposition of the cases. The figures represent the number of cases for which a particular service was performed, not the number of times eaah service was performed. When looking at data some striking, but on the basis of the comparative diagnoses expected, differences can be noted in the handling of the elderly clients as compared with the nonelderly clients: only 3 elderly individuals (7.9\%) were referred to a mental health clinic for treatment while 22 non-elderly individuals (13.8\%) received such as referral; 7 elderly persons $(18.4 \%)$ were evaluated for psychotropic medications while only 12 non-elderly persors $(7.6 \%)$ were similarly evaluated for such medication; 12 elderly persons (31.6\%) and only 8 non-elderly persons (5.0\%) were placed into a sheltered setting, and guardianship proceedings were implemented in 7 (18.4\%) of the elderly cases and in only one $(.6 \%)$ of the non-elderly cases.

Essentially, the elderly are more likely to be placed in a sheltered setting, to be evaluated for psychotropic medication, and to possibly lose their rights to control theix own person and/or property. They are less likely to receive out-patient psychlatric care than the younger population.

Data presented in Chapter II of this xeport imicated that relatively few elderly people utilize any form of public out-patient mental 


\section{TABTE V}

Alternative Planning Dispositions

Mult tnomah Co. Mental Health Section, Pre-Petition Screening Project

September, 1972 through June, 1973

\section{Services Given}

Community Health Nurse home visit (one or more)

Referral to' Mental Health Clinic

Evaluated for medication

Placed in sheltered setting leg. board and room, Nursing Home, etc.

Referral to and/or contact with another agency

Family and/or petitioner's counseled

Hospitalization in private facility

Guardianship implemented

Referral to private psyci, atrist

Significant others interviewed by Social Worker in Mental Health Clinic (\# of persons)
Number of cases receiving Service Elderly* Non-Elderly* Total $24(63.2) \quad 92(57.9) \cdot 116$

$3(7.9) \quad 22(13.8) \quad 25$

$7(18.4) \quad 12(7.6)$

19

$12(31.6) \quad 8(5.0) \quad 20$

19(50.0) 59(37.1) . 78

$9(23.7) \quad 85(53.5) \quad 94$

$1(2.6) \quad 17(10.7) \quad 18$

$7(18.4) \quad 1(0.6)$

$1(2.6)$

$0(0.0)$

Unknown

\section{Clients Hospitalized in State Facilities}

Voluntarily Hospitalized

$0(0.0)$

$7(4.4)$

Involuntarily Hospitalized

$5(13.2)$

26(16.4)

\section{clients Hospitalized in V.A. Facilities}

Voluntarily Hospitalized

$1(2.6)$

$0(0.0)$

$0(0.0)$

$2(1.3)$

Involuntarily Hospitalized

2

*Percent of total Elderly cases provided with services, percent of total Non-Elderiy cases provided-w1th services 
health services. The data from this pre-screening project also indicate that the pre-screening mental health tean considered few of the elderly persons appropriate reclpients of out-patient services. At this time formal out-patient mental health services are not used as an alternative to hospitalization for most elderly persons.

Instead, it appears that most elderly individuals receive no mental health care at all until they become so disturbing that some action must be taken; then placement in sheltered settings (i.e. nursing hones, homes for the aged, or board and care homes, etc.) seems to be the preferred alternative: $31.6 \%$ of the elderly prescreened persons were plàced into sheltered settings, while only $7.9 \%$ were referred to a mental health clinic.

In addition, based upon data collected during this investigation, OSPIRG has concluded that sheltered settings generally do not provide any mental health treatment to their residents. They do not employ any mental health professionals, nor do they utilize publically-funded mental health services on an on-going basis. They provide custodial and/or medical care, not mental health care. (See Chapter IV for more detailed information.)

Also, according to both Mrs. Ruth Ouelette. Social Worker at Dammasch State Hospital and the person in charge of placing elderly indivi-duals in the community upon their release from the hospital, and to Mrs. Joy O'Brien, Director of the Housing and Iiving Arrangements Unit of the Multnomah District Welfare Department, there are no community-based half-kay houses for treating mentally 111 elderly $y_{1}$ ersons within Multnomah County. Half-gay houses are available on a limited basis for use as 
an alternative to hospitajization, or as an immediate discharge destination upon release from the hospital following treatment for some drug-abusing young adults and some alcoholics. Shelter settings inadequately fulfill a similar role in caring for the elderly.

The lack of mental health care within sheltered settings becomes particularly significant when we remember that the new commitment law (SB 510) provides for commitment directly to the State Mental Health Division where the Divison then has the option, if it feels it is appropriate, to place elderly. people dieectly into sheltered settings rather than providing them with mental health treatment in a state hospital first.

When these sheltered settings do not offer any kind of mental health treatment, the net effect is that the disturbed elderly person is being denied access to any mental health treatment at all.

It is small wonder that most elderly persons-seem to be reticent to seek help from the mental health system: they appear to have very little to gain from this system and a lot to lose.

THE EIDERLY RESIDING WITHIN STATE NENTAL HOSPITALS

TABLE VI Admissions data for the three state mental hospitals 196869 through 1972-73, presents detailed data comparing the 18 to 64 year old age group with the 65 plus age group adnitted to all state hospltals during these years. This information was initially factored out for each state hospital individually but no significant trends were found to be unique to or heavily influenced by any one state hospital.

The first issue to consider is the number of elderly residing with- 


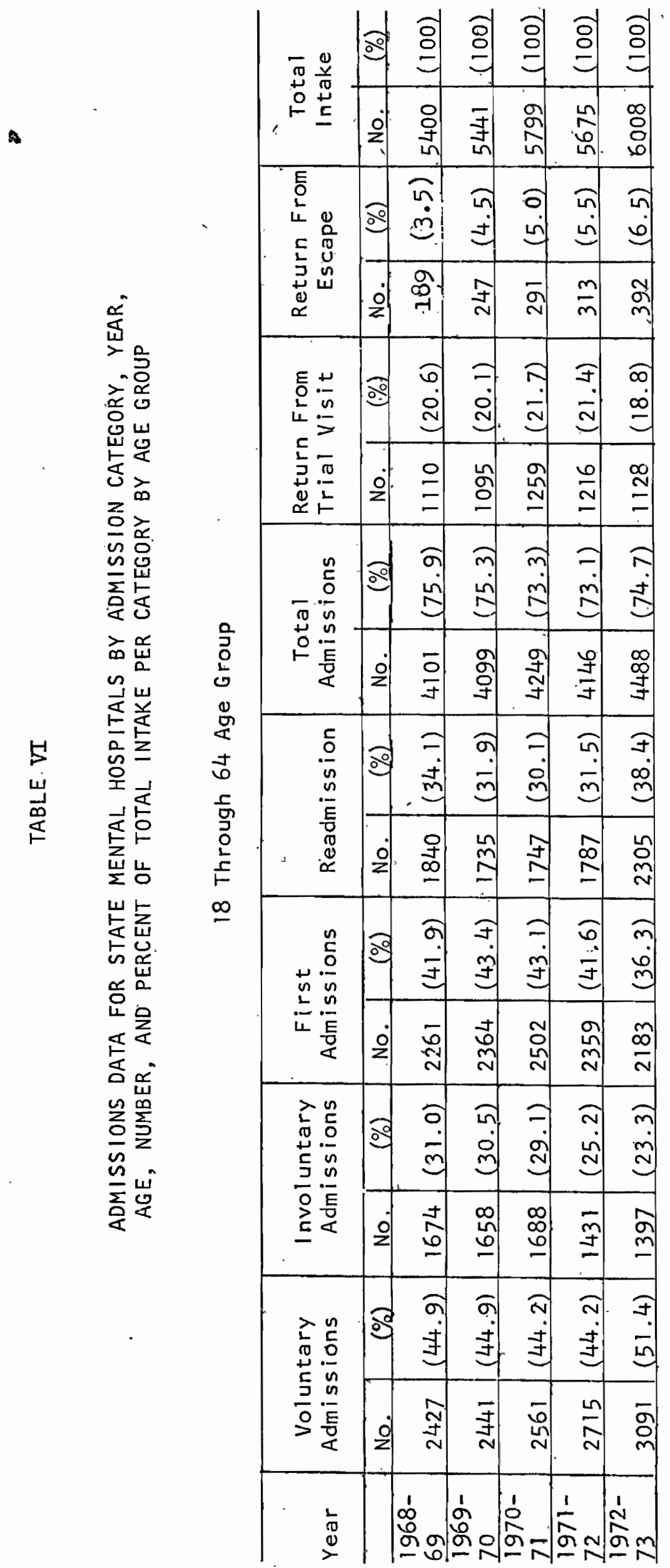


in state mental hospitals. It can be noted that the intakes of geriatrics patients have decreased in size every year for the past five years, dropping from 624 total geriatrics intakes:in 1968-69 to 448 in 1972-73, a net decrease of $28.2 \%$. This decline is primarily due to a decrease in the number of elderly first admissions, which declined from 322 in 1968-69 to 176 in 1972-73, a drop of 45.3\%. The numbers of readmissions (the recidivism rate) and returns from escape have remained relatively stable and the number returned from trial visits has less drastically declined a total of $14.3 \%$, from I6I in 1968-69 to 138 in $1972-73$

Among the 18 through 64 age group a reverse in this trend can be noted. The total intake among this group rose from 5400 in 1968-69 to 6008 in 1972-73, a net increase of $11.8 \%$. While the number of first admission and those returned from trial visits remained relatively constant, the number of readmissions rose $20.0 \%$ from 1940 to 2305 , and the number returned from escape rose $44.2 \%$, from 189 to 392 persons. Essentially, then, the movement out of the hospital is being differentially directed at geriatric residents. They are Iess likely to be initially admitted to a state mental hospital and they are also less likely to be returned from a trial visit. This latter point may be quite significant. During the course of this OSPIRl investigation, we. received numerous complaints that once an elderly person was placed into a sheltered setting of some type, usually on the basis of a trial visit, the hospital was very reluctant to re-admit that person if the placement was not working out well, while the hospltal was more inclined to suggest alternative medications, or to place the findividual into 
a different sheltered setting.

The next issue to consider in relation to the resident population of the state mental hospitals is their admissions status: did they come into the hospital voluntarily or as a result of commitment? The five year totals for all of the state hospitals show that among the 18 through 64 age group approximately $62.8 \%$ voluntarily admitted. themselves to the hospital while $37.2 \%$ were involuntarily committed. Among the elderly population the reverse is true: $34.6 \%$ voluntarlly admitted themselves while $65.4 \%$ were involuntarily committed.

Commitment proceedings data (TABIE VII) for MuItnomah County for the perlod October, 1972, through September, 1973; also indicatei that those individuals over the age of 60 involved in commitment proceedings are more likely to be committed $(59.8 \%$ of those over 60 were committed while only $47.6 \%$ of those under 60 were committed), - while their cases are much less likely to be discharged (only $12.2 \%$ of those over 60 as opposed to $32.8 \%$ of those under 60 have their cases discharged). During a portion of this time period the pre-petition screening program was in effect and so data may have been altered somewhat by the effects of this program. However, the effects of the pre-screening project may very well have been to further reduce the number of geriatric commitments, since a number of these elderly persons was. placed into sheltered settings as a result of the prescreening.

During the five year period, 1968-69 through 1972-73, 65.4\% of the total number of elderly residents in the state hospitals. were there as a result of commitment. There are two important implications of this 
information: a majority of these elderly patients have not willingly sought mental health treatment, and, as a result of their commitment, the hospital has a great deal more control in determining the discharge placements for these committed people. This latter point will be particularly significant when we look at discharge placements.

When asked about the large number of committed elderly individuals, Mrs. Gaynell Alfred, Director of Social Workers, Dammasch State Hospital, explained that "under tho law we cannot accept as voluntary placements those who don't know what they're doing." So, when a person like that appears, they recommend that they be comitted. Specifically, there are more committed elderly persons in the hospital because "there are more older people who don't know what they're doing, and older people are less likely to commit themselves voluntarly to an institution."

However, when looking at the yearly figures it is interesting to note that among the elderly population the number of voluntary admissions rose each year, from 114 to 157 (a $17.3 \%$ imcrease), while the number of commitments per year declined from 343 to 149 (a decrease of 56.6\%). This reflects both an increasing willingness on the part of elderly persons to enter a state mental hospital (or perhaps added encouragement from professionals and family that the do so), and a decreasing tendency on the part of the courts or the mental health system to commit elderly individuals to a state mental hospital. A similar trend of increased voluntary admissions and decreased commitments of younger persons also existed.

Finally, the third issue which is particularly important is the 
diagnosis assigned to each patient upon his admission to a state hospital. The assigned diagnosis determines the treatment approach and goals considered appropriate for the individual.

TABLE VIII shows the distribution of diagnoses assigned to elderly patients admitted to each of the three state mental hospitals during the three year period 1968-69 through 1970-71..* Younger elderly patients (65-74) are distinguished from older elderly patients ( 74 plus) within this table.

The results of these data show that of a total of 1664 elderly persons who were hospitalized during this three year period, 1026 (6I.7\%) were diagnosed as having some type of organic brain syndrome. When this is further examined in relation to the age of the person, we find that among the young, elderly, 492 of a total of 1016 patients (49.4\%) had a general diagnosis of organic brain syndrome, while anong the older elderly group 534 of a total of 648 (83.3\%) patients had their disorders diagnosed as organically based. In looking at the remaining diagnostic categories we find that among the younger elderly there is a large group with a diagnosis of alcoholism or alcohol addiction, and also a relatively large group with a diagnosis of schizophrenia, which would be expected on the basis of usual incidence of schizophrenia within a hospitalized population. However, the relative number of

\footnotetext{
*This information was also made available by the State Divison of Mental Health. There is a minor discrepancy between the total figures given in TABLE VI" (total admissions for this three year period) which indicates that there were a total of 1742 elderly patients admitted during this three year period, and the data given in TABIE VIII which indicate there were a total of 1664 elderly persons admitted during this same three year period.
} 


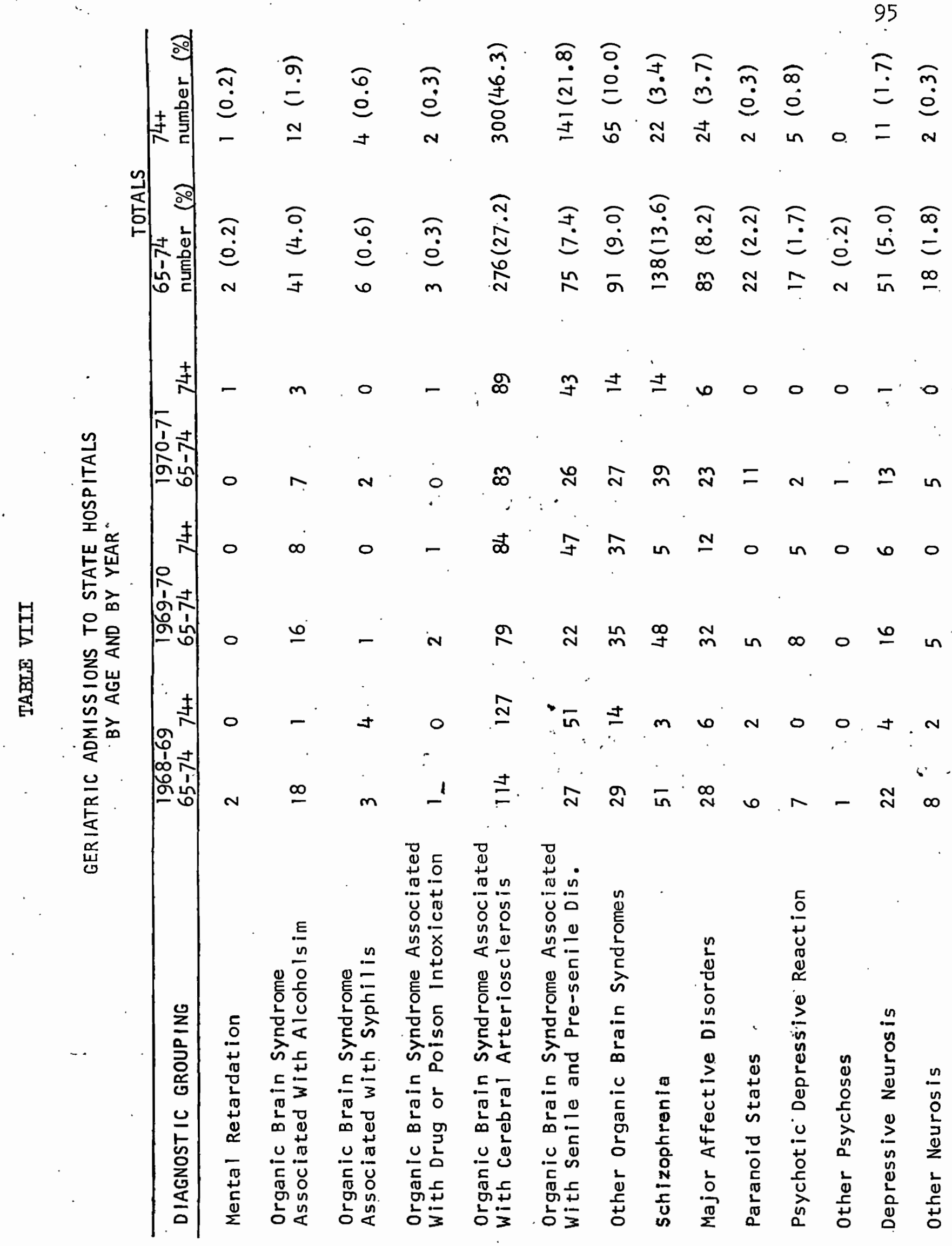




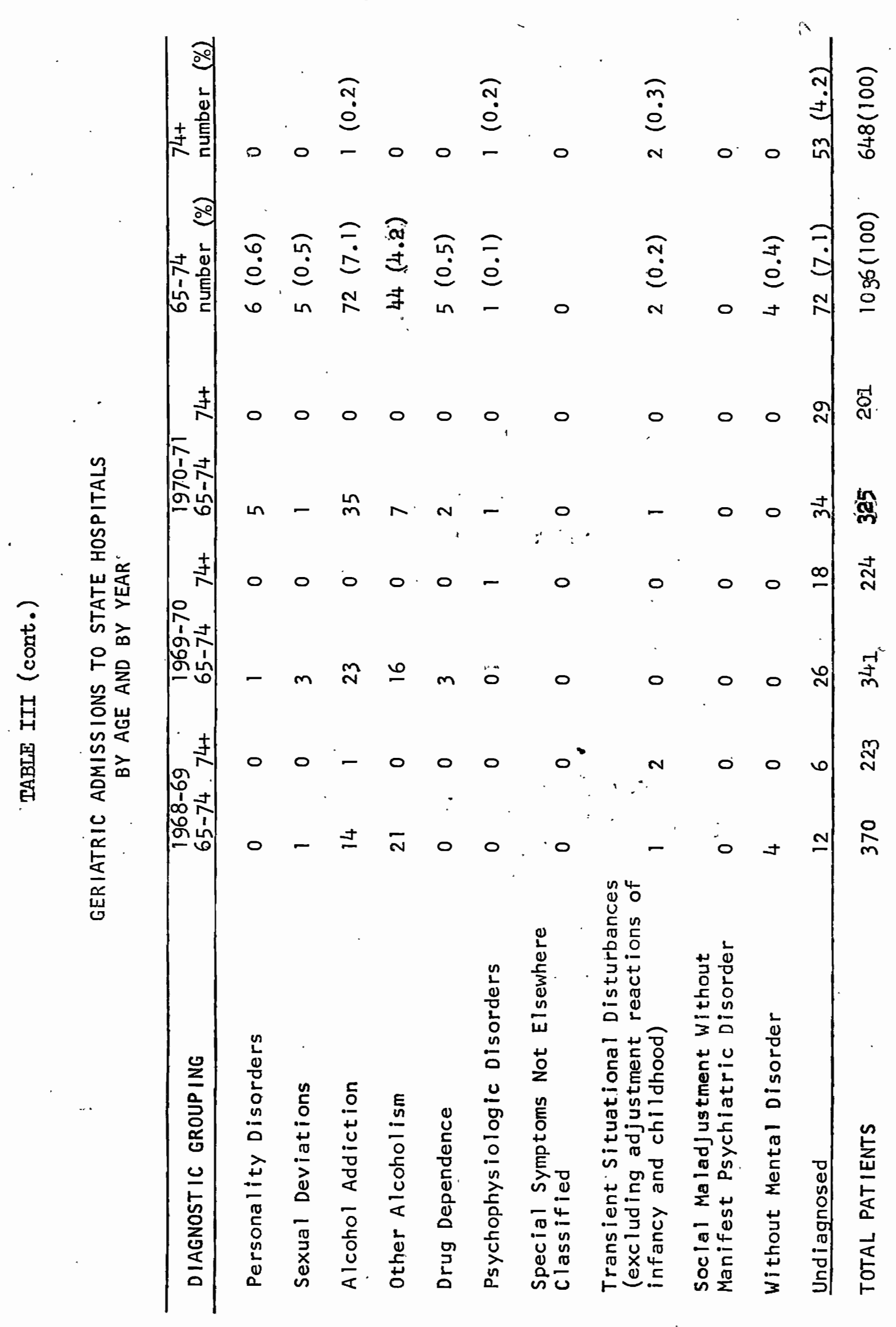


elderly individuals of any age diagnosed as having other forms of psychoses, neuroses, or personality disorders (functionally based psychological disorders) is disproportionately small in relation to overall diagnostic dispersions in a younger population.

Looking at TABLE IX, the geriatric patients in residence at the end of each of these fiscal years, we find that a jority of the elderly patients have diagnoses of organic brain syndromes, although a relatively. larger number have diagnoses: of schizophrenia or major affective disorders.

Comparatively, $44.5 \%$ of the elderly between 65 and 74 ; and $59.7 \%$ of elderly 74 and older in the in-resident group have diagnoses of organic brain symdrome, a respective decrease of $4.9 \%$ of $23.6 \%$ compared to the elderly group admitted to the hospital (TABLid VIII).

The in-resident patients are distinguished from the patients admitted to a state hsopital by virtue of the fact that they are still in the hospital at the end of the fiscal year. Gererally, in-resident patients remain in the hospital a longer perlod of time (as $\mathbb{T} A B L E$ illustrates), so we might assume that these patients receive more extensive psychiatric treatment.

The fact that fewer elderly persons diagnosed as having organic brain sysdromes remain in the hospital supports, OSPIRG's . contention that individuals diagnosed as having an organic brain symdrome tend not to receive extensive mental health care. (The controversy surrounding the diagnosis and treatment of organic brain syndromes was covered in some detail in Chapter I of this report.)

Organic brain syndromes are defined as disorders caused by deteri- 


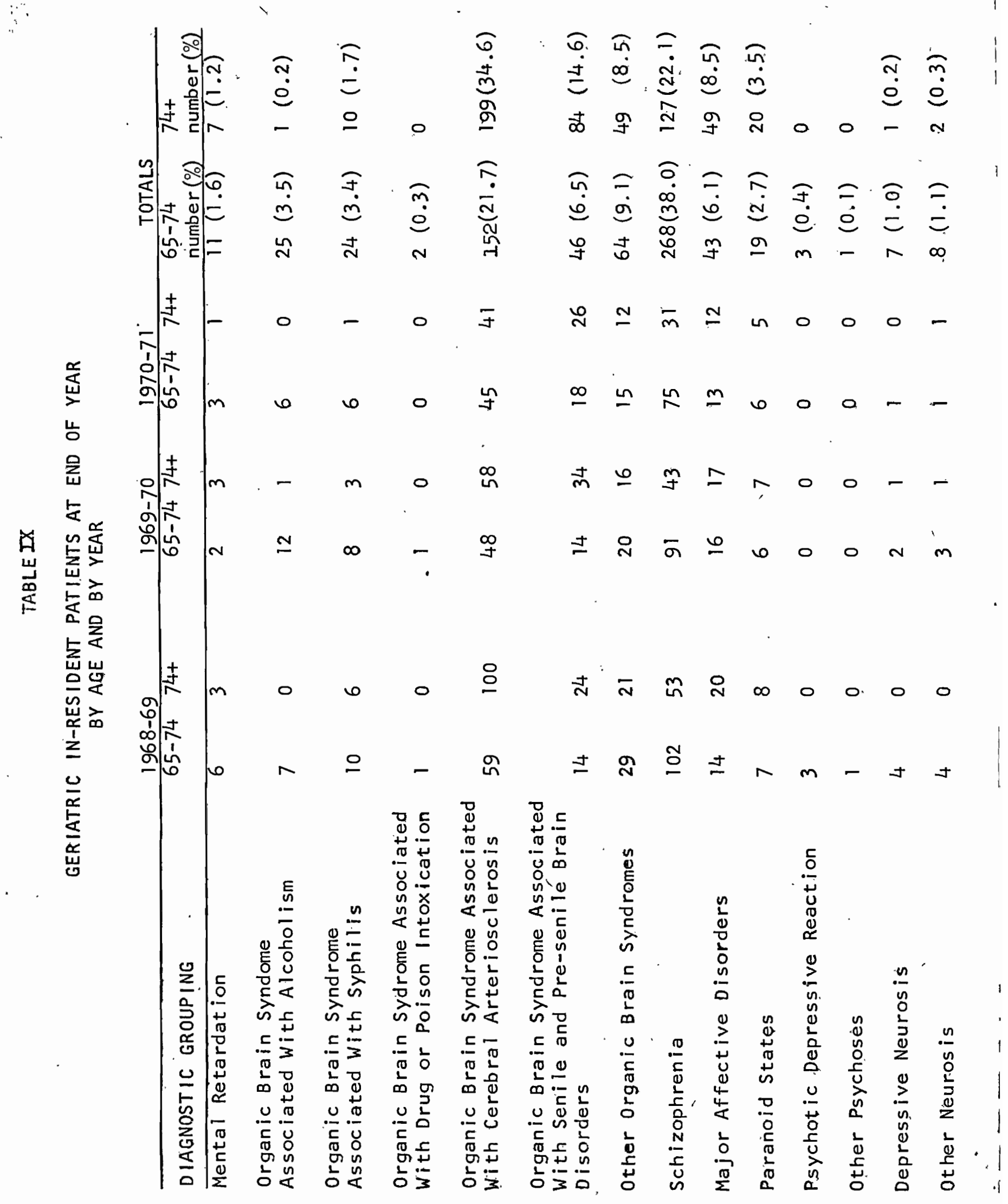




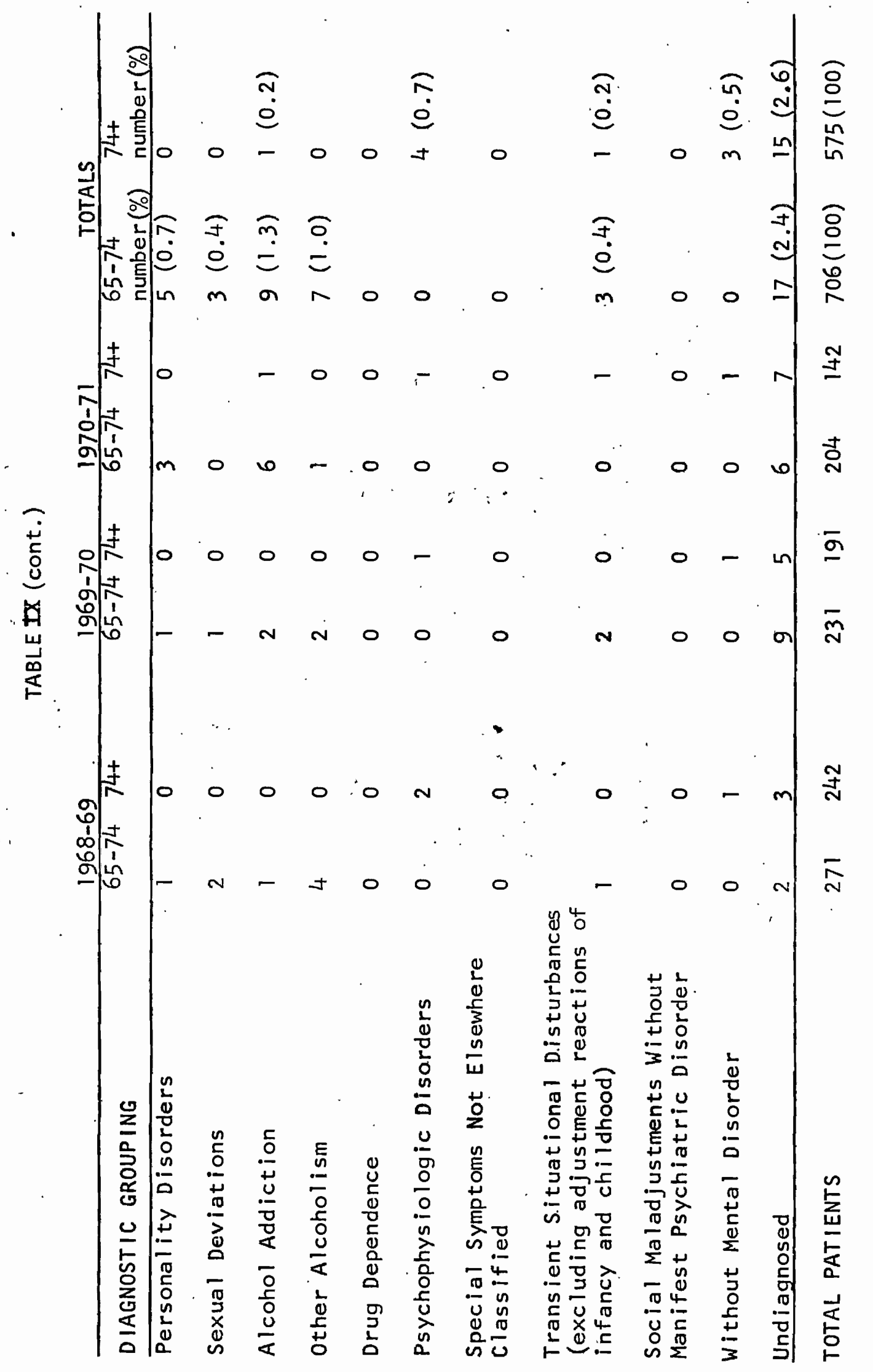


oration of brain or nervous system tissues and are, by definition, psychiatrically untreatable. Therefore, someone diagnosed as suffering from an organic brain syndrome is not a likely candidate for any type of mental health treatment.

However, numerous research studies have shown that it is impossible to conclusively diagnose the presence of organic brain syndromes using any (or all) of the available diagnostic techniques, and in addition, post mortum examinations have showr, that there is of ten times no correlation between observable brain damage and affective disorders. This latter finding calls into question the whole validity of this diagnostic classification. Finally, some treatment programs have had excellent success in dramatically improving the functioning of people diagnosed as having organic brain symdromes, the most noteworthy being Reality Orientation Therapy. (See APPENDIX F for detailed information on Realtiy Orientation Therapy.)

Nevertheless, the most common diagnosis assigned to elderly persons admitted to the three state mental hospitals in Oregon is some type of organic brain syndrome: $60.9 \%$ of the elderly received this diagnosis.

The large number of elderly persons diagnosed as having some type of organic brain syndrome is quite significant in terms of the type of mental health treatment (or non-treatment) they are Iikely to receive. The Modalities and Length of Treatment Provided to the Elderly

Due to limited resources available for this study, OSPIRG concentrated on the treatment program provided to residents of Dammasch State Hospital. We did not collect data from either Oregon State Hospital or Eastern Oregon Hospital. 
According to Dr. George Suckow, M.D., the Director of Clinical Services for Dammasch State Hospital, geriatrics patients, like most adult patients, are spread throughout the wards of the hospital and participate in the treatment programs established for the ward in which the patient is assigned. With the exception of special wards for adolescents and people with alcohol problems, there is no segregation by age or by diagnosis within or between wards.

Dr. Suckow stated that elderly persons are treated no differently than any other patients within the hospital with one exception: the hospital has designated two social workers to work exclusively with gerlatrics patients in planning discharge placements. He justified this type of segregation, explaining that elderly persons tend to have, as a group, different discharge planning needs since large numbers are placed from the hospital into some type of sheltered setting.

The overall treatment concept employed at Dammasch State Hospital is "in-ward milieu therapy." Within Dammasch there are five wards of approximately 100 patients each, with three or four staff clinicians assigned to each ward. Using in-ward milieu therapy, they attempt to capitalize on the use of daily events within the wand to influence the development of more adaptive interpersonal and intrapersonal skills for each patientr: For example, if two patients were involved in some type of conflict the therapists would focus on this situation in an attempt to help each person to learn to better deal with conflicts. issentially, an informal form of Reality Oreintation Therapy is used with all patients in the hospital, since "in-ward milleu therapy is I1terally reality oriented and efforts are made to orlent people to place, person, and time, 
as a part of the milieu therapy.

In addition to in-ward milieu therapy, each staff clinician has the prerogative of utilizing whatever types of individual, group, or activity therapies which he feels are suitable to his patient population. As a general rule, activities including the eatire ward population are emphasized, and elderly persons along with all other members of the ward, are expected to participate in these activities.

Since individual staff clinicians are responsible for developing their own treatment programs, it is difficult to characterize the treatment being provided to the elderly, as a group, at Dammasch State Hospital. In addition, the lack of avallable statistics reflecting the numbers of patients receiving individual, group, or medication therapies, for example, make generalizations even more difficult.

Dr. Suckow stated that the hospital does not keep statistics regarding the treatments provided to patients. Each patient does have an Individual record in which the type(s) of treatment the is receiving is documented, but the hospital does not compile cumulative statistics, and in particular not with age categorization as the comparative basis.

However, it does appear, by and large, that the most prevalent form of therapy used is medication therapy. Mrs. Gaynell Alfred, Director of Social Workers at Dammasch, explained that "medication is the primary tool used - . medication is always the first line of attack with any patient." She went on to say that "only a damn fool would think that we could cure a mentally 111 person. But with psychotropic medications we are able to returm a lot more people to being participating members of the community." 
Mrs. Ruth Ouelette, the social worker responsible for discharge planning for older persons at Dammasch, confirmed that when older: persons are released from the hospltal they are "usually on medication... and it depends upon the doctor, but more are on phenothyazines (psychotropic medications) than not."

However, Mrs. Alfred pointed out that many of the elderly persons within the hospital are unhappy and want to withdraw, so they attempt "to get them involved." The hospital staff focuses on encouraging socialization among elderly p.ersons, and Dammasch has a Colden Age Club within the hospital for this purpose.

According to Ms. Lucille von Cleff, who is in charge of the geriatrics socialization program at Dammasch, the Golden Age Club is for all "elderly" persons within the hospital - those either elderly by age or by disposition. Participation in the activities of the club is optional, and, primarily, the activities are designed to provide stimulation and social opportunities for elderly persons. Within this progxam "the people do crafts, make decorations, go on shopping trips, bus rides - anything to get the people involved and interacting," according to Mrs. Alfred.

For younger residents of the hospital it appears that the occupational therapy program, licensed by the Department of Labor, serves a similar function. This program has specific therapentic objectives which the physician prescribes when he makes a referral to the program, and within this program evaluations for vocational habilitation also. occur. An added advantage of this program is that they contract with private companies for piece work, and patients recelve compensation for 
their work based upon their evaluated level of functioning.

Since the issues surrounding the use of organic brain syndrome

as a diagnostic category, and the lack of treatinent which is often the outcome when this diagnosis is assigned, are quite significant, one added treatment issue which OSPIRG felt was particulariy important was the method by which hospital clinicians arrive at a diagnosis of organic brain syndrome, and how this assigned diagnosis is ifkely to infiuence the treatment provided to the elderly farsons assigned this diagnosis, because a substantial proportion of elderly people within the hospital are assigned this diagnosis.

When queried about how clinicians in the hospital usually Identify the presence of an organic brain syndrome, Dr. Suckon responded that this . is really quite easy, " . . If someone is pretty well advanced you can pick 1t up in the conversation." Dr. Suckow explained that organic brain syndromes result from structural or chemical changes in the brain. He stated that this condition is simple to diagnose since the loss of recent memory and simple intellectual functions, as well as emotional lability and confabulation, are all characteristic of organic brain syndromes and relatively easy to spot. Comparatively, Dr. Suckow stated that psychotic individuals may give bizarre responses, but no memory loss is apparent. Generally, at Dammasch they use some form of a Mental Status Questionnaire to arrfve at a formal diagnosis of organic brain syndrome. (See APPENDIX E for an example of a mental status questionnaire.)

Dr. Suckow also explained that a primary goal of the hospital staff when someone has a diagnosis of organic brain syndrome is to 
attempt to determine the cause of the syndrome, since it is" at times reversible. However, he stated that $1 t^{*}$ most of ten an irreversible condition which has been exacerbated by poor diet and lack of stimulation. Therefore, it appears that 'Dr. Suckow holds a very traditional viewpoint in both diagnosing and treating elderly persons diagnosed as having organic brain syndromes.

Dr. Suckow went on to say that elderly patients are "often the most rewarding to work with," explaining that often times admitted elderly persons have maintained a high level of functioning throughout most of their lives, but as a result of a recent decline are now experiencing mental or emotional difficulties. With the elderly, by simply providing a special diet, vitamin supplements, and perhaps some medication, they will sometimes regain a reasonably high level of functioning. By compari:son, younger patients may never have attained a satisfactory ievel of functioning, which means that the task of the hospital staff is much greater in attempting to help the patient develop an adequate system of interpersonal and intrapersonal skills.

Within this context, however, Dr. Suckow emphasized that people are not discriminated against on the basis of their diagnositic classification in the treatment they are likely to receive within their ward. In evaluating the adequacy of the treatment program at Dammasch, Dr. Suckow stated that hospital personnel are now belng told by some members of the community that they are releasing patients from the hospital too soon at times, and Dr. Suckow speculated that this may now sometimes be the case. The opinion that state hospitals were prematurely releasing some poople was shared by Louis Kahn, Director of 
Social Services for the Multnomah District Welfare Department.

Dr. Suckow explained that recent developments in the use of psychotropic medications has made it possible for them to dramatically reduce the average lengths of stay in the hospital. Often times the medication will calm the person down sufficiently to allow a clinician to then talk with the person so that the patient is then able to start solving some of his life problems. Nationally, there has also been a similar trend toward more rapid discharge. However, in an effort to solve the long-standing problems of chronic hospitalization the pendulum has now swung in the direction of rapid and premature discharge from the mental hospital. Frequently a patient is discharged before his treatment is completed and adequate preparation has been made for his return to the community. Such premature release may interfere with the patient's welfare, just as delayed discharge may impede his progress. In addition, the present trend toward moving aged patients from mental hospitals into the community leads all too often to their placement in nursing homes that provide no psychiatric care at all. (6)

The only statistical information which OSPIRG was able to obtain, to aid in the process of evaluating the treatment program at Dammasch, was data related to the average length of stay of patients.

TABLE $X$, length of stay since admission for released and in-resident patients for each state hospital by year and by age group, provides us with some basic comparative data. Several important trends are . apparent from these data.

First; in comparing the elderly with the younger population, for all years and for all hospitals, there is a marked difference in their 
TABLE X

LENGTH OF STAY STNCE ADMISSION FOR RELEASED AND

IN-RESIDENT PATIENTS AT EACH STATE MENTAL HOSPITAL BY

YEAR, BY AGE GROUP

\begin{tabular}{|c|c|c|c|c|c|c|c|c|}
\hline \multirow{2}{*}{$\begin{array}{c}\text { Year } \\
. \\
\end{array}$} & \multicolumn{2}{|c|}{$\begin{array}{c}\text { Eastern Oregon } \\
\text { Hospital }\end{array}$} & \multicolumn{2}{|c|}{$\begin{array}{c}\text { Dammasch State } \\
\text { Hospital }\end{array}$} & \multicolumn{2}{|c|}{$\begin{array}{c}\text { Oregon State } \\
\text { Hospittal }\end{array}$} & \multicolumn{2}{|c|}{ Yearly Totals } \\
\hline & $\begin{array}{l}\text { Number } \\
\text { Released }\end{array}$ & $\begin{array}{l}\text { Avg. } \\
\text { Length } \\
\text { of Stay } \\
\text { (mos.). }\end{array}$ & $\begin{array}{l}\text { Number } \\
\text { Released }\end{array}$ & $\begin{array}{l}\text { Avg. } \\
\text { Length } \\
\text { of Stay } \\
\text { (mos.) }\end{array}$ & $\begin{array}{l}\text { Number } \\
\text { Released }\end{array}$ & $\begin{array}{l}\text { Avg. } \\
\text { Length } \\
\text { of Stay } \\
\text { (mos.). }\end{array}$ & $\begin{array}{l}\text { Number } \\
\text { Released }\end{array}$ & $\begin{array}{l}\text { Avg. } \\
\text { Length } \\
\text { of Stay } \\
\text { (mos.) }\end{array}$ \\
\hline $\begin{array}{l}1968- \\
69 \\
\end{array}$ & 614 & 24.1 & 2554 & 7.3 & 2311 & 23.4 & 5479 & 16.0 \\
\hline 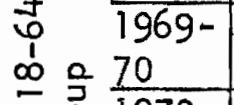 & 642 & 13.7 & 2666 & 7.1 & 2195 & 18.7 & 5503 & 12.5 \\
\hline $\begin{array}{lll} & 1970- \\
0 & 0 & 1 \\
0 & 0 & 71\end{array}$ & 663 & 16.2 & 2904 & 7.5 & 2474 & 21.4 & 6041 & 14.2 \\
\hline$\frac{8}{8} \frac{197.1-}{8}$ & 613 & 11.7 & 2714 & 9.0 & 2425 & 20.1 & 5752 & 14.0 \\
\hline 73 & 495 & 11.6 & 2963 & 7.6 & 2686 & 18.1 & .6144 & 12.6 \\
\hline $\begin{aligned} & 1968- \\
\dot{0} & \frac{69}{1060}\end{aligned}$ & 111 & 48.5 & 316 & 7.7 & 352 & 69.0 & 779 & 75.6 \\
\hline 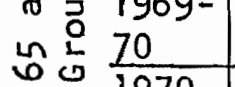 & 99 & 93.7 & 346 & 9.3 & 275 & 79.4 & $720=$ & 47.7 \\
\hline 里 & 98 & 87.2 & 271 & 10,5 & 270 & 94.2 & 639 & 57.7 \\
\hline$\frac{\pi}{8} \frac{72}{1972-}$ & 104 & 64.1 & 256 & 13.0 & 248 & 69.9 & 608 & 44.9, \\
\hline 73 & 84 & 78.9 & 245 & 17.4 & 208 & 82.6 & 1.537 & 52.3 \\
\hline
\end{tabular}


TABLE X (cont.)

\begin{tabular}{|c|c|c|c|c|c|c|c|c|}
\hline Year & $\begin{array}{l}\text { Eastern } \\
\text { Hospi }\end{array}$ & $\begin{array}{l}\text { Oregon } \\
\text { tal }\end{array}$ & $\begin{array}{r}\text { Darnmaseh } \\
\text { Hospi }\end{array}$ & $\begin{array}{l}\text { State } \\
\text { tal }\end{array}$ & $\begin{array}{l}\text { Oregon } \\
\text { Haspi }\end{array}$ & $\begin{array}{l}\text { State } \\
\text { tal }\end{array}$ & Yearly $T$ & otals \\
\hline$\cdot$ & $\begin{array}{l}\text { Number } \\
\text { In- } \\
\text { Resident }\end{array}$ & $\begin{array}{l}\text { Avg. } \\
\text { Length } \\
\text { of Stay } \\
\text { (mos.) }\end{array}$ & $\begin{array}{l}\text { Number } \\
\text { In- } \\
\text { Resident }\end{array}$ & $\begin{array}{l}\text { Avg. } \\
\text { Length } \\
\text { of Stay } \\
\text { (mos.) }\end{array}$ & $\begin{array}{l}\text { Number } \\
\text { In- } \\
\text { Resident }\end{array}$ & $\begin{array}{l}\text { Avg. } \\
\text { Length } \\
\text { of Stay } \\
\text { (mos.) }\end{array}$ & $\begin{array}{l}\text { In- } \\
\text { Resident } \\
\text { Since Yr. } \\
\text { End }\end{array}$ & $\begin{array}{l}\text { Avg. } \\
\text { Time } \\
\text { Since } \\
\text { Adm. } \\
\text { (mos.) }\end{array}$ \\
\hline 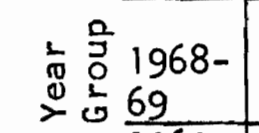 & 330 & 136.7 & 316 & 11.5 & 799 & 119.8 & 1445 & 100.0 \\
\hline $\begin{array}{l}+1969- \\
\text { \% } \\
+\end{array}$ & 306 & 139.1 & 352 & 12.0 & 731 & 111.1 & 1389 & 92.2 \\
\hline 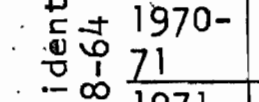 & 275 & 138.0 & 348 & 13.8 & 560 & 108.2 & 1183 & 87.4 \\
\hline $\begin{array}{l}-\infty 1971- \\
\infty\end{array}$ & 233 & 157.7 & 321 & 14.6 & 570 & 85.5 & 1124 & 80.3 \\
\hline $\begin{array}{c}\leq \underline{5} 1972- \\
\underline{73}\end{array}$ & 213 & 156.5 & 305 & 18.2 & 472 & 80.0 & 990 & 77.4 \\
\hline $\begin{array}{ll}\frac{1}{\pi} & 1968- \\
\end{array}$ & 148 & 217.4 & 67 & $15 . i$ & 302 & 149.6 & 517 & 151.6 \\
\hline $\begin{array}{ll}= & 1969- \\
0 & 70\end{array}$ & 127 & 231.8 & 48 & 16.7 & 242 & 154.3 & 417 & 62.0 \\
\hline 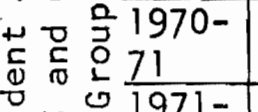 & 112 & 235.0 & 49 & 18.5 & 185 & 134.0 & 346 & 150,3 \\
\hline 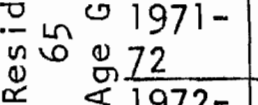 & 98 & 238.3 & 53 & 17.7 & 147 & 112.8 & 298 & 137.1 \\
\hline 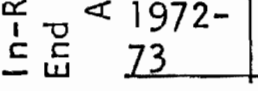 & 82 & 264.8 & 44 & 22.5 & 111 & 102.4 & 237 & 143.8 \\
\hline
\end{tabular}


comparative lengths of stay - consistently the elderly group has stayed in the hospital a longer period of time than the younger population in both "releases" and "in-resident" groups. When Dr. Suckow was asked why the elderly population at Dammasch shows a consistently longer length of stay, than the younger adult population, he was uncertain. He stated that he was of the opinion that elderly people tended to stay in the hospital a shorter perlod of time than younger patients. One explanation may be that this elderly population is made up of two distinct groups: those who were admitted when elderly, and those who grew old within the hospital. Thị latter group undoubtedly is inflating these average length of stay figures. However, when we look at TABLE XI, the average length of stay by digignosis for discharged patients at Dammasch, the comparative figures for different diagnostic categories show that both senile and presenile dementia, and non-psychotic organic brain syndromes (nost often diagnoses assigned to elderly persons, as TABLE IX substantiates), these two categories had relatively long lengths of stay associated with them, although the lengths were not so long as to suggest that there would be a heaxy influence from persons having resided in the hospital for long periods of time inflating these figures. Therefore, a second operating factor may be that elderly persons tend to remain in the hospital a longer period of time since post-hospitalization sheltered setting placements for them are currently in short supply (see TABLES XV and XVI for substantiation of this point), making it necessary for them to remain in the hospital until a suitable placement can be found. A third explanation, that the elderly as a group are simply more difficuli and therefore lengthy to treat, is dis- 
AVERAGE LENGTH OF STAY BY DIAGNOSIS FOR DISCHARGED PATIENTS AT DAMMASOH STATE HOSPITAL, JANUARY I, 1973--JUNE 30, 1973

Diagnosis

Number

Discharged.

Senile and Presenfle Dementia

Non-psychotic Organic Brain

Syndrome

Alcohol Psychosis

Psychosis with other Cerebral Conditions

Psychosis with other Physical Conditions

Schizophrenia.

Affective Psychosis

Paranoid States

Other Psychoses

Unspecified Psychoses

Neuroses

Personality Disorders

Sexual Deviations

Alcoholism

Drug Dependence

Special symptoms

Transient Situational Disturb.

- Behavioral Disorder of Childhood and Adolescence

Mental Retardation

Social Maladjustment without Manifest Psychiatric Disturb.

No Valid Psychiatric Diagnosis
42

7

80

38

29

450

78

12

19

$I$

260

110

3

606

175

4

55

1

12

9

35
66.1

35.9

154.6

20.8

Average Length of. Staj (days)

56.3

104.2

44.1

51.2

49.0

51.8

40.2

63.0

36.1

29.2

47.3

27.0

24.9

87.8

34.3

52.0

59.7 
puted by the statements made by Dr. Suckow previously regarding the relative ease of treating many elderly persons.

A second important trend to note in TABLE $X$ is that, in looking at the figures for each hospital individually, the average length of stay for both releases and in-resident groups has tended to increase for the elderly group, with the exception of thein-resident population at Oregon State Hospital where there is currently a strong push to reduce the size of the hospital population, according to Iucille von Cleff, from Dammasch. Conversely, the average length of stay for releases anong the younger age group have tended to decline over this five year period, while the in-resident average has also tended to increase, again with the exception of Oregon State Hospital.

Therefore, it appears that not only do the elderly tend to remain in the hospital for a longer perlod of time (for both in-residents and releases) when compared with the younger adult population, but this descrepancy in the comparative lergths of stay is generally increasing.

OSPIRG was unable to ascertain why the average lengths of stay have been increasing, but a likely explanation is that some long-term hospital residents are gradually being released from the hospital, inflatIng the releases averages, while the most difficult patients are remaining in the hospital, with their average lengths of stay progressively increasing. Iooking at the numbers of elderly and younger people inresident in the hospital (TABLE $X$ ) supports this theory - their numbers progressively declined over this five year period. The number of releases also generally declined for the elderiy group reflecting the decrease in the number of admissions, while the number of releases for 
the younger age group tended to increase, in line with the relative increase in the admission of gounger people to the hospital.

A final treatment issue which OSPIRG considered significant was the question of the suitability of . placing, these elderly persons in the hospital in the first place.

Earlier the Geriatric Screening Process Study was cited. This study (20) indicated that approximately $25 \%$ of the elderly individuals they studied were inappropriately flaced in the hospital. When Mrs. Alfred was questioned about the appropriataness of most elderly placements in the hospital, she responded that "there are not many aged in the hospital who could be served by community mental health centers because many are either senile and in need of custodial care, or they have physical impairments as well as being mentally ill and so they would need to be in an institution. Mrs. Alfred weat on to explain that there are two ends to the spectrum of elderly patients - "those who are 65 to 71 or 72 and who are mentally ill, and those of any age who are In need of custodial care because they're senile."

When asked whether or not nursing homes of hames for the aged could provide this custodial care, Mrs. Alfred stated that "some people very definitely need to be detoured through Dammasch to get them trained to get along with other people and to get them stabilized on medication. Nursing homes just won't tolerate some of the behavior which people demonstrate in the hospital."

Mrs. Ouelette tended to agree that most hospital placements are necessary, explaining that although Dammasch is not supposed to be a facility for keeping chronically ill people, their mubers in the hos- 
pital are increasing. With some of their patients, they place them into community facilities a number of times, but they are returned to the hospital because their behavior is unacceptable to the insittution. Nevertheless, when asked to assess the likely impact of SB 510, which allows committed persons to be placed into alternative facilities, such as nursing homes, Dr. Suckow anticipates that this new law will result in fewer admissions of elderly persons to the state mental hospitals. If current admissions have generally been appropriate, then what types of elderly persons are no longer going to receive treatment? Dr. Suckow did not adequately clarify this point.

\section{Discharge Data:}

Looking at TABLE XII, we find expected trends based upon the changing admissions picture over these five years.

The total number of elderly people released each year regularly declined, from $763:-1968-69$ to 537 in $1972: \therefore$, a net decrease of $29.6 \%$ in the number of total releases.

The number of escapes and traisfers also similarly declined, while the number of deaths declined and then rose again i 1972-73.

looking more closely at the number of elderly discharged each year the numbers fluctuate somewhat, but the net decrease over the five years was 50.9\% (330 in 1968-69 decreasing to 162 in 1972-73). The sharpest decline was seen between 1971-72 and 1972-73, the same year in which the number of trial vistts rose again after a four year decline.

Overall, the number of trial vistts declined from 364 to 301 , a net decrease of only $17.3 \%$. 


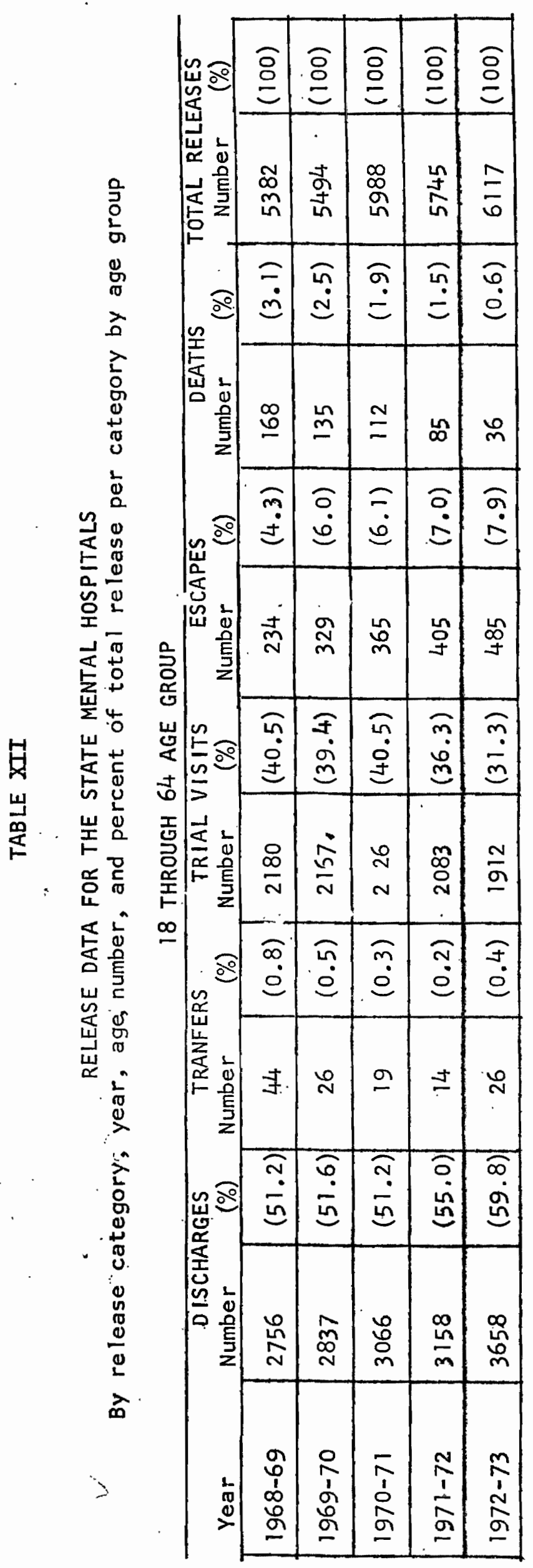




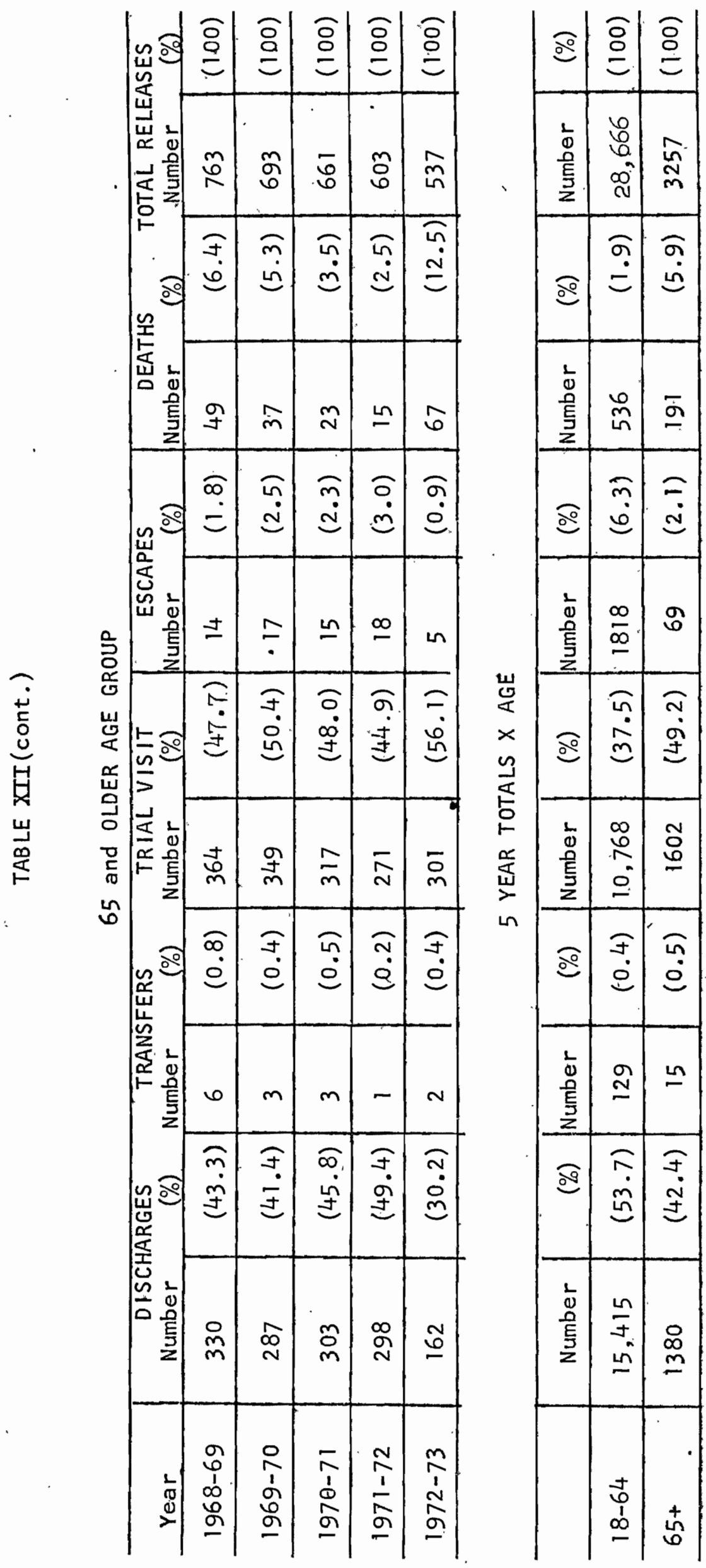


Comparing the decline in totsl releases $(29.6 \%)$, the decline in discharges (50.9\%), and the relative decline in thal visits (17.3\%), it is apparent that, proportionately, more elderly persons are now being placed on a trial visit basis rather than being discharged, while five years ago comparatively more were being discharged.

Stated differently, in 1968-69 a total of 330 elderly individuals were discharged, and a total of 364 placed on trial visits (about 1:1.1), in 1972-73 the numbers were 162 to 301 (about 1:1.9).

It is also significant to note that during each of these five yrars the number of total releases was consistently greater (about 20\%) than the number of total admissions per year among the elderly group. This further substantiates the net flow out of the hospital of gerlatrics patients.

Looking at the 18 through 64 age group, the reverse trends are generally foumd. This is, again, similar to the difference in admission patterns to the state hospitals.

Over this five year rerlod the number of releases among the 18 through 64 rose from 5382 to 6117 , a net increase of $12.1 \%$. The number of total releases per year was also greater than the number of total admissions per year, but compared with the elderly group, the flow out of the hospital was not nearly as substantial.

Considering a breakdown of the total releases, the number of deaths declined substantially while the number of escapes doubled during this period. The number of transfers also declined somewhat. However, when looking at the number of discharges among this group we find an increase of $18.1 \%$ (from 2756 to 3658), and a net decrease 
in the number of trial visits of $12.8 \%$ (from 2180 to 1912). Overall, the net increase in releases was $12.1 \%$.

The trend among the younger age group is opposite that among the elderly age group. This difference is significant because when a person is discharged from the hospital the hospital no longer retains any direct control over the person's actions; however, when a person is placed on a trial visit this release can be revoked, the hospital can authorize: that the person be moved from one location to another, or medications can be ordered changed, since the person is still under the direct control of the hospital.

In other words, while the hospital is increasingly attempting to retain control over released elderly individuals by, granting them trial visits rather than discharges, they are relinquishing similar control and authority over the younger and middle-aged adults.

Where are these elderly persons being placed once they are released from the hospital? Disposition data prepared by Mrs. Gaynell Alfred, Director of Social Workers it Damriasch State Hospital, (TABLE XIII) show that over the three year period 1970-71 through 1972-73 a total of 726 elderly patients released from Damach. Of these, a total of 375 $(51.7 \%)$ w placed in nursing homes of homes for the aged; while 281 (38.7\%) returned to their own homes or went to the home of a relative (1.e. actually returned "to the communtty"); the renaining 67 persons (9.6\%) either died, were transferred to another institution, or their destination ผas not recorded.

Mrs. Alfred factored out those who had been committed, from those who entered the hospital voluntarily, for the year 1972-73. For that 


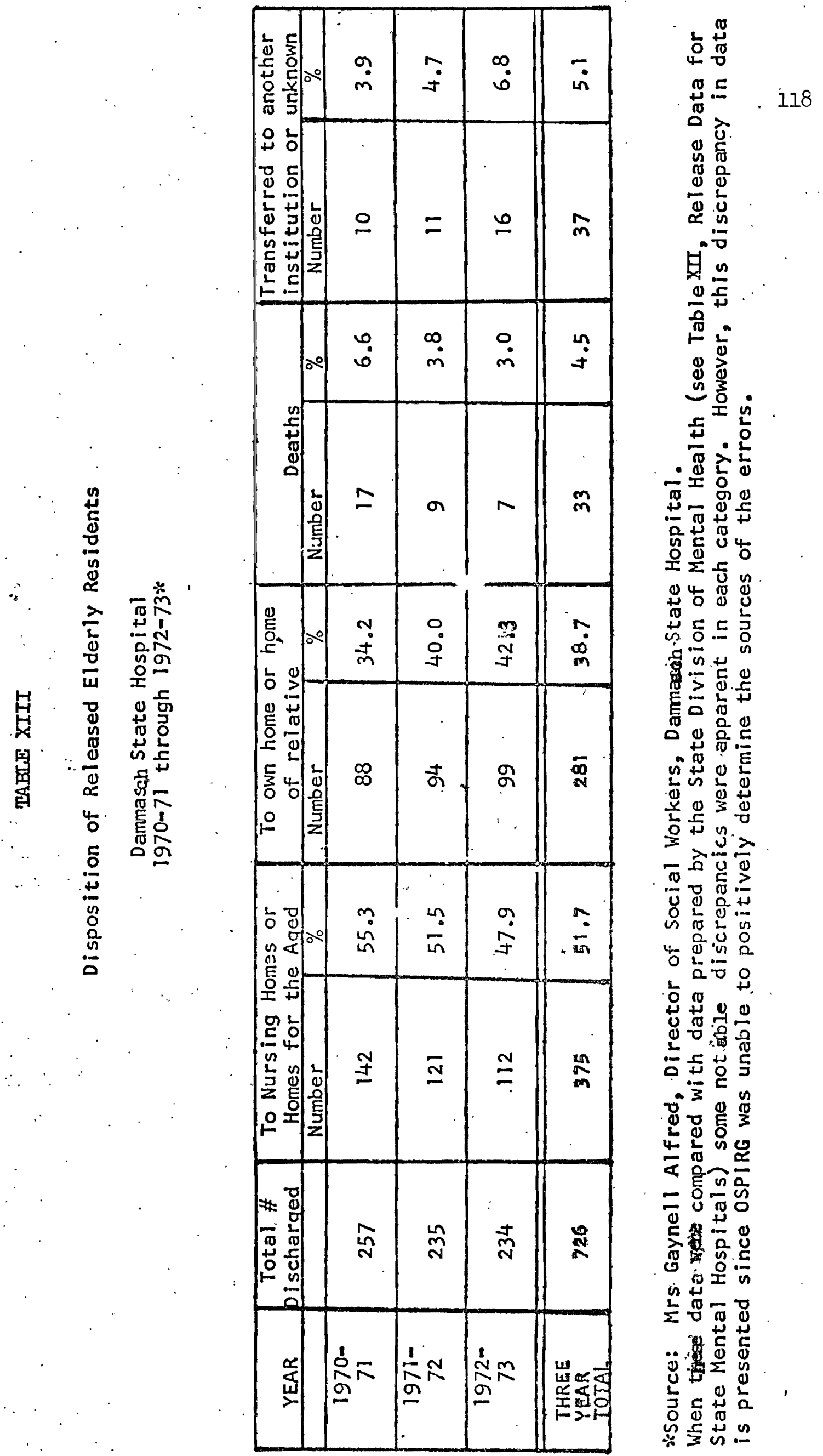


year, of the 112 persons who went to a nursing home or home for the aged, 94 were court committed $(83.9 \%)$ and 18 were voluntary admissions (16.1\%). of the 99. who returned to their own homes or the home of a relative, 61 were voluntarily admitted $(61.6 \%)$ and $38(38.9 \%)$ were persons who had been court committed.

Stated differently, when we compare the relative number of committed persons as opposed to voluntary admissions returning to the community. or being placed in an institution, we find that $28.8 \%$ of those committed returned to the community while $71.2 \%$ were placed in an institution; . while the opposite trend is found among those who voluntarily admitted themselves, with $77.2 \%$ returning home and $22.8 \%$ entering institutions.

Since the hospital has direct cantrol over the discharge destinations of court comnitted persons, it is bbvious that their preference is to place people from the hospital into sheltered settings rather than returning them to community residences. Mrs. Alfred stated that "the hospital is at a disadvantage when we have a voluntary patient because then they (the patient) get to decide where they are going when they leave the hospital. For instance, they will want to go home when you know that won't work, so you just have to let them try it and fail once or twice."

The procedures followed in determining discharge planning and follow-up depend upon whether or not the elderly person entered the hospital voluntarily or was committed. Planning and folkow-up procedures also depend upon whether or not the elderly person qualifies for Public Assistance.

Ms. Ruth Ouelette is the social worker at Dammasch State Hospital 
responsible for placement and follow-up of hospitalized elderly individuals. When Welfare is not involved, Mrs. Ouelette carries the entire planning responsibility herself. When the elderly hospitalized individual qualifies for p'ublic assistance, then Mrs. Ouelette and a welfare liatson worker from the appropriate district usually do cooperative planning, involving the family of the patient (if.there is one), and the patient himself, in the planning effort. According to Mrs. Ouelette, this cooperative planning effort with welfare offices is quite good. According to Mrs. Joy O'Brien, Director of Housing and Living Arrangements Unit, Multnomah District Public Welfare Department, under federal law it is necessary for elderly individuals who have been hospitalized in a mental hospital and who also qualify for welfare to be assigned a Title XIX caseworker upon their discharge from the hospital. This Title XIX caseworker is then responsible for providing follow-up services a minimum of once every six months. Therefore, those ex-hospitalized elderly individuals who qualify for public ossistance are guaranteed follow-up services after their hospitalization, whether they returm to the community or are placed in an institution.

The hospital does not provide direct follow up care to released edderly individuals. Ms. Ouelette explained that when an elderly person is placed in an institution following his release, the hospital sends -medical orders and records with the person to the institution where he is being placed. It is then assumed that if the institution is having any difficulties with the person ....... someone from the instituion will contact Dammasch for assistance. Since most elderiy individuals are regulariy taking some type of medication (usually phenothyazines) at 
the time of their release, it is necessary for the receiving institution to continue to administer and supervise the medication. Most nursing homes and homes for the aged have "house physicians" .who" supervise and prescribe the medications. However, if a home for the aged or boarding home does not have a house physician, then a cooperative arrangement with Community Health Nurses or the Community Mental Health Program can be arranged to provide for medication supervision.

When an elderly individual returns to the community--his own home or the home of a relative--Mrs. Ouelette then contacts the catchment area Mental Health Clinic to arrange for an initial appointment with the Clinic for the individual following his release from the hospital. The hospital forwards medical information to the Clinic regarding the type of follow-up treatment the hospital physician is recomnending: medication, group therapy, or whatever. It is then the released individual's responsibility to maintain conract with the Mental Health Clinic.

However, according tc Mrs. Ouelette, "a lot of these individuals don't want to take medication. No one wants to take medication." As a result, according to Mrs. Ouelette, the hospital has a problem with recidivism because the people go home and discontinue their medication, get sick again, and then must return to the hospital.

The data which OSPIRG obtained from the Community Mental Health $-$. Clinics support: the notion that only a small portion of the elderly persons released from the state hospitals utilizes the Community Mental Health Clinics for follow-up purposes. 
Between 1969-70 and 1971-72 a total of 1957 elderly persons

- W\&s, released from the state's mental hospitals (see Table XII). OSPIRG estimates (on the basis of Dammasch data) that approximately 744 (38\% of the total) elderly persons returned to the community. However, only a total of 349 elderly persons was seen at Community Mental Health clinics throughout the state during this three year period. Since this figure includes all of the elderly seen at Mental Health Clinics, not just those referred for follow-up from the state's mental hospitals, it is obvious that most of those referred from the state mental hospitals are not utilizing the follow-up services of the Mental Health Clinics.

Statements made by both Mrs. Alfred and Mrs. Ouelette have implied that those elderly individuals who have returned to the comnunity account for the major source of recidivism among this age group. Mrs. Alfred stated that those elderly persons who voluntarily admitted themselves tend to return home, and then must return to the hospital again. Mrs. Ouelette stated that those elderly persons who return to the community tend to discontinue their medications and then must return to the hospital. In order to assess the impact of this group of elderly persons on recidivism rates, recidivism, as a whole, must be carefully considered.

People may leave the state hospitals through a variety of avenues: they may die, escape, be transferred, discharged, or released on a trial visit. It is these final two categories with which we are most concerned here. If a person who is discharged from the hospital returns then this is classified as a "return from trial visit"r: (see Table VI). 
OSPIRG was unable to obtain detailed data to indicate the portion of those elderly persons who were discharged and returned to the community, as opposed to the portion who returned to the community on a trial visit; or the relative proportions of institutionalized persons who were discharged or released on a trial visit. However, it is our understanding that, generally, those who are discharged return to the community, while those who are released on trial visits are placed in sheltered settings.

Those elderly persons readmitted to the hospitals between 1968 and 1973 accounted for 641 of the total intake of 2725 elderly persons, or $23.5 \%$ of the total intake. Those elderly persons returned from trial visits accounted for $736(27.0 \%)$ of the total intake. During this five year period a total of .1380 elderly persons (42.4\%) were discharged from the hospital, while $1602(49.2 \%)$ were released on a trial visit (see Table $X \mid I)$. It is, therefore, interesting to note that the recidivism rate of $46.4 \%$ among those who were discharged. (641 of a total of 1380 discharged elderly were readmitted) was only slightly higher than the recidivism rate of $45.9 \%$ among those who were released on a trial visit (736 of a total of 1602).

This lends little support to the idea that thase elderly persons placed back into their own residences or the residence of a relative $\therefore$ are more likely to return to the hospital than those who are placed into a sheltered setting. 
It is also significant to note that $50.5 \%$ of the total intake of elderly persons into a state mental hospital during this five year period were recidivisțic (either readmitted or returned from trial visit) while $53.7 \%$ of the total intake of those between 18 and $64(15,222$ of a total of 28,323 ) were also recidivistic. Obviously, recidivism is a major problem among the adult hospitalized population as a whole, and not merely among the elderly.

In terms of the function of the state hospital system, Mrs. Ouelette stated that Dammasch is not supposed to be a facility for keeping chronically ill elderly people. The hospital does not have the space to maintain these patients. However, according to Mrs. Ouelette, their number is increasing because they are either placed into a number of different institutions but then are returned to the hospital each time because their behavior is unacceptable to the institution, or they are chronic alcoholics or have another illness where the pattern is that they come to the hospital, recover, leave and return home, become sick again and return to the hospital. However, these patients refuse to enter a more "protected" environment permanently.

THE IMPACT THE MOVEMENT OUT-OF-THE-HOSPITAL HAS HAD ON HOSPITALIZED ELDERLY PATIENTS

In recent years there has been a great deal of concern, both nationally and locally, on the part of hospital administrators, clinicians, and legislators regarding what effects the trend out-of-the-hospital has had on hospital patients. Of particular concern have been long-term 
residents, many of whom grew old within the hospital. Unfortunately, no follow-up studies have been conducted in Oregon to assess how the movement out of the hospital has affected hospitalized elderly patients. OSPIRG was unable to obtain post-hospitalization data which had been factored out in relation to the length of hospitalization of elderly patients. Therefore, we do not know how many released longterm patients have returned to the hospital once again, nor do we know how many were released to other institutional settings as opposed to the homes of relatives. Finally, we have no way of assessing the effects of the move from the hospital in terms of increased mortality rates or accellerated deterioration.

The policy decisions which have been the basis of this more rapid movement out-of-the hospital came as a result of the development of psychotropic medications and the increased availability of congregate care homes within the community, and also were due to an increasing awareness of the greater costs associated with mental hospital care.

How has this movement out of the hospital affected the hospitalized patients, particularily the geriatric patient? As we stated, no detailed follow-up information is available for Oregon. However, from a study made of another geriatric population moved from a state hospital in California we might draw some tentative, yet grim, inferences. $\therefore$

This study was based on the transfer of 144 geriatric patients from a California mental hospital to other types of facilities. The experimental group consisted of those geriatric patients who were transferred. They were matched (in terms of age, sex, length of stay, organic or functional diagnosis, and race) with a control group of geriatric 
patients who were not transferred. The experimental group was further differentiated by transfer destination: Group I was transferred to other mental hospitals; Group II to other types of living situations (e.g. Nursing Homes, Room and Board, etc.).

The results of this study found that the older hospitalized geriatric patients who were transferred had a significantly higher mortality rate than the base rate for the matched control patients who had not been transferred. of those transferred to other types of living situations the mortality rate was 4.98 times higher for the experimental group than the control group, of those transferred to other types of living situations the mortality rate was 8.99 times higher. In addition; of those in this Group II who were nonambulatory (26 out of the 65 patients), had a much higher mortality rate--six out of the twenty-six $(27 \%)$ died within the four month follow-up period.

Further examiniation of the data showed that the mean age of those who died was ten years older than the mean age of those in Group 1 , and eight years older than the mean age of those in Group 11. Therefore, it appears that older geriatric patients are more likely to die as a result of transfer.

Other variables such as sex, race, organic or functional diagnosis, and length of hospitalization were not statistically significant. (22)

This study raises some significant questions regarding the care and treatment of geriatric patients, especially when it is remembered that the length of hospitalization was not a factor in post-transfer mortality rates. In effect, we must be concerned about the movement of all geriatric persons, not just those who have been hospitalized for a long period of time.

As Mr. Killian noted, the following significant questions must be raised: (1) With the concept of client-determinism firmily in mind, should the older (especially nonambulatory) geriatric patient's environment be unilaterally and dramatically changed? (2) Should such individuals be moved from a familiar environment at all? (3) Is it possible 
for an individual's environment to assume so much importance that upon sudden removal from it his bodily functions may be affected by emotional traumata that may induce death?

Unfortunately, because no follow-up studies have been conducted regarding the transfer of geriatric patients in Oregon we have no way of definitively stating what type of effects the movement out-of-thehospital has had on the hundreds of elderly persons who have been moved.

Mrs. Joy $\mathrm{O}^{\prime} \mathrm{Brien,}$ Director of Housing and Living Arrangements Unit of the Multnomah District Fublic Welfare Department, reacted to the movement out-of-the-hospitals by saying, "there has been a lot of pressure to get people out of the back wards. For what? You take them out of the situation they're used to, and they're scared of the freedom, and it doesn't do them any good. This is especially true with people who have been in the hospitals a long timfe."

The issue of muving elderly persons from one setting to another will become important once again when we look at the role of sheltered settings in the care of the mentally ill elderly 0regonian.

Since most sheltered settings offer only one llevel of health care (i.e. no available nursing care, part-time nursing care, or 24 hour gursing care), with changes in the health status of the elderly individual it is often necessary for him to be movel from one home to another. This is especially true if the elderly person is receiving Welfare payments to cover the cost of his care in movement is often legally mandiatory (19). 


\section{CONCLUSIONS AND RECOMMENDATIONS}

\section{Problem}

As a result of changes in priorities the State Mental Health Division has developed a policy of discouraging admission of geriatric residents to the state's mental hospitals, and has increased the outflow of elderly residents from the state hospitals. However, the State Mental Health Division has not developed a comprehensive plan in order to adequately care for these individuals within the community.

The most common alţernative to state hospitalization and the most common post-hospital placement used with elderly persons is placement in a sheltered setting. However, these sheltered settings usually have no mental health professionals employed, nor do they have any mental health treatment programs within the homes.

In 1 ine with Senate Bill 510 , the decision to place elderly persons in sheltered settings in lieu of hospitalization, after their commitment to the State Mental Health Division for mental health treatment, blatantly reflects the viewpoint that elderly persons who are mentally ill do not warrant any type of mental health care, but rather, it appears to be more important to place them into less expensive and less visible inst itutions.

$\therefore \quad$ There are also indications thatpeople are now being released prematurely from the state hospitals, before their level of functioning has sufficiently improved to allow them to function adequately within the community or a sheltered setting. Premature releases may also act 
to break down any of the gains in functioning made by the person while in the hospital.

Finally, limited data tend to indicate that the movement of elderly persons from a familiar setting, such as a state mental hospital in which they have been residing for any period of time, is potentially harmful and may result in premature deaths.

\section{Recommendations}

(1) It is strongly recommended that patients be transferred or discharged from a state mental hospital on a purely clinical basis, and not for administrative or financial reasons that ignore human consequences. In addition, since transfer procedures are currently void of any legal standards, it is recommended that the Oregon State Legislature develop statuatory guidelines in this area.

(2) It is also strongly reconmended that until such time as sheltered settings can provide mental heal th care to reeding elderly individuals, these settings should not be used as an alternative to placement in a state mental hospital for mental health treatment for committed elderly individuals.

(3) It is recommended that the State Mental Health Division begin the process of developing policies and guidelines which will facilitate the provision of mental health treatment to those needing this care within sheltered settings by personnel from Community Mental Health Programs. (4) It is also recommended that the State Mental Health Oivision reevaluate its treatment program and discharge procedures in order to discourage premature releases from the state hospitals. 
Problem.

At this time state mental hospitals provide no post-hospitalization follow-up for released patients. The need for follow-up services häs. been recognized by a number of individuals, both within and outside of the state mental health system, including Mrs. Gaynell Alfred, the Director of Social Workers at Dammasch State Hospital, Dr. Del Kole, Region I Director, State Mental Health Division, Mrs. Ada K. Wilson, Assistant Professor of Social Work and Director of the Aging Program, School of Social Work, Portland State University, and Mr. Laverne Jones, the Director of Edgefield Manor, the nursing home/home for the aged owned by Multnomah County.

Although Senate Bill 448 stipulates that "aftemeare for persons released from hospitals with mental or emotional disturbances, mental retardation and developmental disabilities, and alcohol and drug problems" shall be piovided, according to Glen Drugger of the State Mental Health Division, no policies háve been developed to extend this aftercare to elderly persons in sheltered settings.

\section{Recornmendations}

(5) In line with the intent of Senate Bill 448 it is strongly recommended that the State Mental Health Division authorize appropriate

- follow-up and aftercare services for elderly persons who have been placed into sheltered settings, as well as providing follow-up and aftercare services to elderly persons who have returned to private residences in the community. 
(6) In order to facilitate the recognition of mental or emotional disorder among elderly persons residing in sheltered settings, it is recommended that the State Mental Health Division develop and offer to administrators and staff members from sheltered settings, training workshops which are designed to increase general knowledge about the problems of the elderly, and more specifically, to instruct these persors in the identification of mental or emotional dijsorder so that appropriate referral to a Community Mental Health Program can be made.

\section{Problem}

Data provided by the State Mental Health Division indicate that the most common diagnosis assigned to elderly persons within state mental hospitals is that of "organic brain syndrome." Although OSPIRG has no definitive information to indicate that this is the case within Oregon's state mental hospitals, the usual assumption made regarding persons assigned a diagnosis of organic brain syndrame is that this condition is psychiatrically untreatable and irreversible. Therefore, persons considered to have an organic brain syndrome are usually not provided with any type of in-depth mental health treatment.

However, research studies have documented the impossibility of

- conclusively diagnosing the presence of an organic brain syndrome, and have additionally called into question the stereotypic assumption of irreversibility of organic brain syndromes.

Within Dammasch Hospital, OSPIRG did note that there are no specific treatment programs developed for elderly patients. Recreation 
and socialization, in addition to medications, appear to be the primary forms of therapy used with the elderly, although Reality Orientation Therapy has had notable success in treating mental $i l l$ ness and impairment among elderly individuals, particularily those diagnosed as having organic brain syndromes. Both Oregon State Hospital and Eastern Oregon Hospital have formalized Reality Orientation programs within their. segregated geriatrics wards.

Recommendations

*

(7) It is recommended that a formalized Reality Orientation Treatment program be instituted at Dammasch State Hospital for use with all severely disoriented individuals, particularily those elderly individuals who are considered to be suffering from organic brain syndromes. (8) In addition, it is recommended that all state hospitals develop more stringent methods of diagnosing the presence of organic brain syndromes since such a diagnosis tends to have negative effects upon therapists' attitudes concerning the likely outcome of any treatment attempted with persons having organic brain syndromes.

\section{Problem}

Finally, as the problem basic to all of these mentioned previously, is the issue of the legal status of mental health care and the legal rights of mentally ill persons. At this time Oregonians have no legal right to demand adequate mental health treatment from state mental hospitals or Community Mental Health Programs. Obviously, without such 
legal rights, the quality and suitability of treatment is subject to whims, biases, and political and financial pressures to provide less expensive mental health care. However, the alternative is immeasurable losses in terms of social productivity, family disruption, and human misery are tremendous.

\section{Recommendation}

(9). Therefore, it is strongly recommended that the State Legislature affirm the legal right of all Oregonians to receive suitable and adequate mental health treatment when they are in need of such treatment and to assure the provision of such treatment, independent of an individual's ability to pay for care within the private marketplace. 


\section{CHAP'TER IV}

THE ROLE OF SHELTERED SETTINGS IN THE CARE OF MENTALLY ILI ELDERLY ORIGONIANS

Historically, a substantial number of elderly people .hast received treatment in state mental hospitals and have then been placed in "sheltered settings." Now, as a result of legislation passed in 1973, mentally ill elderly persons can be committed by the State Mental Health Division and be placed directly into a "sheltered setting." without first receiving treatment in a State Mental Hospital. For these reasons OSPIRG considered a cursory look at the role of sheltered settings in the care of the mentally ill elderly Oregonian necessary.

What Are "Sheltered Settings"?

The terms "sheltered setting" or "congregate care facllity" refer to, basically, three different types of facilities: foster care homes, homes for the aged, or nursing homes. Each of these types of facilities provides a different level of medical and/or custodial care to its patients.

According to Mrs. Joy O'Brien, Director of the Housing and Living Arrangements Units of the Multnomah District Public Welfare Department, adult foster care homes are private homes which provide a living situation to a maximum the proprietor by blood or marriage. These individuals may require some medical care. A group foster care home is a private home which is sheltering three or more unrelated persons. In group foster care homes elderly residents w1ll not usually require any medical care since the law states 
that any home providing care to two or more unrelated persons needing nursing care must be licensed as a nursing home. Since foster care homes are a fairly new concept, Mrs. O'Brien explained that usually clients arrange their own placements rather than having these arranged by a caseworker. These homes may provide help with hygiene, nutrition, special diets, or other specific concerns, and they usually provide care to people who are unable to live alone without help or supervision. Board and room facilities provide simply boand and room, and do not fall under the title of foster care, per se.

According to 1970 Rules and Regulations Governing the Operation of Homes for the Aged in Oregon (23), prepared by the Oregon State Health Division, a home for the aged refers to "any home or other institution that maintains facilities for rendering board and domiciliary care for compensation to three or more aged persons not related to the operator by blood or maxriage." An aged person means "a person of the age of 65 or more, or a person less than 65 who by reason of infirmity requires domicilary care." Every home for the aged is required by law to be. licensed, and issuance of a license depends upon meeting a number of specific regulations. Most of these regulations pertain to requirements for the physical facility, or ensure basic sanitary and health protection to the residents. Three regulations are, however, related to med- . ical or mental health concerns.

Under Section 23-242 POLICIES,

(7) Persons requiring nursing care shall not be admitted to homes licensed under ORS 442.005 to 442.990 . Bach individual shall present evidence that he has recently been examined by his physician and does not require nursing care.

(9) The guest's physiclan shall be called at the onset of 
11lness or mental derangement At the doctor's discretion, a registered nurse shall be in attendance during the emergency until the patient can be transferred to a hospital or nursing home. .

(10) If any person in the home becomes mentally deranged to the point that he or she is dangerous to himself or herself or to others, or requires restraint, immediate steps shall be taken to remove such person from the home. (23)

The Department of Public Welfare further distinguishes homes for the aged in terms of intermediate care or non-intermediate care facilities. This distinction is based upon whether or not the facility meets Medicald requirements as an intermediate care facility suitable for providing post-hospital care to Medicare reciplents. According to the State Health Division, Licensing Board, there is no distinction made between intermediate care and non-intermediate care facilites in terms of licensing requirements.

Mrs. Miller, a Welfare Placement Officer in the Housing and IivIng Arrangements Unit of MuItnomah Public Welfare District, also stated that "the distinction is primarily a financial. one and we have found no difference in the level of care offered by these two types of homes for the aged.

From these regulations it is evident that one primary distinguishing factor of homes for the aged is that they do not house persons requiring nursing care. In addition, homes for the aged are not considered to be suitable placements for persons considered dangerous or in need of restraint as a result of mental 1Ilness.

According to new Oregon State Health Divison Rules Governing the Intermediate Care Nursing Home adopted in July, 1973, the intermediate 
care nursing home is defined as

a facility which provides care for a period exceeding 24 hours nursing care to two or more patients who are not related to the owner or nursing home administrator by blood or marriage. Such intermediate care nursing homes must provide nursing service to those patients whom, in the judgement of the physician, registered nurse and nursing home administrator, require primarily supportive and preventive nursing measures and secondarily remedial and restorative measures; and excludes persons who are acutely 111 and persons requiring continuous licensed professional nursing care. (24)

In contrast; a skilled nursing home has the same stipulations regarding the relationship of the patients to the owner and nursing home administrator, but must provide services to those patients who require "primarily remedial and restorative nursing measures and secondarily supportive and preventive nursing measures" and includes patients who are acutely 111 and in need of continuous licensed professional care (25). As these particular nursing measures are further defined: "Preventative nursing" means those measures essentially concerned with malntaining total health in all aspects basic to the physical and psychological integrity of the individual.

"Supportive nursing" means those measures directed toward sustaining physiological and psychological patient needs at an optimum level in the presence of stress. It is required when self-help ability is diminished as a result of an impaired state and the patient cannot of his own accord provide for the satisfaction of his personal, needs.

"Remedial nursing" means those measures directed toward reducing or correcting the impaired state in order to increase the selfhelp ability.

"Restorative" or "rehabilitative nursing" means those measures directed toward restoration of the patient to full activity insofar as his health problems permit and to a state in which his total need for care is minimal. (25)

Essentially, then, an intermediate care nursing home is primarily concerned with maintaining the physical and psychological health of the individual, while the skilled nursing home is primarily concerned with 
reducing or correcting the 1mpalred state, or restoring the patient to full capacity.

The regulations which address themselves to the psychological care of patients in intermediate care and skilled nursing homes are presented In rather vague terms. "Supportive nursing" includes the provision of "activities designed to support patients' physical and psychological requirements in the areas of comfort, exercise, rest, sleep and diversional activities." (25) Within "restorative nursing" is the provision for "providing access to resource personnel in related health disciplines." Both types of nursing homes are also required to prepare and implement a written nursing care plan for each patient which shall be based on

the nursing assessment of clinical symptons, patient needs, the nature of the illness, treatment prescribed, long and short term goals, needs for additional services such as social services, occupational therapy and physical therapy, patient expectations and, whenever possible, involvement of the patient's family and their expectations for the patient. (25)

The primary distinction between intermediate care and skilled nursing homes is in the severjty of the medical problems presented by the patients, and the level of nursing care therefore required.

Implied in the definitions of "preventative," "supportive," "remedial," and "restorative" is the necessity of the nursing home to address the psychological, as well as the physiological, requirements of patients. However, nursing homes are also not specifically required to make available to needing patients the services of qualified mental health professionals, nor are they specifically requilred to develop within the home an on-going mental health treatment and/or maintenance program, such as Reality Orientation therapy, sociallzation groups, or group therapy. 
These are some additional regulations which also affect the care of residents of homes for the aged and nursing homes. Welfare regulations state that individuals should be housed in the least restrictive setting necessary. Since nursing homes and homes for the aged, as well as other types of sheltered settings, are distinguished by the level of medical care which they provide, and since most facilities do not combine two or more levels of care (i.e. a home for the aged and nursing home within the same or adjoining facilities) changes in a person's health status often make it necessary for him to be moved from one facility to another, according to Mrs. Joy O'Brien, Director of the Housing and Living Arrangments Unit of the Multnomah District Public Welfare Department.

Another welfare policy also contributes to the likelihood of an individual being transferred from one facility to another. It is the policy of the Public Welfare Department to establish payment rates to nursing homes and homes for the aged based upon the cost of providing care to patients, rather than paying amounts comparable to those of priva.tely paying residents. Ine net effect of this policy, according to Mr. Laverne Jones, Director of Edgefield Manor (a hane for the aged/ nursing home owned by Multnomah County), is that many privately administered homes will admit patients supported by publie assistance, and then will request that these patients be transferred when a privately paying patient is willing to fill this bed space. The logic of the administrator is that a private paying patient is better than a patient supported by welfare, but a welfare recipient is better than a vacant bed. Accoriing to Mrs. O'Brien, the transfer of welfare recipients from one home for the aged or nursing home to another because they are welfare 
recipients "does not happen very often." Rather, "usually bed accommodations can be arranged," she stated. OSPIRG found that most of the nursing homes and homes for the aged which it contacted had few vacancies, Indicating a fairly high demand for the available bed spaces. If nursing home and home for the aged bed spaces are relatively scarce, it would seem that the likelthood of welfare recipients being transferred, as privately paying patients request admission; would be greater.

Obviously, these Public Welfare policies are designed to minimize the cost associated with providing care to institutionalized people. However, increases in the incllence of geriatric transfers may also be inducing accelerated mortality rates (22) as well as increasing the distress experienced by elderly people as they are forced to move from "home" as a result of these policies.

How Many Elderly Persons Are Hiving in Sheltered Settings in Oregon? According to 'J.a Elderly Oregonian Today, in 1971 there were 125 homes for the aged in oregon, accounting for 3,061 beds or units. Since the occupancy rate in homes for the aged was about $92 \%$, there were over 2,800 elderly persons living in these facilities. Within Multnomah County there were 41 homes for the aged with a maximum capacity of 1,371 and an actual occupancy of about 1,240 persons living in these facilities. There were 190 nursing homes statewide in 1971, with a bed capacity of 11.40I. Of this total, 54 homes were located within Multnomah County, with a bed capacity of 3,604 . Since the occupancy rate within nursing homes was about $97 \%$ there were approximately 10,900.persons statewlde and about 3,496 persons within Multnomah County restaling in nursing homes. 
Comparative figures provided by the State Health Divison, If censing Board, for March, 1974, indicate that there were 125 homes for the aged in Oregon, accounting for 3,380 beds. Within Multnomah County there were 38 homes for the aged with a total of 1,472 beds. Overall, this shows a net increase of 329 beds statewide and an increase of 101 beds within Multnomah County. In terms of nursing homes, statewide there were 193 nursing homes with a total bed capactty of 13,284. Within Multnomain County there are 55 nursing homes with a total bed capacity of 3,960. This shows a net increase of 3 nursing homes, an increase of 1,884 beds statewide, and an increase of 356 nursing home beds within Multnomąh County.

Increasingly, providing institutional care to elderly persons is becoming! "big business", within Oregon.

Copsidering these data from a different perspective, TABLE XIV provides; information concerning Old Age Assistance recipients living in congregate care facilities in Multnomah County during the month of June, 1973. These data were prepared by Mrs. Sandra Iippman, Analyst, Research and Statistics, Public Welfare Division. Of the total number of elderly people living in sheltered settings, approximately $23 \%$ receive 0ld Age Assistance payments (8). During the month of June, 1973, therre were 1,945 elderly persons living in sheltered settings in Multnomah County and receiving OAA payments for their care, totaling $\$ 359,244.70$ for this one month of care. (However, this figure does not include the cash payments paid to individual elderly persons for their personal allowances; an amount which OSPIRG estimates to be an additional $\$ 4,000.00$ for the month.) If we were to assume that these fig- 


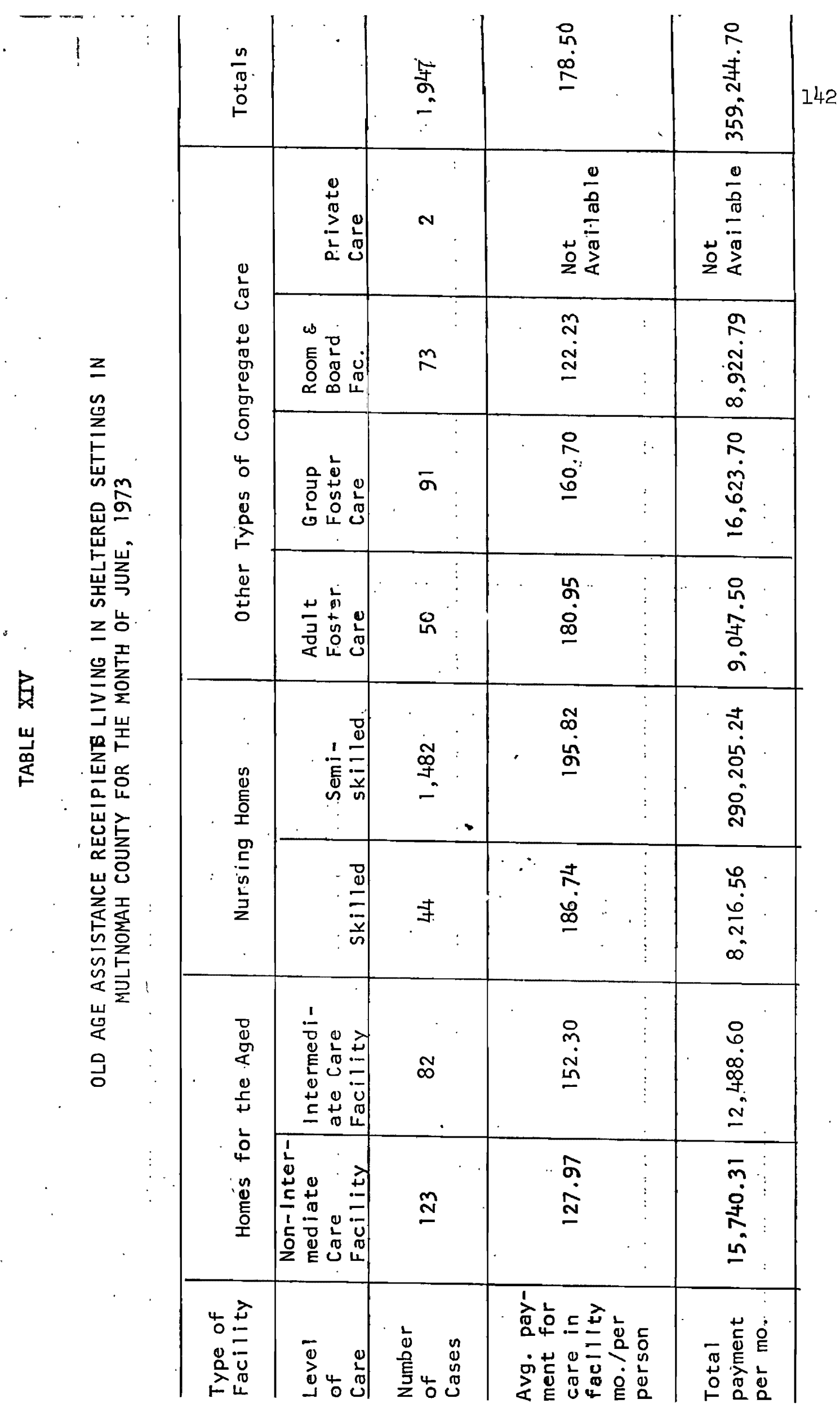


ures remained constant throughout the year, within Multnomah County alone a total of $\$ 4,310,976.00$ a year is being spent, through OAA, to provide care to elderly persons in sheltered settings, and OSPIRG estimates that this figure is $\$ 7,882,560.00$ annually for the State of Oregon (for a total of 3,680 people at an average payment of $\$ 178.50$ per month). Obviously, not all of the elderly persons receiving OAA payments for care in sheltered settings fall within our special study population mentally $11 l$ elderly Oregonians. However, it is important to keep in mind the amount of money which is being spent for the institutional care of elderly persons, as opposed to other types of comunity-based care or treatment, since it has become increasingly evident as a result of Project ABLE that some elderly persons can avold institutionalization if they are provided with adequate supportive services within the community. (Remember, Project ABLE is serving approximately 550 persons during each month and 1000 clients for the year, with a total budget of $\$ 546,307.00$ for 1973-74 fiscal years.) (See Chapter II for additional information reganding Project ABLE.)

The Role of Sheltered Settings in Caring for Mentally III Elderly Persons

Again OSPIRG found that there were no statistics available indicating the number of mentally ill elderly persons residing within sheltered settings in Oregon. Therefore, it was necessary for OSPIRG to estimate the number of mentally ill or mentally impaired elderly persons living in sheltered settings in Oregon based upon national and local indicators.

Nationally, the Group for the Advancement of Psychiatry found that "direct examinations of aged persons who are in old age and nursing 
homes indicate that the mental functioning of at least $80 \%$ is seriously impaired, and that $3 \%$ to $6 \%$ of aged residents : - are sufficiently disondered to meet clinical criteria for involuntary certification to a mental hospital." (20)

Findings of a recent survey of the psychiatric and other medical characteristics of the aged population of metropolitan New York adritted to voluntary nonprofit homes for the aged, proprietary nursing homes, and state mental hospitals, at 65 years of age or over, were also reported by the Group for the Advancement of Psychiatry. The key points of this survey were that:

(1) Homes for the aged and proprietary nursing homes, as well as state mental hospitals, are important centers for the care and treatment of mentally disturbed older people. The vast majority of aged in these homes have mental impairments similar in type and frequency to those found among elderly in state hospitals. However, the proportion with severe mental impairments is greater in state hospitals.

(2) Most older institutional residents are physically as well as mentally impaired.

(3) There is a close relationship between the mental and physical functional status of older institutionalized people, particularly among residents of homes for the aged and nursing homes.

(4) The mental and physical functioning status of older inst1tutionalized persons is greatly influenced by the prevailing "climate" in a specific institution. When environmental factors are favorable, this is reflected in better functioning, when they are less favorable older residents with similar impairments function less effectively.

(5) Most mentally disturbed residents of homes for the aged and nursing homes require adequate psychiatric supervision if they are to receive the care and treatment they need in these non-hospital facilities.

(6) The mental and physical disabilities of older people account only in part for their admission to institutions. Closely related factors are the lack of, or breakdown in, 
socially supportive services ox medical facilities in the community that might have enabled some aged persons with inpairments to remain in their own on a relative's home. (20)

The Special Committee on Aging of the United States Senate has also concluded that sheltered settings are providing care to large numbers of mentally 111 or impalred elderly persons. In a 1971 report, the Special Committee on Aging stated that

nursing homes recelved many of the patients who were removed from State mental hospitals during the past decade, and they also recelved many other persons with mental 1mpairment during that same period. . An estimated 55 percent of the residents in nursing homes and related facilities serving the chronically ill are mentally impaired persons." (13)

Although only $7 \%$ of all elderly Oregonlans reside in sheltered settings, applying these various estimates to the current population of elderly persons living in sheltered settings, we would estimate that there are approximately 8,800 mentally Impaired persons living within Oxegon facilities ( $55 \%$ of a total of 16,000 persons), and we might further conclude that $480-960$ of these people ( $3 \%$ to $6 \%$ of the total) might very well qualify for involuntary commitment to a state mental hospital. (Howevert, a majority of these elderly persons most likely .would have been released from one of the state's mental hospitals.)

OSPIRG found that for the period 1970-71 through 1972-73, there were 726 elderly persons released from Dammasch and of this total $51.7 \%$ (375 persons) were placed directly into some type of sheltered setting from the state hospital, according to Mrs. Gaynell Alfred, Director of Social Workers at Dammasch State Hospital. (See TABLE XIII) Although OSPIRG has no comparable figures from the other two state mental hos-: pitals, were we to assume that this proportion was fairly constant for all of the released elderly persons for the period 1968-69 through 
1972-73, there would be approximately 1684 eldexly persons who have been released from state mental hospitals and placed directly into sheltered settings throughout the state within the past five years. Although this figure represents only a fairly small proportion of the total number of elderly persons residing within sheltered settings, it inaludes only those elderly persons who were identified as mentally $1 I 1$ and who received treatment in a state mental hospital for a period of time prior to their placement in a sheltered setting. This figure does not include those disoriented or "senile" elderly people who were placed directly into sheltered settings in lieu of possible hospitalization; nor does 1t include less severely disordered, yet mentally or enotionally disturbed, elderly people.

Comparing the role of sheltered settings in providing posthospital care with the role of the community mental health clinics, OSPIRG estimates that for the years 1969-70 through 1971-72, approx1mately 1,000 elderly persons from the state mental hospitals were placed into sheltered settings, while a total of only 349 elderly people received out-patient mental health care at any of the community mental health clinics throughout the state during this same time period. Comparatively, sheltered settings appear to be providing post-hospitalization care to a substantially largex number of elderly people than community mental health clinics throughout the state.

Having determined that sheltered settings provide care to a relatively large number of mentally ill or mentally imparred elderly indi-. viduals, OSPIRG solicited information from the administrators of nine homes for the aged and seven nursing homes within Multnomah County. 
The nursing homes and homes for the aged with larger total bed capacity were questioned since OSPIRG belleved that the larger homes would probably be in a better position to provide formalized mental health care to their residents.

Information from administrators was solicited by phone, and OSPIRG Investigators requested the following information: (1) the number of current vacancies in the home; (2) the total number of staff employed by the homes, and the number of their staff considered to be mental health professionals; (3) the type of in-service mental health training provided to the staff as a whole, and the types of mental health programs available to residents within the home; (4) mental health training programs offered by other agencies which staff from the home had attended, or, would like to have staff members attend such a progran if it were available; (5) whether the home accepts welfare recipients, and if so, the number currently residing in the home; (6) whether the home accepts people who have, or have had, mental or enotional problems (e.g. Dammasch discharges or "managenent" problems) and if so, the number currently living in the home; and ( $?$ ) who they contact when they have an elderly resident whom they think is in need of psychiatric care. (TABLES XV and XVI present a summary of the responses which OSPIRG received to these questions.)

Although OSPIRG contacted a relatively small proportion of the total number of homes for the aged (about 22\%) and nursing homes (about 13\%) within Multnomah County, the relative uniformity of the responses given to these questions suggest broader validity of these findings.

(1) Of the sixteen homes contacted, only one home for the aged and 


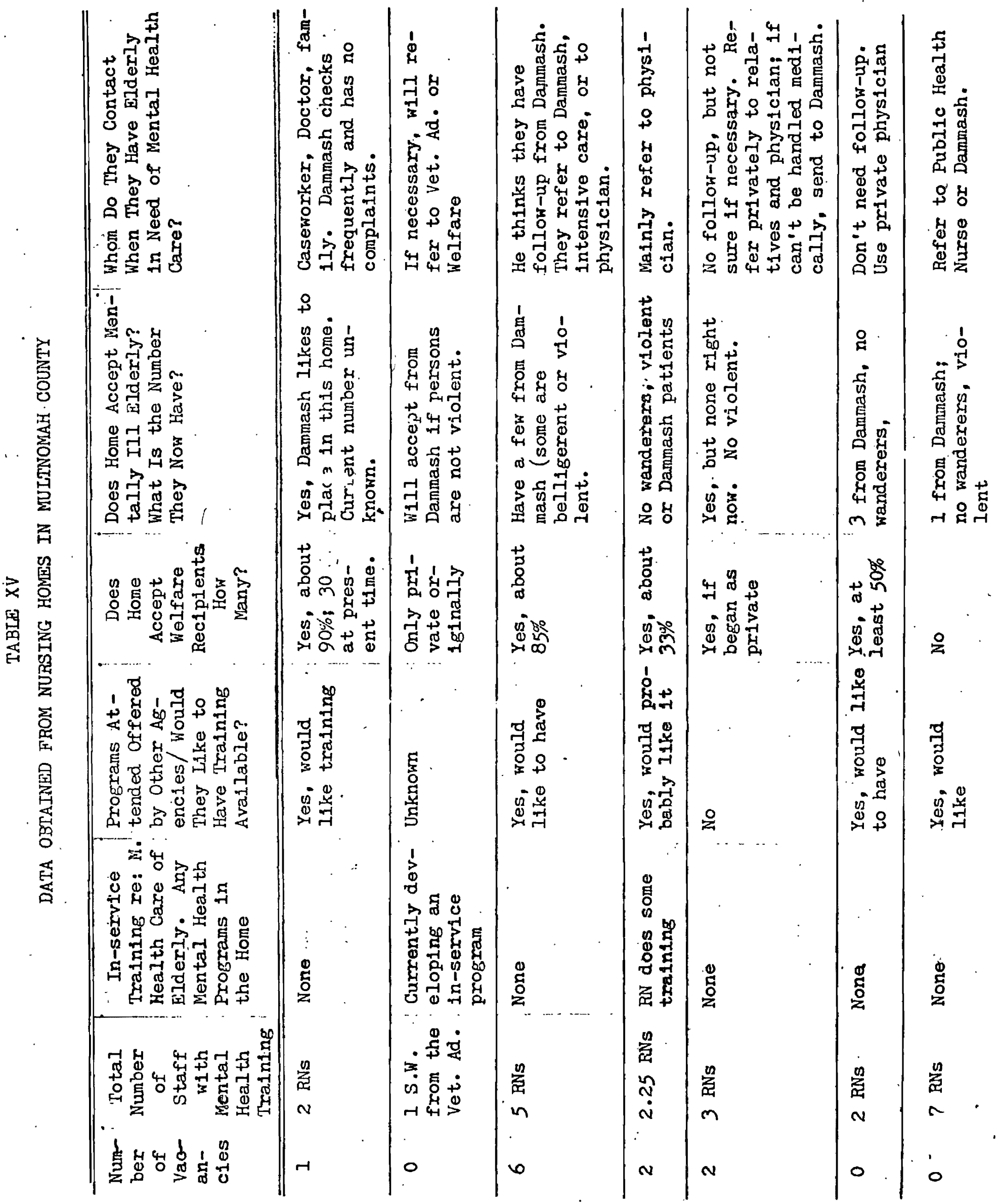




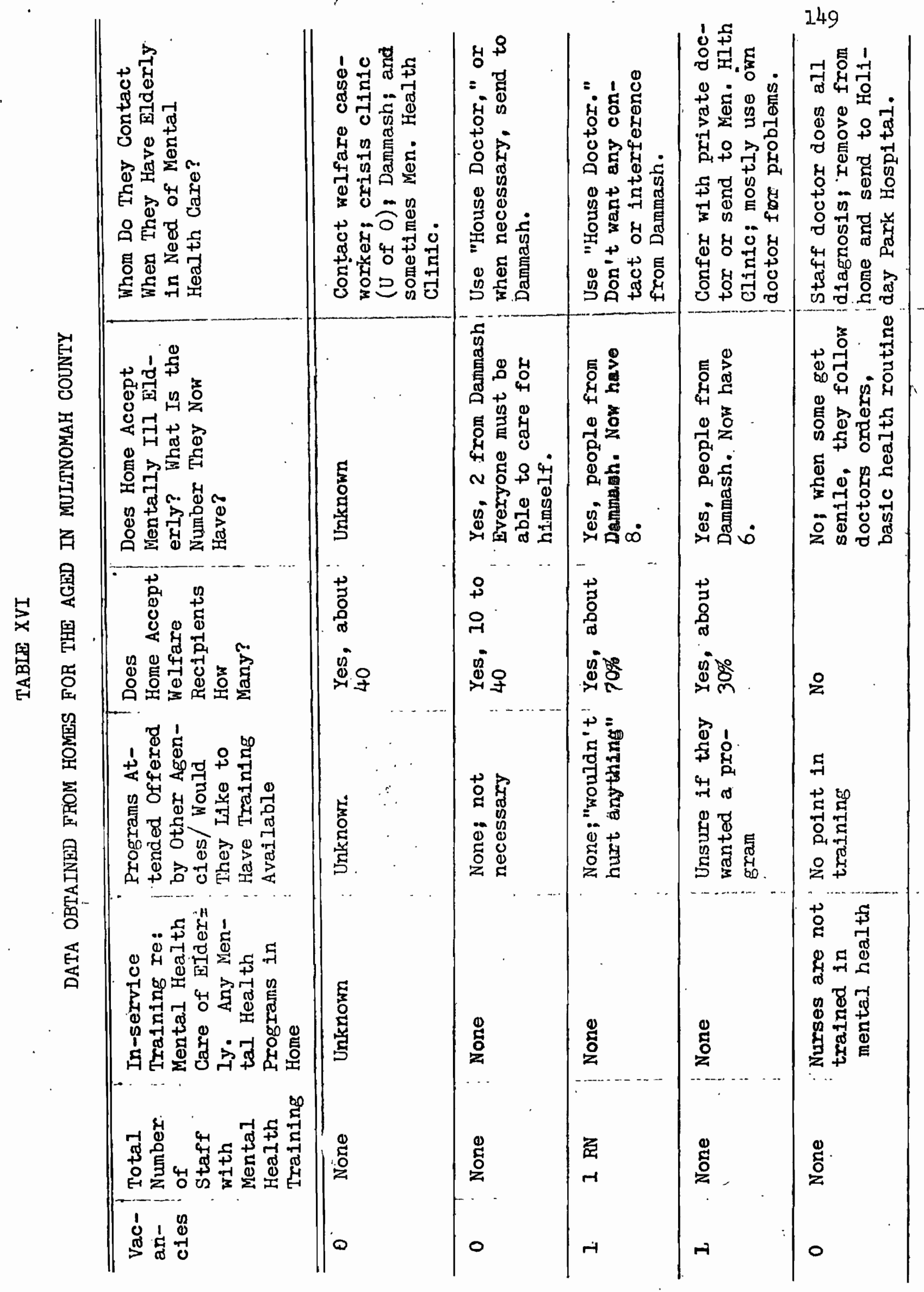




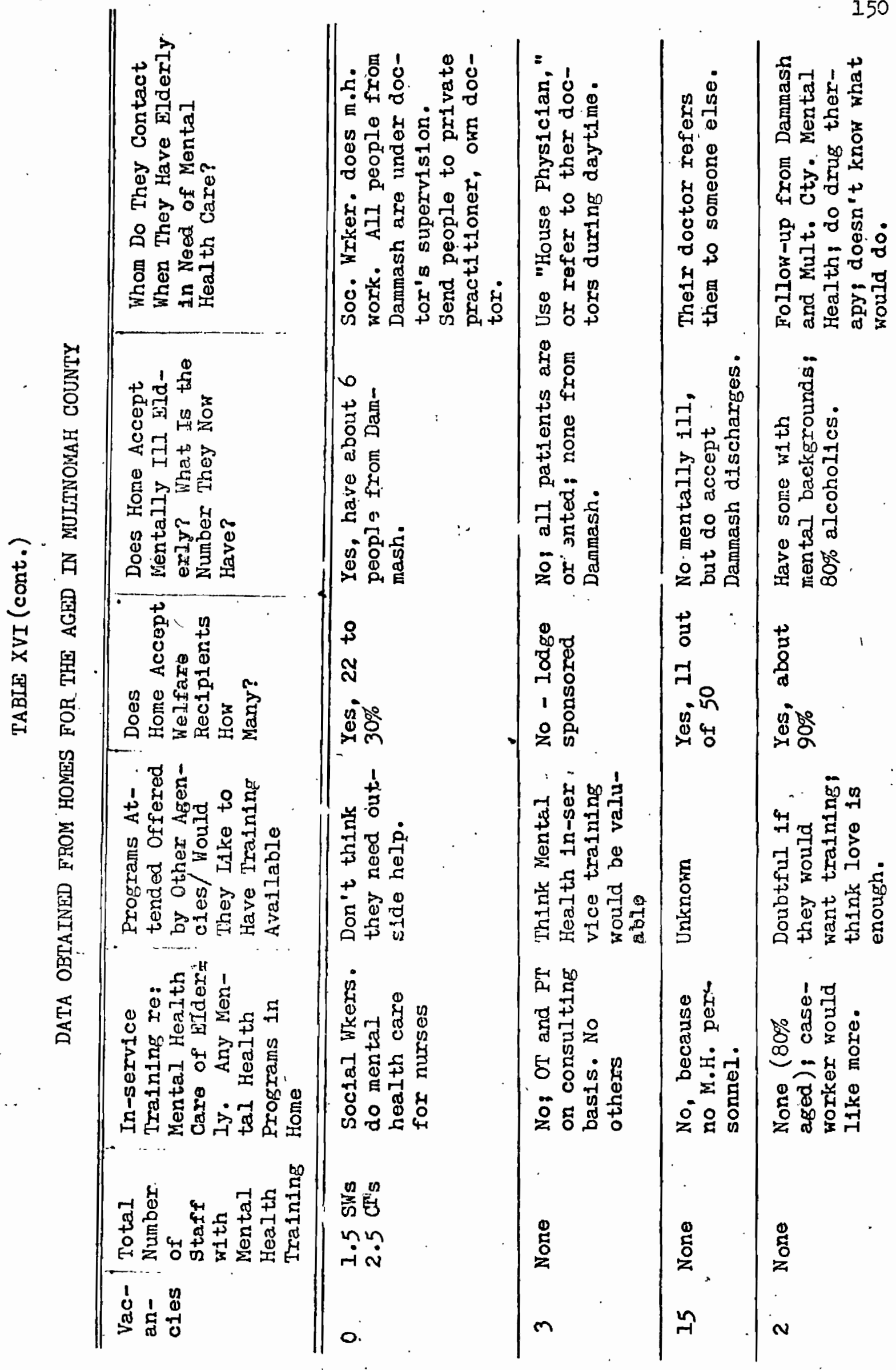


one nursing home had a substantial number of vacancies. The implications of this finding are that these homes can be relatively selective in whom they admit or retain as residents, or conversely, a person seeking placement in a home is not going to receive the advantages of a competitive marketplace in order to attract and retain his' interest in the facility.

(2) The regulations related to mental health care in nursing homes and homes for the aged presented earlier. Essentially, nursing homes are required to develop treatment plans for each patient which take in to consideration his psychological needs. Nursing homes are required to provide for appropriate "comfort, exercise, rest, sleep and diversional activities" in order to support the patients' psychological requirements and they are supposed to provide "access to resource personnel in related health disciplines" when this is appropriate. However, neither homes for the aged nor nursing homes are required to specifically make mentsl health professionals available, nor are they required to develop and implement an ongolng: mental health treatment or maintenance program within the horne.

In assessing the number of mental health professionals employed by these homes OSPIRG used as a definition of "mental health professional" as being persons . who possess a professional degree from a mental health related field; i.e. a psychiatrist, climical psychologist, psychiatric social worker, or a M.Ed. With training in counseling and guldance, for example.

Of the homes for the aged which OSPIRG contacted, one home had an equivalent of $1 \frac{1}{2}$ social workers and $2 \frac{1}{2}$ occupational therapists employed. 
The remaining homes for the aged had no mental health professionals employed.

Of the nursing homes which OSPIRG contacted, all had varying numbers of RNs employed, but only one nursing home had a mental health professional, a social worker from the Veterans Administration, available on a parttime basis. A couple of the nursing home administrators also mentioned welfare caseworkers as mental health professionals. Therefore, the qualtfications of the RNs and welfare assistance and service workers as mental health professionals need to be considered. OSPIRG contacted Ms. Mary Hughes, R.N., Assistant Director of Community Health Nurses for Multnomah County, and questioned her regarding the type of mental health training provided to all registered nurses as part of their professioanl training. According to Ms. Hughes, all RNs are required by state law to receive either three months or one semester of training on the psychiatric wand of a general hospital or at one of the state mental hospitals. Therefore, all Rus trained within Oregon have had some basic training in working with rentally ill persons. However, RNs are not generally considered to be mental health professionals unless they have received additional specialized training in mental health work beyond their usual RN training.

In terms of the training provided to welfare caseworkers, Mr. Iouis Hahn, Director of Social Services for the Multnomah District Welfare Department, told an OSPIRG investigator that assistance workers are given no special training regarding the identification of mental health problems or mental health treatment. Mrs. Joy O'Brien, Director of the Housing and Iiving Arrangements Unit of the Multnomar District Welfare 
Department, stated that the service caseworkers within her department are provided with in-service training, some of which pertains to mental health problems and special problems of the aged. She stated that service workers are in a position to identify mental health problems for referral to mental health professionals for treatments. However, both service workers and assistance workers from Public Welfare are not generally trained to be, nor are they considered to be, mental health professionals.

Therefore, with one exception, none of the homes for the aged or humsing homes which OSPIRG contacted employed any mental health professionals.

One additional factor, however, should be considered in evaluating the knowledge of mental health problems within nursing homes and homes for the aged. Although there are no specific educational requirements for the licensing of operators of homes for the aged, nursing home operators are required to pass witten and oral examinations in order to be licensed by the State Health Divison. According to John Richard of the Oregon Health Cara Association, the written examination which nursing home administrators are required to pass, consists of approximately 200 questions, of which approximately 40 deal with the area of professional nursing, including questions pertaining to the terminology of geriatric nursing, information on mental health problems, and quite frequently information regarding the symptomatic relationship of health problems, and special problems of the aged, Howeves, these operitors are not mental health professionals.

(3) None of the homes which OSPIRG contacted had any on-going 
mental health prograins avallable to residents within the home. In addition, only two of the homes (one home for the aged and one nursing home) had any type of in-service staff training related to mental health care of the elderly. One additional nursing home was in the process of planning an in-service mental health training program.

(4) None of the homes which OSPIRG contacted had had any of their staff attend mental health training programs offered by any other agencies. However, when administrators were asked whether or not they would like to have such training workshops available to their staffs, response generally differed for homes for the aged and nursing home administrators. Only two of the home for the aged administrators thought that such training either "wouldn't hurt anything" or "would be valuable," while seven of the nine nursing home administrators contacted stated that they would like to have mental health training avallable. This difference in responses may be a reflection of the different training required of nursing home administrators than that required of home for the aged administrators, or possibly, the higher incidence of mental impairment usually associated with the more severe physical impairment found in nursing homes may have been the determining factor.

In any case, if the State Mental Health Division were to make avallable mental health care and treatment workshöps, we might expect a favorable response and participation from a substantial number of nursing home administrators and from some home for the aged administrators. An additional note is that during the course of the study, OSPIRG heard of no workshops which had been offered to nursing home or home for the aged administrators or staff in Multnomah County within the last 
several years.

(5) OSPIRG asked $\ldots$ the home administrators whether or not they accepted welfare recipients, and if so, the number of recipients they had currently residing in their home. Out of nine homes for the aged, seven accept welfare recipients; and of the seven nursing homes, six accept welfare recipients. The proportion of welfare recipients found in these homes varied widely.

OSPIRG requested this information in order to assess the proportion of homes for the aged and nursing homes which are supported, at least in part, by public funds. From the data which we received, it appears that over $80 \%$ of these homes receive at least some public assistance funds, The impact of this finding becomes apparent when we consider the potentially beneflcial effects that mental health care, or a "therapeutic milieu," can have on the physical, as well as psychological, well being of institutionallzed persons. Essentially, the likelihood of improvement and eventual discharge from an institution is enhanced when mental health care is provided. Financially, this can represent a substantial savings in the expenditure of public funds for institutional care, as well as increasing the contentment of individual elderly persons.

(6) OSPIRG also asked the administrators whethex ox not their homes accepted people who have, or have had, mental or emotional problems (such as Dammaschdischarges, or people considered to be "management problems"), and if so, the number currently living in the home. Six of the nine homes for the aged do accept discharges from Dammasch and another one of the homes has some people who beame "senile." Six 
of the soven nursing homes also accept discharges from Dammasch. Some of the homes stipulated that they would accept "no wanderers" or "no violent" people, however. The numbers of persons who have, or have had, identified mental health problems varied widely among the homes.

Therefore, from data wich OSPIRG collected, it also appears that most homes for the aged and nursing homes have residents who have, or had had, mental or emotional problems. This futher confirms OSPIRG's contention that sheltered settings play a vital role in providing posthospital care, or care in lieu of hospitalization, to many mentally 111 elderly people.

(7) Finally, OSPIRG asked the home administrators who they contact when they have an elderly resident who they think is in need of psychiatric care. The responses made by administrators of homes for the aged and nursing homes were similar, although home for the aged administrators more frequently mentioned using "house physiclans," and so all of the responses have been combined and are given below. Most administrators gave multiple responses to this question.

13. mentioned contacting their own "house physicians" or private physicians

7 contact Dammasch or eventually refer residents to Dammasch for treatment

4 contact one of the branches of Multnomah County Mental Health Clinic

4 contact a welfare caseworker

2 contact the resident's family

I mentioned contacting the University of Oregon Medical School Crisis Clinic

1 mentioned contacting the County Hospital

1 contacts a Community Health nurse

1 home uses its? own social workers initially

1 refers to a private psychiatric hospital

1 uses the Veterans Administration

It is revealing to note that eleven different sources of mental 
health care were mentioned by these sixteen administrators. The array of responses which OSPIRG investigators received to this question indicates the lack of systematization in obtaining mental health care for residents of homes for the aged and of nursing homes.

\section{Sunmary:}

The data which OSPIRG obtained from home for the aged and nursing home administrators wi.thin Multnomah County indicates that these homes, generally, do not employ mental health professionals, nor do they have in-service training programs related to mental health care, nor have they attended training programs offered by other agencies, while most of the homes do accept people who have, or have had, mental and emotional problems. Finally, when faced with a patient who: they feel is in need of psychiatric care, most administrators gave responses which would indicate that they lack a systematic approach to providing even temporary or emergency mental health care to their residents.

Based upon this, admittedly sketchy, information regarding the level of mental health care within Oregon homes for the aged and nursing homes, the implications of the San Francisco Geriatrics Screening Project become apparent:

The San Francisco Gerlatrics Screening Project, . . Initiated in 1963 with the support of the California Department of Mental Hygiene, attempted to reduce the number of inappropriate commitments to state mental hospitals, to provide alternative plans by developing and utilizing communtty resources, and to provide consultation and information to persons and agencies' responsible for services to persons aged 60 and over...

The main goal of reducing the number of placements in state mental hospitals was attained without question, the nursing home most often substituted for the state hospital. The question left unanswered, however, is whether better treatment for these patients was and is being provided in the nursing home than, 
in the state mental hospital. Admittedly limited and post facto follow-up study does not permit real evaluation of the experimental project, but findings do indicate that better orientation and self-maintenance prevailed anong the patients in the control sample (mainly the state hospital patients) than among these in the screening unit institutionalized group (mainly nursing home placenents). The implication is that those "not needing" the extensive services that state mental hospitals provide and who were therefore referred to nursing home care may have been worse off after one year than those in the state hospital control group. Thus, it is not at all clear that small privately managed nursing and boarding homes, with fewer staff, less state control, and fewer capital alternatives, will serve the mental patients any better or indeed. as well. (13)

The central question, then, is what type of antal health care can be feasibly provided within sheltered settings, given the limited capital alternatives available to hese homes.

One form of mental health care, Reality Oriemtation Therapy, seems to be particularly suitable for implementation in sheltered settings. Information about the therepeutic techniques and the materials required for its use, are contained in Appendix F.

Reality Orientation Therapy has been sl an to be especially effective with geriatric patients who are severely disorliented. This would include a large proportion of the muntally ill or impaired elderly individuals within sheltered settings. However, what is essential to note here is that the theory and techniques which constittate Reality Orientation Therapy are fairly simple and easily learned by non-mental health professionals (e.g. nurses or attendants already in homes), no special facilities are required, the materials used in Reallity Orientation Therapy cost very little (about $\$ 20.00$ is adequate for a home), and the overall morale of employees, as well as patients, is improved as they experience gratifications as "therapists" they never approached in providing simply custodial care. 
Reality Orientation Therapy has been shown to be effective in reducing the length of institutionalization, the degree of restrictiveness of institutionalization, and/or the amount of personal care which the individual requires.

These are obvious advantages for patients, employees, and employers alike. The fact that apparently very few homes within Oregon now have Reality Orientation Therapy programs appears to be due to lack of knowledge of its effectiveness, ease of implementation, and usefulness in these homes, rather than due to its basic unsuitability.

\section{Conclusions:}

(1) Nursing homes and homes for the aged within Oregon house approximately 16,000 elderly people at the present time (about 7.1\% of the total elderly population in the state).

(2) These sheltered settings recelve a substantial amount of public money (OSPIRG estimates approximately $\$ 7,882,560.00$ annually, through Public Welfare 0ld Age Assistance) in order to partially finance the costs of institutionalization for about $23 \%$ of the individuals residing in sheltered settings.

(3) Nationai studies and local indicators suggest that .. large numbers of these institutionalized elderly people are mentally impaired and/or emotionally disturbed. OSPIRG estimates that approximately 8,800 are mentally impaired or emotionally disturbed, with 480 to 960 possibly qualifying for involuntary commitment to a state mental hospital. (4) The number of mentally ill elderly people residing in sheltered settings is likely to increase as a result of recent state legislation which established that people are committed to the State Division of 
Mental Health and allows the Division, at its discretion, to place people directly into nursing homes without first receiving treatment In a state hospital if this seems most appropriate. (5) However, by law, nursing homes and homes for the aged are not required to provide mental health care or treatment to residents on a systematic basis. These homes are not required to employ any mental health professionals on an on-going basis to provide treatment within these homes. The data which OSPIRG collected indicate:; that post homes for the aged and nursing homes do not provide any mental health treatment to their residents on an on-going basis. (6) Therefore, OSPIRG concludes that a large number of inentally ill elderly persons living in sheltered settings in Oregon are being deprived of the mental health care which they need. (7) OSPIRG further concludes that since mental health treatment programs have been developed which are both particularly suitable for implementation in sheltered settings (e.g. Reality Orlentation Therapy, see Appendix F for additional information), and which have been shown to be effective in reducing the length of institutionalization and/or the anount of personal care which the individual requires, this lack of mental health care for institutionalized elderly people is resulting in excessive expenditures of public money.

\section{Recommendations:}

(1) It is recommended that the State Health Divislon determine regulations for nursing homes and homes for the aged, keeping in mind the concept of the "prosthetic" environment.. These regulations should 
assure the presence of Iiving arrangements which are sensitive to accessibility, stimulation, and social interactlon, for example, for the residents of sheltered settings.

(2) It is recommedned that the State Mental Health Division, through Community Mental Health Programs, make available, to any interested administrators of homes for the aged or nursing homes, training workshops designed to familiarize these personnel with basic treatment concepts, information related to the diagnosis of emotional and/or mental disturbances, and appropriate sources for referral.

(3) It is also recommended that the State Mental Health Division, through Community Mental Health Programs, establish and conduct mental health. treatment programs within sheltered settings, particularily within those settings which are used for post-hospital placements or placements in lieu of state mental hospitalization for committed mentally ill elderly individuals.

(4) It is recommended that the State Public Welfare Division increase the level of payments to sheltered settings for persons receiving public assistance in order to discourage frequent transfers and other forms of discrimination against this grolp. It is also furthar recormended that the State Public Welfare Department encourage the development of comprehensive programs within sheltered settings, imcluding a continuum in the level of care available, by contracting for services at a set fee for the care of the individual independent of slight variations in his level of functioning, thereby encouraging sheltered settings to maintain a rehabilitative environment which will maximize the level of health of the individual and minimize the amount of custodial care required. 
(6) It is furthar recommended that the State Public Welfare Division make its alternate care program operational by providing sufficient funding to allow service workers within individual districts caseloads which are sufficiently small to allow for the necessary planning of supportive services necessary in the implementation of an alternate care plan as an alternative to institutionalization. One additional suggestion is that an ABIE-like program designed to provide a spectrum of services would be an appropriate adjunct to this program and could be contracted from a private company, or linked with publically funded community-based preventitive mental health services.

(7) It is recommended that sheltered settings be encouraged to provide arrangements for couples, and that adequate compensation for this added service be provided.

(8) It is strongly recommended that the State Legislature extend to residents of sheltered settings a "bill of rights" to include the right to rehabilitative services an a humane, prosthetic environment which will maximally maintain the level of functioning of the individual, as well as other basic human rights . 


\section{A SELECTED BIBLIOGRAPHY}

References Cj.ted in the Text

(1) Freedman, Stephanie. "Mental Health Services in Multnomah County," prepared by the Multnomah County Mental Health Section

(2) Psychiatry And the Aged: An Introductory Approach. Group for the Advancement of Psychiatry, New York, Vol. V, No. 59, 1965.

(3) Mental Disorders of the Aging. National Institute of Mental Health, United States Department of Health, Education, and helfare, 1968.

(4) Phillips; Donald F. "Reality Orientation," Hospitals, Vol. 47, July 1, 1973.

(5) Oberleder, Muriel, Ph.D. "Emotional Breakdawn in Elderly People," Hospital and Community Psychiatry, Vol. 20, No. 7. July, 1969.

(6) Toward a Public Policy on Mental Health Care of the Elderly. Group for the Advancement of Psychịatry, New York, Vol. VII', No. 79, November, 1970.

(7) Butler, Robert M., M.D. and Myrna I. Lewis, ACSW. Aging and MentaI Health: Positive Psychosocial Approaches, C.V. Mosby Co., St. Louis, 1.973 .

(8) The Elderly Oregonian Today, State Program On Aging, 1971.

(9) Hansen, Gary D. Mental Health and Aging in Oregon, Report and recommendations of the task force on mental health and aging, Oregon State Mental Health Division, State Council on Aging, Oregon Gerontology Study and Training Center, Mt. Angel College, Mt. Angel, Oregon. March, 1965.

(10) State of Oregon Cornprehensive Alcohol Problems Plan, State Mental Heaith Division; 1973.

(11) Oregon State Health Division, Office of Vital Statistics (written communication)

(12) Project Mobility: Access to the City, Office of Commissioner Iiloyd Anderson, Portland, Oregon. 1972.

(13) Mental Health Care and the Elderly: Shortcomings in Public Policy, Special Committee on Aging, United States Senate. Pub. \#38-596 0, November, 1971. 
(14) Busse, Bwald W., M.D. and Eric. Pfeiffer, M.D. (eds.) Behavior and Adaptation in Later Life, Little. Brown and Co., Boston, 1969.

(15) Anon., "Can Aging Be Cured?" Newsweek, April 16, 1973.

(16) Post,. Felix M.D. The Clinical Psychiatry of Later Life, Pergamon Press, London, 1965.

(17) Wolff, Kurt M.D. Geriatric Psychiatry, Charles C. Thomas Co., Springfield, III., 1963.

(18) Stephens, Louise P. (ed.) Reality Orientation. Hospital and Community Psychiatry Service: American Psychiatric Assciation, Washington, D.C., 1969.

(19) Oregon Public Welfare Department Staff Manual, Manual Letter \# VIII-97, Vol. VIII.

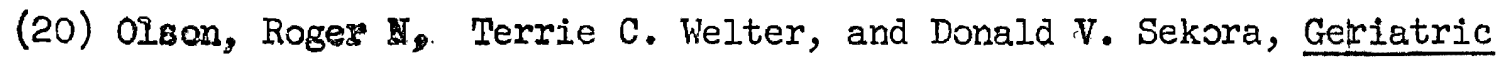
Screening Process Study, Tri-County Community Council, Portland, . Oregon, 1971.

(21) The Aged and Cormunity Mental Health: A Guide to Program Development. Group for the Advancement of Psychiatry, New York, Vol. VIII, No.81, November, 1971.

(22), Killian, Eldon C. "Effect of Geriatric Transfers on Mortality Rates," Social Work, Vol. 15, No. 1, Jănuary, 1970.

(23) Rules and Regulations Concerning the Operation of Homes for the Aged in Oregon, Oregon State Health Division, Fib. \# HFLC 10A. 1970

(24) Oregon State Health Division Rules Governing the Intermedicate Care Nursing Home, Oregon State Health Division, July I, 1973.

(25). Oregon State Health Division Rules Governing the Shilled Nursing Home, Oregon State Health Division, July 1, 1973.

(26) Kahora, Eva and Rodney M. Coe. "Self and Staff Conceptions of Institutionalized Aged," The Gerontologist, Vol. 9, No. 4, Winter, 1969.

(27) "Guide for Reality Orientation," Nursing Services, Veterans Administration Hospital. Tuscaloosa, Alabama, February, 1971.

(28) Brody, Elaine M., "Serving the Aged: Educations I Needs as Viewed by Practice," in Research, Planning and Action for the Elderly. Donald P. Kent, Robert Kastenbaum, and Sylvia Sherwood, Eaitors. Behavioral Publications, Inc., New York, 1970.

(29) Kent, Donald P. "Social Policy and Program Consideration in Planning for the Aged," in Research, Planning and Action for the Elderly. Donald P. Kent, et. al., editors - Behavioral Fublications, Inc., New York, 1970. 
Personal Communications

Alfred, Gaynell M.S.W., Director of Social Workers, Dammasch State Hospital, personal interview, August 21, 1973.

Davis, Robert Ph.D., Director of Clackamas County Mental Health Clinic, personal interview, Augus't 7, 1973.

Davis, Verne. Director of the Oregon Mental Health Association, personal interview, July 3I, 1973.

Drugger, Glen. Planning and Evaluation, State Mental Health Division, telephone interview, May 22, 1974.

Freedmen; Stephanie. Multnomah County Mental Health Planner, personal interview, July 31, 1973.

Goodman, Robert, Ph.D., Assistant Coordinator, Muztnomah County Mental Health Section, personal interview July 31, 1973.

Hahn, Louis. Director of Social Services, Multnomah District Welfare Department, personal interview, August 16, 1973.

Hands, Elizabeth. Research Analyst, Oregon State Program on Aging, personal interview, September 4, 1973.

Hitchcock, Glenn. Research and Biostatistics Section, State Mental Health Division, personal interview, August 15, 1973.

Hudson, Ruth. Director of Protective Services Unit, Multnomah County Mental Health Section, personal interview, July 17, 1973.

Hughes, Mary R.N., Assistant Director of Community Health Nurses, Multnomah County Department of Medical Services, telephone interview, August 20, 1973.

Hunter, Les. Director of Social Services, University of Oregon Medical School and Teaching Hospital, personal interwiew, August 22, 1973.

Jones, Laverne. Director of Edgefield Manor, personal interview, August 8, 1973.

Kasameyer, Janet, Attorney, Multnomah County Public Defenders Office, written communication, August 12, 1973 and September 20, 1973.

King, Dr. Director of Downtptin Branch, Multnomah County Mental Health Section, personal interview, June 26, 1973.

Klopfer, Walter, Ph.D., Professor of Psychology and instructor in the Institute on Aging, Portland State Univeristz, personal interview, July 25, 1973. 
Kole, Del M.D., Director of Region I, State Mental Health Division, personal interview, August 15, 1973.

Lippman, Sondra. Analyst, Research and Statistics, State Public Welfare Division, written communication August 13, 1973, sevtembér 5, 1973.

Iissitz, Sam. Director of Robison Jewish Hiome, and Gerontological Soclety Fellow, personal interview, August 1, 1973.

Luckett, Elizabeth. Caseworker at the Protective Services Unit, Multnomah County Mental Health Section, interview, August 28, 1973.

O"Brien, Joy. Director of Housing and Living Arrangements Unit, Multnomah District Public Welfare Department, personal interview, August 27, 1973.

Olson, Roger M.S.W. (former) Program Director for Pioject ABLE, City-Cjunty Commission on Aging, personal interview, August 3, 1973.

Ovelette, Ruth. Social Worker, Dammasch state Hospital, personal interview, August 28, 1973.

Richard, John. Oregon Health Care Association, telephone interview, August 20, 1973.

Strnad, Lydia, M.S.W., Social Worker, Family Counseling Service, personal interview, June 22, 1973.

Suckow, George M.D., Director of Clinical Services, Danmesch State Hospi-. tal, persona:- interview, May 17, 1974.

Sullivan, Caroline. Program Director for Project ABlW, City-County Commission on Aging, personal interview May 18, 1974.

von Cleff, Lucile. Director of the Geriatrics Socialization Program, Damnasch State Hospital, personal interview, May 17, 1974.

Williams, Lois M.S.W., Director of the Senior Prominam at the First Presbyterian Cnurch, Portland, persona] interview August 7, 1973.

Wein, Richard M.S.W., Coordinator, Multnomah County Mental Health Section, personal interview, July 31, 1973.

Wilson, Ada M.S.W., Assistant Professor of Social Whrk, School of Social Work, Portland State University, personal interview, July 30, 1973. 
APPENDICES 
APPENDIX A

EXAMPLES OF THE QUESTIONRAIRES USED TO SOLICIT INFORMATION

Two different questionnaires were used to gather information for this investigation. Essentially the same cover letter format was used to explain the purposes of each questionnaire. Copies of the cover letter and questionnaires follow.

Questionnaire 003 was sent to all counseling, family service, and crisis intervention centers within Multnomah County. This included approximately thirty agencies. This questionnaire requested information pertaining to adolescents as well as the elderly since, initially, this investigation attempted to focus on both of these populations. However, after a relatively short period of time it became evident that the investigation had to be further narrowed and so the dolescent portion of the study was discontinued.

Questionnaire 004 was designed for, and administered to, Community Mental Health Nurses within Multnomah County. Unfortunately, we received a rather poor return of responses to this questionnaire and so this datum vas not incorporated into this report. 


\section{Please Note}

This questionnaire is only concerned with mental health services (such as individual, group, and family counseling; medication supervision; etc.) offered by your agency, rather than other types of services which might also be offered. Leave blank any questions which are not applicable to your agency. Please give approximations when complete statistics are not available, and indicate any approximations with an asterisk $(*)$ placed beside the figure.

Name of agency:

Date:

SECT ION

$$
\text { \# Full-time \#Part-time }
$$

IA. 1. Total number of mental health staff IA.1. (including psychologists, psychiatrists, psychiatric nurses, social workers, paraprofessionals, etc.).

2. Number of professional mental health staff (for our purposes include only

2. those with post-graduate or professional degrees).

3. Number of paraprofessional mental health staff (including all others offering clinical services not included in \# 2).

IB. Total population of geographic area IB. served by the agency.

3. 


\section{SECTION 11}

SECTION II. REFERS ONLY TO CLIENTS 65 AND OVER OR 12 THROUGH 17 FOR THE TIME

PERIOD $1 / 1 / 73$ through $3 / 31 / 73$ ONLY

IIA. REFERRAL, SOURCE (Who reforred the client to your agency or initiated the contact?)

\# of Clients

65 and over

1. Number who were self-referred IIA. 1.

2. Referred by family member or relative

3. Referred by concerned other (such as minister, physician, neighbor, etc.)

4. Referred by another agency

Please indicate the number of referrals made to your agency by each of the following agencies:

4a. Police Dept. or Courts

4b. Public schools

4c. A state mental hospital

4d. A medical hospital socia! worker or staff member.

4e. Project A.B.L.E.

4f. Another counseling agency

4g. Other (please specify)
2 .

3.

4. $4 a$.

$4 b$.

4c.

$4 d$.

4 e.

$4 f$.

$4 \mathrm{~g} \cdot$
\# of C.lients 12 through 17

\section{IIB. TREATMENT DATA}

Length of treatment. (A contact refers

to any time you work with a client regarding his case; i.e: office or home visit, telephone cal1, etc.)

1. 1 contact

2. 2 to 5 contacts

IIB. 1.

2. 
IIB. TREATMENT DATA (Cont.)

\# of $\mathrm{Clients}$

65 and over

3. 6 to 10 contacts

3.

4. 11 or more contacts

5. Other (please specify)
4.

5.
.

Modality of treatment used (a client may be counted in more than one category)

6. Individual counseling

6.

7. Group counseling

7 .

8. Family counseling

8.

9. Medication

9.

10. Other (Please specify)

10. 
3d. Children's Services Division 3d.

3e. A public school

$3 e$.

3f. A state mental hospital

$3 f$.

3g. A residential treatment center

$3 g$.

3h. Police Dept. or Courts

$3 h$.

3i. City-County Commission on Aging

$3 i$.

3j. Project A.B.L.E.

$3 \mathbf{j}$.

3k. A nyedring home or home for $3 k$.

31. Other agency (please specify) 31

IID. PRIMARY PROBLEM AREAS (sources of client's problems) More than one problem area per client may be indicated

1. School-related academic problems IID.I.

2. School-related behavior problems

2.

3. Family-marital problems

3.

4. Drug-related problems

4.

5. Alcohol-related problems

5 .

6. Delinquency or police-related (has had contact with police)

6.

7. Interpersonal

7.

8. Other psychological problems

8.

9. Medical--physiological

9.

10. Economic

10.

11. Other (please specify) 11. 


\section{SECTION III}

\section{IIIA.}

1. Have any of your staff members had any special training related to work with adolescents? If so, please specify the type of training and the position of the staff members(s).

2. Describe any special programs, services, or special adaptations made in existing services, which you offer to adolęscents. Include the number of clients who participated in these special programs between January 1, 1973 and March 31, 1973.

3. Is your agency planning to introduce other programs or services for adolescents? If so, please describe the proposed service and indicate when it will begin.

III B.

1. Have any of your staff members had any special training related to work with the aged? If so, please specify the type of training and the position of the staff member(s). 


\section{Q 003}

2. Describe any special programs, services, or adaptations made in existing services, which you offer to the aged. Include the number of clients who participated in these special programs between January 1, 1973 and March 31, 1973.

3. Is your agency planning to introduce any other programs or services for the . aged? If so, please describe the proposed service and indicate when it will begin.

III C.

THE FOLLOWING INFORIATION WILL BE CONSIDERED STRICTLY CONFIDENTIAL.

1. In your opinion, what, if any, changes should be made in existing mental health services available to adolescents in Multnomah County? What additional services should be offered?

2. What are the major obstacles to the successful implementation of your suggested changes? 
3. In your opinion, what, if any, changes should be made in existing mental health services available to the aged in Multnomah County? What additional services should be offered?

4. What are the major obstacles to the successful implementation of your suggested changes?

Additional comments:

Prepared by:

,

$\frac{\text { Name }}{\text { Pasition }}$

Pasition 
We are interested in obtaining some information about the aged clients ( 65 and over) that you serve. While we realizo that jour primary consideration is with the meaical needs of your clients, you are probably in a position to identify mental health needs

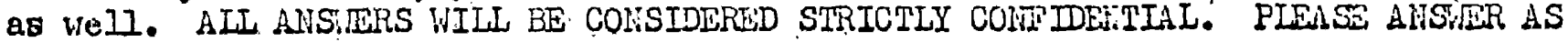
CANDIDLY AND AS SFECIPICALLY AS POSSIBLE.

In your opinion, which four of the following mental health problems are trost common among your aged clients? Please identify them and rank them in order of fruquency:

\begin{tabular}{|c|c|}
\hline $\begin{array}{l}\text { anxious } \\
\text { confused } \\
\text { hostilo }\end{array}$ & $\begin{array}{l}\text { depressed } \\
\text { frightened } \\
\text { forgetful }\end{array}$ \\
\hline
\end{tabular}

exploited by others danger to self/others conflict with commity

In your opinion, which four of the following areas most often present acute problems to your aged clients? Flease identify them and rank then in order of frequency:

$\begin{array}{ll}\text { physical health } & \text { housing } \\ \text { mental health } & \text { nutrition } \\ \text { economic } & \text { transportation }\end{array}$

home help needed social relationships other

To which four of the following sources do you most often mate referrals for mental health care for your aged clients? Please identify them and rank them in order.
a Multnomah Courity lental: $\because \therefore$ Health Clinic
Nultnotiah County liental Health, Protective Services Division
U. of 0. Medical School,
Psychiatric Out-patient Clinic
City-County Commission on Aging

a Public Health physician

Project Able

a nursing hore or home for the aged

a private paysician

a relative or friend of client

a state mental hospital

a private paysician

other

In your opinion, are there adequate sources in the communit to provide montal health care (counseling, medication, protective services, etc.) to your eged clients when they need it? What problems, if any, do the aged have in obtaining this caro?

In your opinion, what changes, if any, should be made in existing mental health scrvices available to the aged in lwalnomah County? What additional services should be offered?

What are the major obstacles to the successful implementation of your suggested changes? 
In your opinion, what are the main factors operating in the failure of the aged to utilize many of the services available to them?

What portion of your aged clients are now receiving some type of mental health care ( $i . e$. counscling, medication, etc.)? 3 What portion of your aged clients who are not now receiving any type of mental hoalth care mould, in your opinion, benefit from some type of care? 8

Have you had any special training or education related to the problems of the aged? - If so, please specify the type of training or education.

Describe any special programs, services, or adaptations in existing services which you offer to your aged cliénts: .

What is the total: sige of your current caseload?

How many aged clients do you have in your caseload?

Any additional comsents which you would like to make would be greatly appreciated.

Name

Position Dato

Thank you very much for completing this questionaire. 


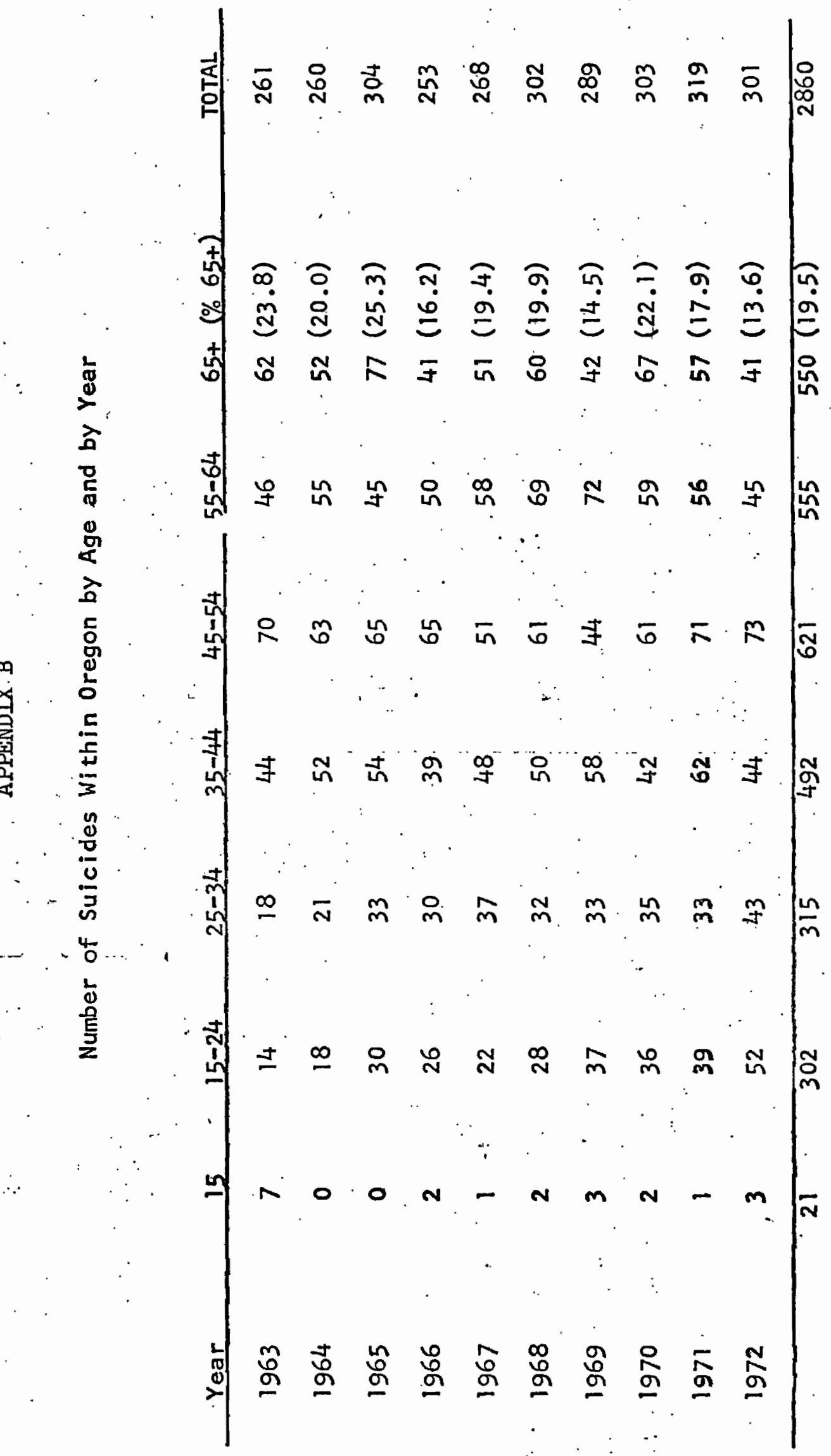




\section{APPENDIX C}

DATA USED TO DETERMINE PREVALENCE OF ALCOHOLISM ESTIMATES

The E.M. Jellinck Formula is $A=\frac{P D_{X}}{K} X_{R}$

where:

$A$ is the total number of alcoholics alive in a given year

$P$ is the percentage of cirrhosis of the liver deaths attributable to alcoholism (40\%)

$D$ is the number of reported deaths from cirrhosis of the liver in a given year

$K$ is the percentage of alcoholics with complications who die of cirrhosis of the liver (.00694)

$R$ is the ratio of all alcoholics to alcoholics with complications $(694$ to 100,000$)$

DEATHS CAUSED BY CIRRHOSIS OF THE IIVER

BY YEAR AND BY AGE

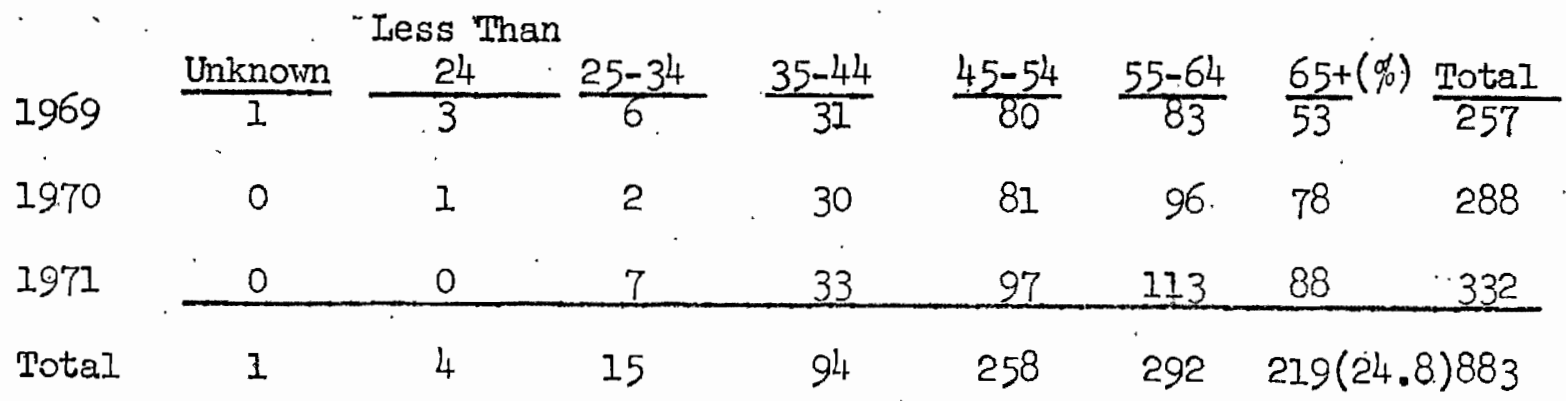




\section{APPENDIX D \\ TRANSPORTATION NEEDS OF THE ELDERTY WITHIN-2WES CITY OF PORTIAND}

The following information was collected from Project Mobility: "Access to the City" (12), which was an investigation sponsored by the Portland City Council and conducted in the summer, 1972, under the auspices of the Office of Commissioner Lloyd Anderson, and under the direction of Transportation Coordinator William S. Dirker.

The population which was studied included both elderly and physi.cally handicapped residents of the City of Portland, Oregon. The sample which was studied included an estimated $4.3 \%$ of this study population (or, 2,660 persons).

Four mobility categories were established as follows: (I) is confined to the house all or most of the time, (2) meeds a special aid of human assistance in getting around the house, (3) has trouble getting around freely outside the house, and (4) not limited in physical mobility。 These first three categories were combined to compose the "chronically handicapped" category, and the fourth represents the "physically Iimited" category。.

These categoies were operationally defined by the National Center for Health Statistics (NCHS) of the United States Department of Health, Education, and Welfare. The NCHS furthar operationelly defined these categories as follows:

The chronically handicapped are pople whose mility is limited as a result of a chronic condition or impairment for more than three months.... The physically limited are those individuals who are not chronically handicapped, but do experiemce the cumulative difficulties generally associated with advenced age.:. 
Individuals commonly referred to as 'physically handicapped' are represented entirely in the "chronically handicapped", category. This category includes persons from all age groups, and includes approxiately $20 \%$ of the total elderly population within Portland. The "physically limited" category includes only those persons 65 or older who have no limitation in their physical mobility although they may have one or more chronic conditions.

Mobility was determined to be a significant factor for this study population by the research team because

Any limitation of mobility restricts a person's access to existing opportunities such as employment, education, recreation, and even the social and medical programs designed to assist them. Lack of mobli1ty imposes a very large cost on the impaired individual and on eqciety as a result of reduced productivity and participation of the individual in society.

This research team determined that two basic factors influence an individual's ability to travel: (1) the ability to perform the physical actions required by the transportation system, and (2) the ability to purchase transportation services.

Nine basic actions were identified as being involved, to varying degrees, in the use of existing transportation systems. These nine tasks were: to go more than one block, to go up and dom staj.rs, to sit down and get up from a bench, to go up and down inclines, to move in crowds, to manage crosswalk signals, to hear a car hor, to wait - standing for up to 30 minutes, and to go up and dom curbs.

of these nine basic actions generally required in using current transportation systems, the actions of 'waiting standing for up to 30 minutes' and 'going up and down stairs' and 'up and down curbs' presented the most difficulty for both groups, with from $35 \%$ to $50 \%$ of the chronically 
handicapped unable to perform these tasks, and from $5 \%$ to $10 \%$ of the physically limited population unable to perform these tasks.

The ability of this study population to purchase transportation services is based upon their incomes, the portion of their incomes. available for the purchase of transportation, and the cost of their transportation. The median annual incomes for the study population ranged from $\$ 3,000.00$ per year for the physically limited group, to $\$ 2000.00$ per year for the elderly members of the chronically handicapped group, with younger members of the chronically handicapped group also averaging $\$ 3,000.00$ per year. By comparison, the general population of Portland has a median incoive of $\$ 8,500.00$.

While these figures put the study population well below the Federal Government Poverty Level of $\$ 3,500.00$ per year, their abilities to purchase transportation services are further limited. First, these groups cannot-afford to spend a comparable proportion of their total incomes for transportation is the general populatior.. Comparatively, the chronically handicapped spend 13.0\%, the physically Iimited 14.5\%, and the United States population under 55 spend $16.0 \%$ of their total incomes for transportation. This situation arises largely because the needs of the study population for food, housing, and medical care absorb a disproportionately lorge amount of their total income.

Secondly, the fewer physical barriers that exist in a transporta- tion system, the greater its cost. Comparatively, the chronically handicapped spend 90.4 cents per trip, the physically limited 80.0 , and the general population 75.0 cents per trip.

"The data clearly indicates that the total study population is measurably less mobile than the general population. The extent of: 
immobility of the study population is indicated by two basic conclusions: One, the study population makes an average of $40 \%$ fewer trips than the non-limited population. Secondly, the study population pays approximately $35 \%$ more per trip than the non-limited population per trip."

The significance of these findings becomesmore apparent when it is realized that the chronically handicapped population is comprised of 16,106 persons within Portland, or $4.2 \%$ of the city's population. - The physically limited population has a total of 46,147 (elderly) persons in it, or $12.1 \%$ of the city's total population. Obviously, major mobility restrictions being experienced by $16.3 \%$ of the city's population represent; a serious crisis.

According to Beatrice Wright, Physical Disability--A Psychological Approach (12), "a person's attitude toward himself and others is strongly affected by the effects of immobility。" The primary social-psychological effect appears to be described as an "all encompassing fear that the world will harm or reject the individual." It is in response to his physical limitations that the person often recognizes the he is more vulnerable to the dangers of the environment, and this in turn serves to reinforce this feeling of fear. "It requires additional courage to challenge the. barxiers pressently serving to increase these dangers and discomforts. The removal of environmental dangers and physical barriers allows the person an increased feeling of self-confidence and courage to overcome the remaining obstacles." 
CRITERIA USED FOR A DIAGNOSIS OF ORGANIC BRATN SYMDROME AN EXAMPLE OF A MENTAL STATUS : QUESTIONNAIRE"(2) *

Quantification of brain symarome is possible, for instance; by : means of a standardized rating system of mild, moderate, and severe brain syndrome, derivêd from scoress on a 10-point "mental status questionnire." The response to simple questions that test orientation for time, place and person, recent and remote memory, and general information identify. those with no to mild brain syndnome, (0-2 errors); moderately advanced brain syndrome ( $3-8$ errors); and severe brain symdrome $(9-10$ errors $)$.

The questions are:

(1) Where are we now? (place orientation)

(2) Where is this place located? (place orientation)

(3) What month is it? (time orientation)

(4) What day of the month is it? (time orientation)

(5) What year is it? (time orientation)

(6) How old are you? (memory--recent or remote)

(7) What is your birthday? (memory-mecent or remote)

(8) Where were you born? (memory)

(9) Who is the President of the United States? (general information, nemory)

(10) Who was the President before him? (general information, . memory)

Such rating methods may make it possible to identify patients as presenting "pre-brain syndrome" disturbances and mild, moderate, or severe degrees of mental functional impairment. This would permit measurement of the progression of the disorder with time or as related to care and treatment. Rating methods such as those developed by Halstead and Reltan may permit more subtle and precise measutent of brain damage, with or without clear-cut brain syndrome.

* This material was recorded verbatim. 
Recommended Criteria For Diagnosis of Brain Syndrome. Thersug gestions that follow are made to assist in the diagnosis and class tion of 'aged patients.

For the diagnosis and classification of brain syndrome, the.

following characteristics should be noted as present:

(a) Disorientation for time, place, or person.

(b) Evidence of impaired immediate recall.

(c) Deficits of recent and remote memory.

(d) Weakening of intellectual functions as indicated by difficulty and errors in doing simple calculations or in recalling simple items general information.

(e) Defects of grasp and comprehension: These defects may be discernable as difficulty in retaining, and reacting to, questions or commands. They may also be identified through faulty reaction to the situation or the interpersonal transaction, revealing that it is not understood. This can briefly be called situational disorientation.

(f) A reliable history, from the patient or other sources, of episodes, intermittent or persistent, or occuineres of the above.

In the absence of stupor, coma, satatonia, excitement, complete deafness, marked language difficulty, or other factors which make examination impossible its results questionable, the rour signs " $\mathrm{a}$ " through "d" are diagnostic of brain syndrome. All four factors should be present on examination. In chronic brain sjndrome one of these deficits is rarely found without the others, although some of these deficits may be less obvious or severe than others. If only one or several of the signs are found then developing brain syndrome may be suspected. The diagnosis is probably best made only when all the signs are found to be present in some, even though slight, degree.

In addition to and supporting the above, consideration may be given to such clues as emotional lability, focal neurological signs (including aphasias, agnosias, and paraxias), slovenliness or poor habits, poor judgement not clearly related to emotional disturiamce, and apathy. 
When these signs appear to be irreversible and related to brain damageas opposed to brain dysfunction of a reversible or transient nature-the condition is termed chronic. 


\section{APPENDIX $F$ \\ REALITY ORIENTATION THERAPY}

Reality Orientation therapy is a form of therapy which focuses upon orientating. 'individuals to basic concepts such as who they are, where they are, who the people are around them, and the time, such as day, month, and year. Essentially, it is a phase of rehabilitation.

The type of patient for whom this program is most appropriate is one who is "confused or disoriented from any cause. He may have a moderate to severe degree of organic cerebral deficit resulting from arteriusclerosis, ...a head injury, or a stroke. He may have a dlagnosis of organic brain syndrome. His confusion may be the result of sensory deprivation of overmedication." (27) Patiants who need reality orientation are found in a.] age groups; however, a majority are found in the geriatric group.

Reality Orientation attacks these processes by continually stimulating the patient through the "reception of basic motifis such as the patient's name, where he is, the day of the week, the month, the year, what meal comes next, and so on. This approach helps the patient regain his sense of reality." The patjent is in this way oriented to his own identity, and to time and place, and he is taught to interact appropriately with others. Historically, one of the earliest reality oriemtation programs was called the "aide-centered activity program for elderly patients" and was initiated at Winter Veterans Administration Hospital in Topeka, Kansas in 1958. In 1961 a similar program was established at the Mental Health Institute in Mount Pleasant, Iowa, where the staff was dedicated to the belief that mentally ill elderly patients could be treated with some. 
success. The techniques were furthar refined by James C. Folsom, M.D., and his associates at the Veterans Administration Hospital, Tuscaloosa, Alabama, in 1965 (4).

Since then, some of the comporents of reality orientation have been adopted by nursing homes, "as well as general or psychiatric hospitals, all of which rely heavily on nursing aides for patient care.

According to Dr. Benjamin Wells, M.D., Ph.D., Coordinator of the Regional Nedical Program, Birmingham, Alabama, "in no other patient care situation known to me have significat treatment roles been defined and delegated to practically all levels of personnel. Those who developed reality orientation have thus created a working model in which rudimentary medical services can be successfully dellivered by sub-professional personnel" (18). The use of all levels of staff in the treatment program is obviously one of the more innovative, and important, contributions of Reality Orientation Therapy.

Reality Orientation Therapy focuses on re-establishing an individual's orientation for person, place, and time. Consistency of approach is the key to the therapy's success. This is why all members of the staff of an institutional are involved in the process.

Reality Orientation always proceeds on two levels. It is maintained in the general institutional environment, where signs, clocks, calendars, menus:; instruction sheets, and nameplates continually identify for each person orientations for time, place, and person. He is always addressed by his name, and he is always reminded of the name of the person with whom he is talking. The critical point in reorientation is reached when the person reassumes his own identity by remembering his name. From that moment on it becomes inereasingly difficult for him to maintain his withdrawn 
and regressive defenses (18).

The other leveI of Reality Orientation is more structured and form mal, and consists of half-hour classes conducted on a daily basis. The classes are made up of no more than eight members, and are graciated i by difficulty of the material to be masterëd.

At the simplest level, the classes consist of date and place recognition, and self-identification exercises. Gradually, various types of object recognition exercises are introduced, such as the identification of various types of foods, utensils, or articles of clothing. Along with these orientation procedures, patients experience and must identify different tastes, sounds, and visual stimuli.

At this most elementary level of reality orientation individual differences soon emerge; and more intact patients are quickly advanced to more difficult classes, where the classification of objects by color, shape, use, and finally by abstract qualities, slowly occurs (18).

of course, most patlents have known all of these things for most of their lives. But the purpnse of veality orientation is not education, but rather, re-education of severely regressed and withdrawn individuals.

Once a patient has "graduated" he may move on to other group programs, such as special interest groups, remotivation classes, occupational therapy and crafts, or other recreational activities (4).

"As an adjunct to Real.ity Orientation Therapy, attitude therapy is employed to establish consistency of attitude, which is maintained by all who come into contact with a particular patient" (4). The attitudes employed consist of 'kind firmness','active friendliness, 'passive friendliness; the'matter of fact'attitude, and the 'no demand'attitude. There may be many explanations of how Reality Orientation Therapy 
works, but according to Dr. Muriel Oberleder, Ph.D., "there may be actual alteration of neurological structure through this type of psychological patterning, or unused neurone may be activated to compensate for actual brain losses. Or it may be the matter of restoring function through exercise, function that was lost through disuse, lack of motivation, de pression, ...or it may be a combination of all these things" (18). Or, it has also been suggested that "1t may be the social interaction with others rather than the actual activity or project that the patient is working on that helps him return to reality as his self-confidence and dignity are restored" (4).

For whatever the reason, studies have shown that Reality Orientation Therapy does work in helping to improve the functioning of severely disoriented persons. A reality orientation program was initlated at Santa Ana Hillhaven Convelescent Center in February, 1972 and by October of that year, 55 patients had gone through reality orientation classes. 19 of them showed significant improvement in terms of retaining what they had learned in the classes. They showed improved physical appeárance anci mental outlook, becoming more aware, alert, and sociable. These were patients who at one time were withdrawn, depressed, and in poor physical condition and who expressed fear and anger.

Another 20 patients showed moderate improvement. They were more aleit, but they did not retain as much of the facts as the significantly inproved group... 5 or the 55 showed slight or no improvement, and 11 were discontinued because of illness or because they were too disruptive to the program. Every one of the 55, however, went through some positive changes (4).

In another study conducted by the Veterans Administration Hospital, Tuscaloosa, Alabama, where 227 persons had been placed into classes within a four year period,

with 50 graduating and recelving diplomas, 47 (20\%) of those who attended classes are now discharged or on trial visit at home with their families or in community facilities, 113 (49\%) remain in the hospital, and 21 have current discharge plans, 22 are presently in 
reality orientation classes, five have been brought out of their confused state but were found to need intensive psychiatric care and have been transferred to the psychiatric service, eight have improved and are now in the geriatric rehabilitation service for a more active physical program, and 27 became acutely ill and have been transferred to the medical service (18).

These. successful results become amazing when it is remembered that $\therefore:$

these patients were severely disoriented, often not remembering where they were or who they were with, no longer knowing how to use a fork or even what a fork is, no longer, ir fact, even knowing their own names.

"The problem of the senile patient who is confused and disoriented is a large one, and one, that exacts an enormous social, economic, and humanistic tolz. Reality Orientation is only one of many methods of rehabilitation. Its goals are often modest, but their achievement is a triumph when seen in relation to the drabness of total senility that might have been" (18). 